\title{
ZU NEUEREN IRANISCH-BALTOSLAWISCHEN ISOGLOSSEN-VORSCHLÄGEN*
}

V. I. ABAEV geht in seiner umfangreichen Abhandlung "Skifo-evropejskie izoglossy. Na styke vostoka i zapada", Moskva 1965, von einer Hypothese aus, die für das Ossetische spezielle Verbindungen mit einzelnen Sprachen des europäischen Areals postuliert. Im Rahmen seiner theoretischen Bestimmung der skytisch-europäischen Isoglossen ${ }^{l}$ vergleicht er bestimmte Phänomene im Skytischen auf der einen und im Slawischen, Germanischen, . Italischen und Keltischen auf der anderen Seite. Weil uns in diesem Rahmen besonders die ossetisch-baltoslawischen Zusammenstellungen interessieren, werden wir uns auf diejenigen $A b-$ schnitte seiner Ausführungen beschränken, die sich in erster Linie mit diesen Fragen auseinandersetzen. In diesem zusammenhang werden mehrere lexikalische, eine phonetische und einige sog. grammatische Isoglossen behandelt. Den historischen Hintergrund der behandelten sprachlichen Beziehungen bestimmt Abaev (S. 4) folgendermassen: "Skifskaja gruppa iranskix jazykov, k kotoroj prinadležit osetinskij, byla ot glubokoj drevnosti daleko prodvinuta $v$ Evropu $i$ mnogo vekov sosedila s evropejskimi jazykami, $v$ to vremja kak ostalnye indoiranskie jazy-

* Der Aufsatz ist ein Teil meiner in 1979 beendeter Dissertation "Baltoslovansko-indoiranski jezikovni odnosi v luči raziskav indoevropske arealne lingvistike" ("Baltoslawisch-indoiranische sprachbeziehungen im Licht der Untersuchungen der indogermanischen Areallinguistik") (Mentor und Referent Univ.-Prof. Dr. Bojan Cop). Die Dissextation wurde am 16. oktober 1979 verteidigt. Das Text ist in einigen zügen abgerundet worden, stellt aber im allgemeinen den stand der Literatur bis 1979 dar. Die zahlreichen zitate sollen dex Übersichtlichkeit und leichterer vergleichsmöglichkeit dienen.

Herren Universitätsprofessoren Dr. Bojan Cop, Dr. France Bezlaj, Dr. Tine Logar und Priv.-Doz. Dr. Heiner Eichner verdanke ich wichtige Ratschläge, Herrn Eichner auch die sprachliche Korrektur des deutschen Textes. 
ki uže davno peremestilisb na vostok i na jug i utratili vsjakij kontakt s Evropoj. Kak i sledovalo ožidatb, osobenno mnogočislenny i značitelıny izoglossy, svjazyvajuščie osetinskij so slavjanskimi jazykami. Zdesь my imeem ne tolbko leksičeskie, no $i$ nekotorye važnye grammatičeskie svjazy, čto ukazyvaet na osoboju dlitelbnostb i intimnostb kontaktov." $\mathrm{Zu}$ den theoretischen Möglichkeiten der Beurteilung des Isoglossenmaterials vergleiche man noch die stellungnahme M. Mayrhofers, die von Abaev, ibid. S. 6, angeführt wird: "Wenn ein Wort westlichen idg. Sprachen und auch dem Baltischen und slawischen angehört, und dann im Ossetischen gefunden wird - kann man dann gleich sicher sagen, es sei 'auch indoiranisch'? Ist es nicht möglich, dass das Ossetische mit den westlichen Sprachen Übereinstimmungen hat, an denen - im Sinne moderner sprachgeographischer Erkenntnisse - das übrige Iranische, und gar das Indische, nicht teilhat? .. Sollte es nicht 'Isoglossen' zwischen Germanisch - Italisch - Baltisch - Slavisch - Nordiranisch (Ossetisch) geben, an denen das übrige Iranisch und das Indische nicht teilhat?" Aus dem zitat ist aber nicht ersichtlich, wie man derartige Isoglossen historisch interpretieren muss bzw. kann. In den Fällen, in welchen wir nicht mit Entlehnungen, d. h. mit einem direkten Einfluss einer Sprache auf die andere rechnen können, scheint ein solcher theoretischer Ausgangspunkt, ohne konkrete Vorschläge bezüglich des Ursprungs bzw. der Entstehungsweise der behandelten Wortbeispiele problematisch. Abaev stimmt (S. 7) der Mayrhoferschen Stellungnahme zu. ${ }^{2}$ Man kann ihr theoretisch zwar kaum widersprechen, doch bringen Abaevs eigene Analysen einzelner Isoglossen keine konkreten historischen Rekonstruktionen, die imstande wären, dieses theoretisches postulat praktisch zu rechtfertigen. Die von Abaev angeführten skytisch(balto)slawischen bzw. skytisch-balto(slawischen) Isoglossen sind folgende:

Auf S. 8 vergleicht er osset. xsyrf/cexsirf "Sichel" mit dem aksl. *s $6 p p r$ (bezeugt im apoln. sirp, russ. serp, skr. ŝ̂p, slowen. sîp, tschech. srp usw.) und lett. sirpis, sirps. Abaev zitiert auch andere etymologische Deutungsversuche (Miller, OE 
III 143; Čop, $\mathrm{Kz}, 1956,3-4,231 \mathrm{ff.}$ ), die er aber als unbefriedigend bezeichnet. Bei der von Abaev vorgelegten Deutung muss man eine phonetische Regel, nach welcher osset. anlautendes $x s-$ idg. *s- entspricht, annehmen. Er führt noch zwei weitere Beispiele an, bemerkt aber (S. 8, Anm. 14), dass dieses Verhältnis nicht genug untersucht worden ist. Es wird zwar in der Literatur eine Regel angeführt, nach welcher uriran. *s+Kons. zu xst +Kons. wird (Bartholomae, GIPh. I/1, 36) und dem entsprechen auch die beiden von Abaev angeführten Beispiele (osset. xsyn/ cexsnun "waschen" < *snā- und xscez "sechs" < *swek's). Bei osset. $x s y r f$ dagegen haben wir mit einer ursprünglichen Gruppe ${ }^{*} s+V$ zu tun und das erläutert Abaev (S. 8, Anm. 14) folgendermassen: "Os. $x s i r f$ govorit o tom, čto $x s-$ iz $s-$ moglo vozniknutb $i$ pered glasnym. Perehod $s \mathrm{~V} x s$ kak by 'spasal' načalnyj soglasnyj, kotoromu grozilo polnoe isčeznovenie (čerez perehod $v$ h). Innymi slovami, $x$ - voznikal $v$ načale slova pered $s$ kak 'Schutzkonsonant'." Da er keine Beispiele mit der entsprechenden Lautentwicklung anführt, müsste man das Material auf die zitierte Hypothese hin erst überprüfen. Wenn das Material eine solche Lautentwicklung nicht fordert, ist die Regel nur ad hoc angesetzt. Vgl. vielleicht in diesem zusammenhang aw. $h \bar{\alpha}(y)$ "binden, fesseln" (Präs. hayeiti, Ptz. hita-) <*sē(i) "binden" (Pokorny 891); aw. haēk-, hinčaiti (hičaiti)< *seik ${ }^{w}$ - "ausgiessen usw." (Pokorny 893); osset. xurx "Molken, Käsewasser" (< ar. *sukra-) zu *seu- "biegen, drehen" (Pokorny 914); osset. xui "Eber, Schwein" ist eine k- Erweiterung von *s schwein, Sau" (Pokorny 1038). Vgl. auch Miller, GIPh. I Anh. $\$ 24.4$. mit den Beispielen, wo er z.B. w.osset. xed, o.osset. $x \vec{\imath} d$ "Brücke", aw. haētuš, ai. sétu- usw. anführt, jedoch weiter $\left(\$ 44 . \mathrm{k}_{\text {.) }}\right.$ folgendes bemerkt (S. 38): "... ir. $h$ (aw. $h$, ai. s) ist im Oss. stets geschwunden: w.oss. istun "stehen", aw. hištaiti (...)". Čop, $\mathrm{KZ} \mathrm{74,3-4,} \mathrm{s.} \mathrm{232,} \mathrm{führt} \mathrm{das} \mathrm{oss.} \mathrm{Wort}$ auf ein idg. *qsiph-ró- zurück und stellt gr. ksíphos "schwert, Dolch" dazu. Ähnlich geht auch Benveniste, Études sur la 1. ossete, s. 39f., von einer ir. Urform *xšifra- aus. Die Rekonstruktion einer solchen Anlautsgruppe scheint jedenfalls besser 
begründet und wahrscheinlicher als der oben erwähnte Erklärungsversuch $x s-<{ }^{*} s-$. Pokorny 9lif. führt ksl. sprpr, lett. sirpis usw. auf idg. *serp "Sichel, krummer Haken" zurück. Vgl. noch Vasmer II 616.

Bei der Behandlung des sak. păs sa "Sau" bemerkt Abaev, dass das sakische einige sehr archaische Sprachzüge aufweist ${ }^{4}$ und folgert daraus (S. 13): "Možno predpolagatı, čto i v tex sovremennyx vostočnoiranskix jazykax, kotorye preemstvenno svjazany s sakskimi narečijami - v afganskom (puštu) i pripamirskix, takže soxranilisb sledy specifičeskix svjazej s evropejskimi jazykami." In diesem Zusammenhang führt er (S. 13f.) 19 derartige Isoglossen an, unter welchen sich auch einige befinden, die neben den iranischen nur noch baltische bzw. slawische Parallelen aufweisen.

Eine solche Zusammenstellung wäre (S. 13) afgh. wroza (< bruša-) "Floh" aksl. blrxa, blsšica, russ. bloxa, lit. blusà, bei der sich aber dennoch, wie teilweise zwar wahrscheinlich aus tabuistischen Gründen veränderte Parallelen aus anderen Sprachen zeigen, um keine isolierte baltoslawisch-iranische Sonderübereinstimmung handelt. Vgl. Pokorny 102, Vasmer I 94, Fraenkel 51f. und Frisk II $140 f$.

Abaev verbindet weiter (S. 13) afgh. pünda ( $\left.{ }^{*} p a \bar{n} t \bar{a}\right)$ "Ferse" und aksl. peta< <pentā, russ. pjata. Vasmer II 477 stellt jedenfalls noch lit.péntis "Ferse; dickes Ende, Rücken der Axt oder Sense" und apreuss. pentis "Ferse" dazu. So auch Pokorny 988. Abaev nimmt wahrscheinlich eine semantische Isoglosse im Sinne einer Bedeutungsinnovation an. Man kann aber auch an eine unabhängige, parallele Entwicklung denken. Es ist nicht ganz klar, welche Bedeutung in diesem Kontext der Übereinstimmung des Vokalismus der baltoslawischen und iranischen Form zuzuschreiben ist.

Ibid. vergleicht Abaev afgh. yumba "Geschwulst" mit lit. gumbas in der gleichen Bedeutung. Fraenkel 176 stellt lit. gumbas "Erhabenheit, Konvexität, Auswuchs am Körper, Beule, Geschwulst, Knorren, Knoten, Blähung, Kolik", lett. gumba "Geschwulst, Erhöhung, Haufe" entweder zu aisl. kumpr "Klumpen", 
norw. dial. Kump "Klumpen, Kloss, halbkugelförmige Exhöhung am Erdboden", kamp "(rundlicher) Stein, Bergknollen, Stumpf von Stöcken" oder zu aisl. Kumbr "Holzklotz". Diese Zusammenstellung ist, wie es scheint, nicht eindeutig, da die germanischen Formen auch andere etymologische Deutungen zulassen. Vgl. dazu z.B. Johanesson, Isl. etym. Wb., S. 329 . und Pokorny 378. Pokorny (S. 396) führt unter der Wurzel ${ }^{*} g e \bar{u}-,{ }^{*} g a u-,{ }^{*} g \bar{u}-$ "biegen, krümmen, wölben" vorsichtig auch npers. gumbed "wölbung, Kuppel, Becher", die zitierten baltischen Formen, sowie einige slawische und germanische wörter an, die aber bedeutungsmässig etwas abweichen. Die Annahme einer iranisch-baltoslawischen Isoglosse scheint demnach nicht berechtigt zu sein. Selbst wenn die entsprechenden Belege aus anderen Sprachen nich vorhanden wären, schiene die Annahme von Exklusivisoglossen - und ihre Interpretation zugunsten der Bestätigung von speziellen Sprachbeziehungen - in den Fällen unnötig, in welchen normale, produktive wortbildungsprozesse und einfache Bedeutungsentwicklungen vorliegen.

Es folgt (ibid.) die Zusammenstellung von afgh. mēšta "Wohnort" und aksl. město, russ. mesto. Pokorny 709 behandelt die Rückführung von aksl. město, sbk. mjësto usw. auf das ursprüngliche *mōits to- bzw. ${ }^{*} m \bar{e}(i) t^{s}$ to- (Wz. *mei- "befestigen") als "wahrscheinlich". Vasmer II 124 vergleicht mit der slawischen Sippe u.a. lit. mã̌stas "Nahrung", aw. maêrana- "Aufenthaltsort, Wohnung, Haus", das Pokorny 715 (ohne slaw. město) gesondert unter *meit(h)- "Aufenthaltsort, woraus balt. auch Lebensunterhalt, Nahrung" behandelt. In diesem Falle könnte es sich um eine iranisch-baltische Isoglosse handeln. Wie aber aus Bedeutungsverhältnissen ersichtlich, dürfte es sich wohl um unabhängig entwickelte Bildungen handeln, die nur zufälligerweise auf dem beschränkten Territorium belegt sind. Slaw. město wird von Pokorny - wahrscheinlich wegen der Intonation, die auf einen ursprünglichen Langdiphthong hinweist - anders verknüpft. Eventuell könnte man von einer Vrdahi-Bildung zu *meit(h)- ausgehen, was die etymologische Zusammenstellung von Vasmer 1.c., Trautmann 185 u.a. rechtfertigen würde. Es besteht aber, wie 
es scheint, noch eine andere Möglichkeit. Fraenkel 460 lehnt die Zusammenstellung von aw. maêrana-n. "Aufenthaltsort, Haus",

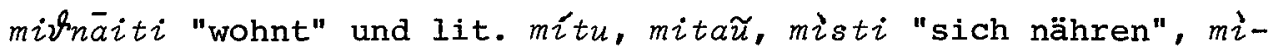
tas "Lebensunterhalt", lett. mítu, mitu, mist "wohnen", aksl. město "Ort" wegen Intonations- und Bedeutungsdifferenzen ab. 5 Fraenkel 1.c. geht für das Baltische von. einer ursprünglichen Bedeutung "Nahrung, Fütterung, Mästung" aus und es wäre dann die Möglichkeit gegeben, die zit. aw. Formen unter der Wz. ${ }^{*} m e i-$, bzw. *mēe(i)t-, *ma(i)t-, *mit- "befestigen, Pfahl, Holzbau" (Pokorny 709) mit slaw. město $\mathrm{zu}$ verbinden. In dem Falle könnte es sich um eine unabhängig erfolgte Bedeutungsentwicklung handeln, es könnte aber auch eine archaische Bildung vorliegen. Gemeinsame Innovation wäre schwer $\mathrm{zu}$ beweisen. (Es bleibt endlich noch problematisch, ob afgh. méšta aus derselben iran. Vorstufe als aw. maềqana- zu erklären ist.)

Weiter vergleicht Abaev (ibid.) afgh. kanai (< *karna-ka-) "Stein" und lit. Kálnas "Berg". Das lit. Wort wird von Fraenkel 209f. zu gr. kolōnós, kolónē "Hügel", lat. collis "Hügel, Anhöhe" usw. gestellt. Ebenso Pokorny 544 (*kel(a)- "ragen, hoch (heben)", *k!n-is "Hügel"). Abgesehen davon, ob die Deutung bzw. Rekonstruktion der afgh. Form zutrifft, kann es sich unmöglich um eine iranisch-baltische Isoglosse handeln, da die Etymologie des lit. Wortes offensichtlich nicht umstritten ist. Bei der afgh. Form müsste man ausserdem noch die verhältnismässig stark abweichende Bedeutung berücksichtigen.

Weiter vergleicht Abaev in seiner Abhandlung (ibid.) afgh. pinal "aus der Hand essen" und lit. penù, penéti "füttern". Fraenkel 569 stellt lit. pênas "Nahrung, Futter, Kost", penéti "mästen, füttern, nähren", lett. penêt "verwöhnen" usw. zu ai. panasa- "Brotfruchtbaum". Diese Verbindung ist aber fragwurdig - vgl. z.B. Mayrhofer II 209. Pokorny 807 führt unter der Wz. *pen- "füttern, Nahrung, Aufbewahrungsort der Nahrung" neben den zitierten baltischen Formen auch mehrere lateinische Bildungen, wie z.B. penus, -oris/-üs "Mundvorrat; das Innere des Hauses", und (mit Vorbehalt) got. fenea (*finja) "Gerstenspeise". Es ist mir nicht klar, welche Erklärungsmöglichkeiten die 
afgh. Form zulässt. Könnte man sie vielleicht (!) zu idg. *pei(a)-, *p $\frac{u}{z}-$ "fett sein, strotzen" ( $\sim$ aw. fra-pinaoiti "bringt zum Gedeihen" usw., vgl. Pokorny 793f.) stellen? Die Annahme einer afgh.-Iitauischen Isoglosse scheint - zumindest ohne genau angeführte Deutung - nicht begründet zu sein. Es folgt (S. 13) die Gleichung zwischen afgh. wuža "Ader", munjI wūrž (wury) "seidener Faden" und lit. viřxzis "Strick". Zur Deutung des lit. Wortes vgl. Fraenkel 1264. Pokorny 1154 geht von *wer-g" $h$ - "drehen, einengen, würgen, pressen", einer weit verbreiteten Erweiterung zu *wer- "drehen, biegen", aus. Auch wenn die afgh. Bildung auf dieselbe Form zurückzuführen ist, kann es sich nicht um eine afgh.-lit. Isoglosse handeln (vgl. z.B. aisl. virgizl "strick", as. wurgil "strick", poln. powróz "strick" usw.).

Weiter vergleicht Abaev (S. 14) waxi skan, sangl. skanok "junger Hund" mit slaw. šěen- $(k$ *ken-) in russ. ščenok usw. Ausführlicher behandelt Abaev diese Gleichung auf S. 2lf. Hier geht er von osset. stcen "männl. Hund" aus, das er aus *sccen herleitet und mit weiteren slawischen Bildungen, wie aksl. šten6c6, ukr. ̌̌ěenja, poln. szezenie, tschech. štěně, serb. štene, bulg. šenee, vergleicht. Dabei nimmt er an, dass "gruppa -st- $\mathrm{v}$ ossetinskom možet voznikatb iz -sc- ( $c$ posle $s$ perexodit $v t) "(s .21)$. Auf $s .22$ führt er Entsprechungen in den Pamir-Sprachen (waxi skan, skon, munjī saken, sangl. skanok, usw.) an. Abaev zitiert ausserdem noch arm. skund, wo er aber offensichtlich nicht an ein iranisches Lehnwort im Armenischen denkt, was schon an sich die Annahme einer iranisch-slawischen Isoglosse bedenklich macht. Vgl. dazu Vasmer III 448. Pokorny 563 geht von einer Wz. *(s)ken- "frisch hervorkommen (vielleicht eigentlich: spriessen), entspringen, anfangen; auch von Tierjungen und Kindern" aus, unter der er neben den zitierten slawischen Formen noch mir. cano, cana "Wolfsjunges", cymr. cenau "junger Hund oder Wolf" anführt. 6 Es scheint nicht glaubvürdig, dass z.B. die Verwendung des $s-$ mobile in den iranischen und slawischen Belegen eine plausible Voraussetzung für die Annahme einer slawisch-iranischen Isoglosse bilden könnte, noch dazu bei 
einer auch in anderen Sprachen verhältnismässig gut bezeugten Wurzel mit ähnlichen Bedeutungen.

Auf S. 14 wird als letzte ostiranisch-slawische Verbindung die Gleichung zwischen šughnì tap- : tapt "trampeln, stampfen" und slaw. trp-, trprt, russ. topot, topat6, toptat6 "stampfen" behandelt. Da es sich, wie auch Abaev selbst bemerkt, um eine Onomatopöie handelt, entfällt die Zusammenstellung im Sinne einer gültigen Exclusiv-Isoglosse. Zu russ. tópat6 vgl. auch Vasmer III 120, wo auch baltische Formen, wie lett. tapa, tapu Interj. "Bez. von Schritten", tapat "schreiten", lit. tapuoti "treten" angeführt werden. Vgl. jedoch Fraenkel 1057.7

Es ist zu den angeführten ostiranisch-baltoslawischen Gleichungen zusammenfassend festzustellen, dass in den meisten Fällen keine Exclusiv-Isoglossen vorliegen und sie demnach nicht als Beweismaterial für besondere iranisch-baltoslawische Beziehungen verwendet werden dürfen. Bei einigen der oben behandelten Gleichungen bekommt man wegen der äusserst lückenhaften Materialanführung fast den Eindruck, dass der Verfasser in erster Linie eine schematische Darstellung der vermutlichen ostiranisch-baltoslawischen Isoglossen, nicht aber eine detaillierte, historisch berechtigte, einleuchtende Analyse derselben vorlegen wollte.

In der Weiterführung seiner Abhandlung vergleicht Abaev (S. 15) osset. kajyn, a-gajyn "berühren" (< *kah-) mit baltoslaw. *kas-, *kos-, das in aksl. kasati se "berühren, angehen", kosnqti "anrühren", russ. kasat6sja, kosnut6sja und lit. kasyti, kàsti "kratzen" belegt ist. Dabei scheint ihm "polnaja identičnost značenija $v$ skifskom i slavjanskom" von grösster Bedeutung. Ebenso Abaev, IES I 567f. Zu den slaw. Formen vgl. Vasmer I 640. Pokorny 585 führt unter *kes- die zitierten slawischen und baltischen Bildungen, aber keine iranische an. Vgl. noch Fraenkel 226f. Die Zusammenstellung mit dem Ossetischen scheint möglich, es ist jedoch nicht klar, ob Abaev von einer unabhängigen Entwicklung aus einer gemeinsamen idg. Wurzel in den beiden Sprachgruppen ausgeht, oder ob die ossetische Bedeutung unter dem Einfluss des Slawischen zustande gekommen sei, 
was weniger wahrscheinlich erschiene.

Auf S. 16 führt Abaev zwei Isoglossen an. In der ersten verbindet er osset. mcecyn "sich in etwas Flüssigem wälzen" und slaw. moěiti, russ. modit6 usw. In IES II 80 geht er von iran. *maxy- oder *mad- aus, wobei er - nach Gershevitch, BSOAS XVII, 1955, 479f. - eine Entwicklung iran. $x \bar{s}>$ osset. c voraussetzt. Wenn man von einer idg. Wurzel *mă $k$ - "nass, feuchten" (Pokorny 698) ausgeht, erscheint seine Rekonstruktion der iranischen Urform *maxs- zweideutig. Es ist nischt klar, ob er von einer s-Erweiterung, also *-ks-, ausgeht. Man könnte auch eine Palatalisation des ursprünglichen $-k$ - wie sie auch im slawischen vorliegt, erwarten. Vgl. dazu Miller, GIPh. I Anh., § 28.2. Anm.). Erweiterungen von derselben wurzel kennt auch das Armenische und Albanische. Vgl. noch Vasmer II 166.

Die zweite vorgeschlagene Isoglosse verbindet osset. solyn "gefrieren" und lit. šálti "(ge)frieren, abkühlen, kalt werden", lett. Salt (< * $k^{\prime} e l$ - "frieren, kalt usw." Pokorny 551f.). In diesem Zusammenhang weist Abaev ausdrücklich auf das Verhältnis osset. -z- : - - - in anderen iranischen sprachen hin. ${ }^{8}$ Die Frage, ob Abaev dabei mit einem direktem Einfluss des Litauischen oder aber mit einem ererbten 2 -Reflex im ossetischen rechnet, bleibt offen. Bei der ev. zweiten Deutungsmöglichkeit könnte man die Verhältnisse bei der Realisierung des idg. $*_{p}-l$ im Altindischen vergleichen. Vgl. Bartholomae, GIPh. I/1, S. 23f. $\$ 56$ und Miller, GIPh. I. Anh. S. 35f. $\$ 4 l f .{ }^{9} \mathrm{Vgl}$. ausführlicher weiter S. 211 .

Auf S. 17 vergleicht Abaev unmittelbar osset. bcelon und lit. bazañdis "Taube"10, lässt aber auch die Möglichkeit weiterer Anknüpfungen aus anderen Sprachen $z u .{ }^{11}$ Die Bildungen werden auf ein idg. *bhel(a)- "glänzend, weiss; auch von weisslichen Tieren, Pflänzen und Dingen" (Pokorny 118f.) zurückgeführt. Es liegt, wie es scheint, sowohl im Litauischen als auch im ossetischen ein alter $n$-Stamm vor, was für die Annahme, dass es sich um eine archaische Bildung handelt, spricht. Diese stämme wurden nämlich oft für Tierbezeichnungen verwendet. ${ }^{12}$ Weiterverbreitete Wurzel, für das Indogermanische normale, produktive 
Wortbildungsweise und regulär entwickelte Bedeutung - das alles spricht für die Annahme archaischer, ererbter Bildungen in beiden Fällen. Methodisch interessant ist die Bemerkung Abaevs, IES I 249: "Forma bcelon (vmesto ožidaemogo bceron), a takže konečnoe -œw v digorskom - vtoričnye javlenija", die auch bei der oben unter scelyn vorgeschlagenen Hypothese bezüglich des möglichen Ursprungs von osset. $\tau, \mathrm{zu}$ beachten wäre. Vgl. noch weiter $S$. 218 .

Es folgt (S. 17) "verojatna svjazb" zwischen osset. $k_{0} y r m /$ kurmce "der Blinde" und lit. kùrmis "Maulwurf". Für die lit. Bildung rekonstruiert Abaev eine mögliche ursprüngliche Bedeutung "der Blinde" und führt als Erläuterung das syntagma $k_{0} y r m$ myst "Maulwurf" < *"blinde Maus" an. Die Verbindung mit dem Element kur- in $k_{0} y r œ f c c g$ "mit einem kurzen Hals (versehen)", scen$k_{0} y z$ "ohne eine Hand" scheint ihm wegen $-m$ problematisch. Diese Zusammenstellung würde jedoch eine verhältnismässig plausible Anknüpfung an die idg. Wurzel *(s)ker-, *(s)ker(a)- "schneiden" (Pokorny 938ff.) ermöglichen, die auch u. a. in krbnz "verstümmelt", russ. dial. kórny "von kleinem wuchs, kurz" (ibid. 940) usw. vorkommt. Das Verhältnis zwischen slaw. krznz und lit. kùrmis wäre mit dem des lit. kürpe : aksl. krbpa $<* k \bar{u} r p i a<*^{0}-$ rap-) von der Wurzel *kerap- (alles Pokorny 581) vergleichbar. Wie es scheint, könnte man sowohl für die ossetische als auch für die slawische Bildung von einem *(s)kro- ausgehen. Zu lit.

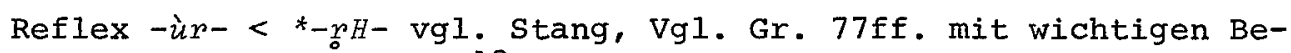
deutungs-Implikationen. ${ }^{13}$ Weitere Beispiele für das Bedeutungsverhältnis "verstümmelt" $\rightarrow$ "blind" verzeichnet Fraenkel 317 . Die Wurzel * $(s) k_{r} H$ - wäre nach der vorgeschlagenen Deutung mit einem m-Suffix, lit. -mi- erweitert, ähnlich wie z. B. * $q^{w}{ }_{0} m i-s$ (lit. kirmis "Wurm" usw. Pokorny 649) oder *wrmi-s (lat. *vormis vermis, got. waúrms "Wurm, Schlange" usw. Pokorny 1152). Für das Ossetische müssten wir wahrscheinlich von einem -mo-Stamm ausgehen (wie z. B. auch *wrmo-s Pokorny ibid.). Vgl. noch Brugmann, Grdr. II/1, S. $254 \mathrm{f}$.

Im Weiteren vergleicht Abaev (S. 18) osset. mcexstc/mcexstcentto "Beutel" und lit. makštis (normalerweise Pl. mãkštys) 
"Scheide, Futteral, Pfeil", lett. maksts "Tasche, Pfeil", lit. mãkas "Ranzen", makšnà "Pfeil", aksl. moš6na, russ. mošna, mosonka. Die ossetische Form ist als Plural von einem *moxston, das mit einem osset. produktiven Formans -on gebildet ist, aufzufassen. Vg1. auch Abaev, IES II 110. ${ }^{14}$ pokorny 698 geht von "mak- etwa "Haut-, Lederbeutel" aus. Die angeführten Formen sind, wie es scheint, mit einem Suffix -s-ti-, das oft mit -s-ni-bzw. -s-no- im Wechsel steht, gebildet. Vgl. dazu Brugmann, Grdr. II/1, S. 282, 289 und 437. Offensichtlich könnte es sich um unabhängige, ererbte Bildungen handeln, wobei die verhältnismässig beschränkte Vertretung auf der iranischen Seite immerhin zu beachten ist.

Auf S. 19 vergleicht Abaev osset. qœZoes/ğœZos "Kehle, Stimme" und russ. golos, aksl. glasz und bemerkt zu der Etymologie folgendes: "Vozmožno, čto my imeem zdess tot že korenb, čto v os. qoer/ğcer 'krik', no po forme (soglasnyj $Z$, formant -s-) qœelos/ğcelcs primykaet k slavjanskomu." Er lässt sogar die Möglichkeit, dass die ossetische Bildung aus der slawischen entlehnt wäre, $z u$. In seinem IES II 288 lehnt er wegen des osset. - I- und des zweiten -c- die Möglichkeit einer iranischen Urform ab: "Pravilnee dumaţ, čto pered nami specifičeskoe slavjano-skifskoe sxoždenie, vozmožno zaimstvovanie $v$ skifskij iz staroslavjanskogo $s$ zakonomernym $v$ etom slučae polnoglasiem $v$ osetinskom." Vgl. Vasmer I 287 und Pokorny 350. Es ist ohne weitere Beispiele dieser Art schwer zu sagen, ob schon die Vertretung von -z- und -o- im Ossetischen ein ausreichende Argument für die Annahme einer slawischen Entlehnung vorstellen kann.

Weiter (S. 20) verbindet Abaev osset. kur, kul in kur-œfcog "kurzen Hals habend", $\operatorname{ccen}(g)-k_{0} y z$ "ohne eine Hand" mit dem Element kur in russ. kur-nosy, kur-zubyj und weiter mit kornat6 "beschneiden, kürzen", koxnouxij, kornoxvostyj usw. Vg1. Vasmer I 628f., Abaev, IES I 608 und 301 und oben S. 184. (Abaev erwähnt die Möglichkeit einer Zusammenstellung beider osset. Bildungen nicht.)

Es folgt (ibid.) die Gleichung osset. $x \bar{u} r x / x \circ r x$ "Kehle, Rachen" und aksl. *krrkr "Kehle, Hals" ( tschech. krk, poln. 
kark). Sie ist wegen des Vokalismus der osset. Bildung unklar. Wosset. $0=$ oosset. $\bar{u}$ wird normalerweise auf iran. *au zurückgeführt (vgl. Miller, GIPh. I Anh. S. 20, $\$ 11$ ), während Pokorny 935 für tschech. krk usw. von einer stufe *(s)krek-zu*(s)ker"drehen, biegen" ausgeht. 15

Als eine slawische Entlehnung betrachtet Abaev (S. 21) osset. xumcetce, xumcetcgi "einfach, auf einen Menschen bezogen: unbedeutend, unscheinbar", das er aus slaw. *kumet( $i)$ - mit einem osset. Formans - $\propto g$ erklärt. Von slawischen Bildungen führt er an aruss. krmeţ "Bauer, Krieger, Soldat", serb. kmět "Bauer", tschech. kmet, slk. kmet', poln. kmieé "dass.", während baltische Formen Entlehnung aus dem Slawischen voraussetzen. ${ }^{16}$ Bei der Annahme einer Entlehnung aus dem Slawischen ins Ossetische sollten Zeit und Weg der Entlehnung festgelegt werden. In Zusammenhang damit stellen sich mehrere Fragen: Ist die ossetische Bedeutung erst im Ossetischen endgültig festgesetzt worden oder sei sie schon in der angeblichen slawischen Ausgangsform vorhanden gewesen? Ev. könnte eine Antwort auf diese Frage einer genaueren Bestimmung des chronologischen Verhältnisses hilfreich sein. Eine partielle Antwort auf solche Fragen gibt Abaev, OJF 333f., wo er bemerkt: "My dolžny predpoložits, čto slovo kmet bylo usvoeno iz drevnerusskogo $v$ alanskih (osetinskij) jazyk $v$ značenii 'poseljanin', 'prostoj (ne znatnyj) voin' i polučilo zdess formu xumœtœg. Roditelbnyj padež ot nego xumœtœgi "xumatogovskij", t.e. 'krestbjanskij' stal označatb voobšče 'prostoj' $v$ primenenii uže ne tolbko $k$ ljudjam, no $i \mathrm{k}$ životnym, veščam $i$ pr." Bezüglich der Zeit, in welcher die Entlehnung zustande gekommen sei, meint er folgendes: "Zaklučitelbnaja faza epoxi voennoj demokratii i načalo feodalizma - vot period, kogda eto moglo proizojti. K etomu imenno periodu my otnosim usvoenie iz drevnerusskogo v alanskij (jasskij) termina kmet $\rightarrow$ xumœtœg." Die ideale Ausgangsform für die ossetische Bildung laute *kumet (S. 333). Als eine Parallele führt Abaev russ. xme lo $_{6}$ : osset. xumcelog "Hopfen" an. Es ist nicht klar, ob - laut der vorgeschlagenen Interpretation - die aruss. Form in der zeit der vermuteten Entlehnung einen noch wahrnehmbaren $u$-Vokalismus der 
Wurzel enthalten habe oder ob man besser mit einem Reflex für *-m- (bzw. mit einem sekundär entstandenen -ə-) rechnen könnte, da im Ossetischen wegen des angefügten Suffixes die Silbengränze verschoben wurde und eine solche Möglichkeit wahrscheinlich bestünde. ${ }^{17}$

Weiter vergleicht Abaev (S. 22) osset. uZcen "Welle, Woge", das - nach einigen anderen Beispielen dieser Art zu schliessen auch ein paralleles *uInce haben könnte, mit aksl. vrina, virna, russ. volna und lit. vilnià, lett. vilna in derselben Bedeutung. Für die ossetische und slawische Bildung rekonstruiert er gemeinsame Urform *wl-na ( *wel(a) - "drehen, winden, wälzen" Pokorny 1140f.). Vgl. noch Vasmer I 218 und Fraenkel 1254. Obwohl die Bildung *w $n \bar{a} \bar{a}$, wie es scheint, wirklich auf das Baltoslawische und Ossetische beschränkt ist (vg1. Pokorny 1143), handelt es sich um eine normale Wortbildungsweise, was auch das parallel gebildete *wn̄a "Wolle" $\sim$ *wel(a)- "Haar, Wolle" (Pokorny 1139) beweist. Man könnte demnach mit ererbten Bildungen in beiden Fällen rechnen. Aus den Ausführungen Abaevs ist nicht ersichtlich, wie er die Gleichung deutet, und so bleiben manche Fragen offen. Ist man schon wegen des Fehlens der Vertretung in anderen iranischen Sprachen berechtigt, auf eine sekundäre Entstehung im Ossetischen $\mathrm{zu}$ schliessen? Wie müsste in einem solchen Falle die konkrete Entwicklung des Wortes aussehen, wenn es keine Indizien für die Annahme einer Entlehnung gibt. Soll man sich einen derartigen Prozess so vorstellen, dass eine ursprünglich vielleicht anders gebildete protoiranische Form unter dem slawischen Einfluss umgebildet wäre? Es bleiben im Grunde eigentlich nur vor zwei realistische Möglichkeiten: Entweder liegt die Entlehnung vor (was womöglich $\mathrm{zu}$ beweisen wäre) oder aber handelt es sich um ererbte Bildungen, die nur zufälligerweise auf das genannte Territorium beschränkt blieben bzw. deren Beibehaltung in den beiden sprachgruppen durch die ursprüngliche Nachbarschaft gefördert wurde. Es ist unbefriedigend, dass man keine von den erwähnten Möglichkeiten begründet ablehnen oder bestätigen kann. Abaev geht, wie in den meisten anderen Fällen, auf solche Einzelheiten nicht ein und es bleibt infol- 
gedessen oft unklar, mit welcher Art sprachlicher vorgänge er tatsächlich rechnet.

Weiter (S. 23) vergleicht Abaev osset. fcext/fcestce "Mörser" und russ. pest, lit. piestà, piestas "dass.". Beachtung verdient seine Analyse dieser Beziehung: "Ceredovanie $s / x$ (fcestce/f(ext) xarakterno dlja slavjanskogo. Sr. rjadom s pest dialektnye pextal6, pextizo s tem že značeniem. Poetomu estestvenno dumats o starom zaimsvovanii iz slavjanskogo $v$ skifskij. Odnako po značeniju osetinskij primykaet ne k russkomu, a litovskomu" (sic!). Auch in seinem IES I 466 kommt er zu demselben Schluss, dass nämlich die genannte Doppelheit im Ossetischen als "staroe (ešče v skifskuju epoxu) zaimstvovanie iz slavjanskogo" zu erklären sei. ${ }^{18}$ Bezüglich des Verhältnisses osset. $\infty$ : slaw. e verweist Abaev auf osset. $x_{0}$ ymotoeg, $x_{0}$ ymcelog. Die Bedeutungsseite der vorgeschlagenen Entlehnung begründet Abaev folgendermassen: "S točki zrenija istoričeskix realij predložennoe razъjasnenie takže ne vyzyvaet vozraženij: vpolne ponjatno čto nazvanie stupki skotovody - Skifi mogli usvoitb u zemledelscev Slavjan." Vgl. Vasmer II 348 und Fraenkel 586f. und zur Varian-

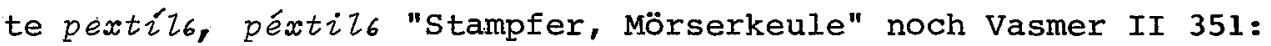
"Wird gewöhnlich zu pixát6 "stossen" gestellt (...), doch befremdet die Bildung." Vasmer zitiert die Etymologie von Kalimov, der an eine Entlehnung aus dem Mordwinischen denkt. Das Verhältnis -s- : - $x$ - ist jedenfalls nicht so einfach erklärbar, wie es Abaev darzulegen versucht. Vor dem Verschlusslaut bleibt nämlich $-s$ - sogar hinter $i, u, r, k$, wo Wechsel $-s->-\check{s}-/-x-$ sonst regelmässig auftritt, erhalten (vgl. z. B. prost6<*p6rst6: prax6 usw. Vaillant, Gramm. comp. I 29f.). Weil somit keine reguläre, erwartete Doppelheit vorliegt, müsste das Ossetische sowohl russ. pest als auch anders gebildetes pextil6 in der Opposition fœstœ/fœxt wiedergegeben haben, wenn das Verheltnis $s: x$ mit einem slawischen Ausgangspunkt zu erklären wäre. Das würde allerdings eine gleichzeitige Verwendung der beiden Varianten auf diesem Teil des russischen Gebiets, in welchem die Entlehnung zustande gekommen sei, voraussetzen. 19

Es folgt (S. 23) die Verbindung osset. cod/coedce "Paar 
(Stiere)", Erweit. cedis/codes "Gespann, Teilnahme im Gespann"

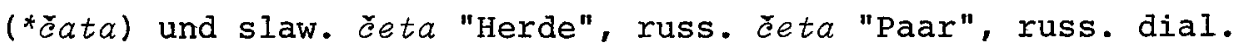
četa bykov "Gespann". In IES I 293 reiht Abaev diese Gleichung "v plane staryx slavjano-skifskix snošenij" ein. Für diese Einordnung spreche das Verhältnis russ. $e$ : osset. $\propto$ und russ. $t$ : osset. d. Er rechnet offensichtlich auch hier mit der Möglichkeit einer slawischen Entlehnung ins Ossetische. ${ }^{20}$ Obwohl klare vergleichbare Bildungen aus anderen sprachen fehlen, ist die Möglichkeit der Urverwandtschaft wohl nicht ganz auszuschliessen. Vgl. Pokorny 534 .

Ibid. verbindet Abaev osset. $k_{0} y r d / k u r d ~ " S c h m i e d "$ und aruss. krrěii "dass.", wobei er die ossetische Form aus *kurto- und die russische aus *kurtyo- (< *kur- "Feuer entfachen") herleitet (idg. *ker(a)- "brennen, glühen, heizen" Pokorny 571f.). Als weitere Anknüpfungen führt er aksl. kuriti, russ. kurit6, lit. kùrti "heizen, Feuer entfachen", pers. kura "Schmiedeherd", arm. krak "Feuer" an. Obwohl die Wurzel, wie schon aus dem Zitierten ersichtlich, breiter belegt ist, folgert Abaev, dass "Toždestvo značenija i blizostb slovoobrazovanija pozvoljajut videtb zdesb skifo-vostočnoslavjanskuju izoglossu". Vgl. noch Abaev, VJa 8, $N^{\circ} 1,1959$, S. 96-99. Seiner Interpretation nach würde es sich entweder um eine gemeinsame Bedeutungsinnovation oder um eine Entlehnung handeln. In seinem IES I 610 korrigiert Abaev den Ansatz der idg. Urform: "Vosstanavlivatb sleduet i.e. *keur-, *kur-, a ne *ker-, vopreki Pokorny (57lf.)." Zum baltoslawischen Vokalismus der Wurzel vgl. die Bemerkung Pokornys auf $\mathrm{s}$. 572, wo er von der Schwundstufe der Wurzel ausgeht, und weiter Vasmer I 636, 700 und Fraenkel 319. Es scheint, dass man sowohl die baltoslawischen als auch die ossetischen Bildungen aus einer gemeinsamen, ererbten Form herleiten kann. Die Bedeutung könnte in beiden Fällen auch unabhängig zustande gekommen sein. Ob man mit russischem Einfluss auf die ossetische Form (wenigstens was die Bedeutung betrifft) rechnen kann bzw. muss, ist schwer zu entscheiden. Wie ist in diesem zusammenhang das persiche kura "Schmiedeherd" zu verstehen? Kann man wirklich von einer nur skythisch-slawischen Isoglosse sprechen? 
Weiter (S. 24) vergleicht Abaev osset. cūr/cor "neben, bei" (< * "Ende"), cojrag "das letzte Tier beim Dreschen" und russ. ăur "Ende, Grenze". In IES I 316 deutet er das Verhältnis folgenderweise: "Možno dumatb o staryx skifo-slavjanskix ili alano-russkih svjazax." Vgl. zum russischen wort Vasmer III 358 (čur in: čur menjá, čur, ěur ěurá "halt, nicht weiter, hüte dich" usw.) mit den angeführten Etymologie-Vorschlägen, die aber alle mehr oder weniger unzuverlässig sind. Wegen der unterschiedlichen Bedeutung im Ossetischen und Russischen nimmt Abaev, IES 1. c., für die ossetische Bildung eine ambivalente Bedeutung an, einerseits "Nähe", andererseits aber "Entfernung, Ende, Grenze" . Das russische Wort ist, wie die Belege zeigen, wahrscheinlich eine Onomatopöie und in diesem Falle wäre der Vergleich mit der ossetischen Bildung hinfällig, es sei denn, es läge eine Entlehnung vor. Auch die phonetische Seite der Gleichung, die Abaev vorschlägt, ist nicht einwandfrei. Osset. $\bar{u} / 0$ entspricht normalerweise iran. au (vgl. Miller, GIPh. I Anh., S. 20), oder auch iran. va. Es wäre wahrscheinlich besser, die ossetischen und russischen Belege gesondert zu behandeln.

Es folgt (S. 29f.) das osset. Verbum maryn "töten". Das Ossetische kennt sowohl das Grundverbum (mcl-<*marya- "sterben, im Sterben liegen") als auch das Kausativum (mar- < *māraya-) und eben dieses verbinde - nach Abaev - das Ossetische mit dem slawischen. Er führt in diesem Zusammenhang von der baltoslawischen Seite aksl. umoriti, aruss. moriti, russ. morit6, serb. mòriti, tschech. mořiti, poln. morzić, lit. marinti an. Da aber auch das Altindische das Kausativum māráyati aufweist und die gleiche Bildungsweise im Iranischen bekannt war (vgl. z. B. Bartholomae, GIPh. I/1 S. 84), könnte man sich vorstellen, dass die entsprechende Bildung von ${ }^{*} m e r-$ in den iranischen sprachen - mit Ausnahme des Ossetischen - nur zufällig nicht vertreten ist. Es scheint keinen zwingenden Grund für die Annahme einer ossetisch-baltoslawischen Exclusiv-Isoglosse zu geben. Man wäre eher geneigt einen erhaltenen Archaismus anzunehmen. Vgl. Pokorny s. 735 .

Osset. woldoe "Luft" $(<$ wol "Gipfel" und tof "Geist, 
Hauch, Atem") deutet Abaev (S. 31) als Lehnübersetzung nach dem Muster des aksl. vrzduxz "Iuft" (< vrz "hinauf" und duxz "Geist, Atem, Hauch"). Vgl. Vasmer I 214. Die Annahme einer Lehnübersetzung scheint möglich, es bleibt aber die Frage, wie alt der Vorgang sei. Handele es sich um den Einfluss der schon aksl. oder erst der russischen Form, die aber selbst eine ksl. Entlehnung vorstellt? ${ }^{21}$

Weiter (ibid.) vergleicht Abaev osset. mat/met "Schnee" mit dem slaw. met-, das in wörtern für "Schnee, Gestöber" vorkommt (so z. B. russ. met-e $\imath_{6}$ "Schneegestörber", dial. o-met "Haufen, Scholle", za-met6 "Gestöber", ukr. peremet "Gestöber", poln. zamieé "Schneegestöber" usw.). Wie aus dem osset. Lemma in IES II 124 ersichtlich, rechnet Abaev mit einem slawischen Lehnwort im Ossetischen und verweist dabei auf rumän. omát, omete "Schnee, Gestöber": "Predstavljaetsja estestvennym, čto predki osetin, kak i predki rumyn, živja $v$ bolee južnyx širotax, zaimstvovali u svoix severnyx sosedej slavjan slovo 'sugrob, sneg'." $\mathrm{Zu}$ der semantischen Wandlung "Aufgeworfenes" $\rightarrow$ "Schnee" weist er auf die altindische Parallele vapati $\rightarrow$ vapra- hin. ${ }^{22}$ Weil osset. $\vec{\imath} / e$ normalerweise iran. ai entspricht, müsste man wahrscheinlich ein sekundäres *-ai- in der wurzel annehmen, das ev. mit Epenthese aus einer entsprechenden Vorform (? Suff. *-(i)yo-) zu erklären wäre. ${ }^{23}$ Weiter bleibt die Frage, ob nicht ein auslautendes $-a$, wie $z$. B. im osset. vad "Sturm", zu erwarten wäre. Es ist auch nicht geklärt, aus welcher slawischen Bildung das ossetische wort entlehnt sei. Es scheint deshalb angebracht, auch die Möglichkeit einer Urverwandtschaft der Bildungen im Auge zu behalten (Pokorny 703f. $*_{m} \bar{e}-, *_{m e-t-)}$, wobei ev. (!) nur die Bedeutung unter slawischem (konkret: russischem?) Einfluss stünde. Es wäre wichtig festzustellen, ob idg. *sneig ${ }^{w} h$, das auf der iranischen seite z. B. im aw. snaēza- "scheien" und pamir. šughni żanij "Schnee" vorliegt, in irgendeiner Form noch im Ossetischen bezeugt ist. Vgl. Pokorny 974.24

Auf S. 31 nimmt Abaev eine Sonderübereinstimmung zwischen dem Ossetischen und Slawischen bei einer wurzel an, die auch sonst auf der iranischen seite gut bezeugt ist. Es handelt sich 


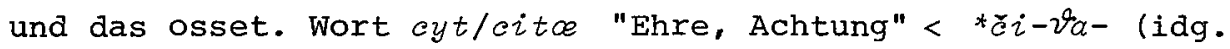
$* k^{(1)} e y-(t)$ - "worauf achten, ehrerbietig beobachten, scheuen, ehren usw." (Pokorny 636ff.). Nach Meinung des Autors bestehe eine spezielle bedeutungsmässige und formale übereinstimmung

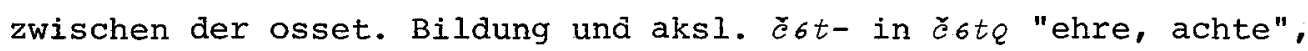

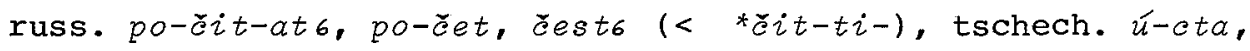
po-cta "Ehre, Achtung" (also ëit-, ëita-). Vgl. Abaev, IES I 327. Das ossetische Wort ist formal mit den sehr ähnlich gebildeten iranischen wörtern vergleichbar, vgl. z. B. aw. ¿̇i $i \bar{a}-\mathrm{f}$. "Busse, Sühne einer Übeltat, usw. durch Geld-, Vermögensstrafe", čilli- f. "Sühne" (Bartholomae 585). Das Bedeutungsverhältnis zwischen den osset. und aw. Bildungen ist nicht überraschend, da beide Bedeutungen $z$. B. in gr. tǐmé "Schätzung, Preis, Wert, Ehrenamt" und "Entschädigung, Busse, Strafe" (Frisk, GEW II 901) vorkommen. Es scheint, dass man ohne weiteres mit einer unabhängigen Realisiexung der indogermanischen Mustern rechnen darf, besonders noch, da das Ossetische die t-Erweiterung nicht weiter, z. B. in verbalen Ableitungen, ausnützte, wie das z. B. im Altindischen (cétati "nimmt wahr, beachtet", cikéti "bemerkt, nimmt wahr") und im Baltoslawischen (aksl. ètq, ěisti "zählen, rechnen, ehren", lit. z. B. skaitýti "lesen, zählen" usw.) der Fall war. Vgl. Vasmer III 343, Fraenkel 792.

In der Fortführung seiner Abhandlung geht Abaev zur Untersuchung der sog. phonetischen Isoglossen, die angeblich das Ossetische mit einzelnen europäischen sprachen verbinden, über. Bei der Behandlung des Phonems $l$ im ossetischen bemerkt er ( $S$. 38), dass es "v strogo opredelennoj Gruppe slov: v arealbnyx izoglossax, t. e. $v$ slovax, kotorye $v$ skifo-osetinskom ne unasledovany iz drevneiranskogo, a voznikli $v$ rezulbtate kontaktov s evropejskimi jazykami: slavjanskimi, baltijskimi, pratoxarskim, germanskimi, italijskimi" vorkommt. Er führt so neben einigen schon unter den lexikalischen Isoglossen behandelten Beispielen folgende ossetisch-slawische Gleichungen an: osset. $z \bar{u} \tau / z \circ Z$, zylyn/zuZun "schräg, schief, krumm, falsch, schuld" $\sim$ aksl. zrlz "bösartig, schlecht" ${ }^{25}$; lit. atžúlas "grob, scharf", pražu崋as "schräg, schief, krumm", ižulnùs, pažùlnus 
"schräg, steil, schief". Die Bildung ist offensichtlich alt, ererbt, sekundär sei nur das - - (vgl. zu den Belegen Pokorny 489f.). Beispiele solcher Art können, selbst wenn sie real sind, nicht als eine ossetisch-baltoslawische Isoglosse gelten, da sie eine Tendenz wiederspiegeln, die auf ein grösseres, europäisches Gebiet verbreitet sei. Der so gedeutete Verlauf der Entstehung bzw. des Ursprungs des osset. - - - beruhe auf einer langsamen Assimilation. Die Eigenschaften dieser Entwicklung stellt Abaev auf S. 38 dar und man muss sie kennen, wenn nam die Glaubwürdigkeit einiger schon behandelten sog. lexikalischen Isoglossen auch auf dieses, dort nicht erwähnte Postulat hin überprüfen will. 26 Auf S. 39 versucht er die absolute Chronologie dieses Vorganges $z u$ bestimmen und bemerkt (dem Material bei Herodot folgend): "Čto skifskomu jazyku (...) byl ot glubokoj drevnosti čužd iranskij rotacizm i zvuk $l$ byl ravnopravnym členom fonetičeskoj sistemy." Zur Datierung schreibt er (S. 40) folgendes: "Fonema $l \mathrm{v}$ skifo-osetinskom $\mathrm{v}$ otličie ot drugix iranskix jazykov svidetelbstvuetsja s drevnejšix dostupnyx vremen - ne pozdnee $\mathrm{V} v$. do $n$. e."

Unmittelbar auf die iranisch-slawischen sprachverbindungen bezieht sich das Kapitel "O proisxoždenii fonemy $\gamma(x)$ v slavjanskom" (ibid. S. 41-52). Hier macht Abaev auf die bekannte Tatsache aufmerksam, dass "v rjade slavjanskix jazykov - južnorusskom, ukrainskom, belorusskom, českom, slovackom, verxnelužickom - smyčnyj $g$ perešel vo frikativnyj $\gamma$ ili $x^{\prime \prime}$ (S. 43). Er stellt dieselbe Entwicklung auch in ostiranischen sprachen fest und versucht beide Erscheinungen zu verbinden. Hinsichtlich der vermuteten geographischen Ausbreitung des zit. Phänomens erschliesst Abaev (S. 46): "... areal slavjanskogo (h) sovpadaet (esli ostavits poka v storone českij $i$ slovackij) s arealom skifskoj toponimiki, skifskoj arxeologii i skifskix vlijanij v Južnoj Rossii. Dostatočno skazatb, čto etot areal vključaet basseny trex velikix rek, kotorye do six por soxranjajut svoi skifskie nazvanija: Don, Dnepr, Dnestr. (...) Stalo bytb, severnaja granica izoglossy $\gamma(h)$ proxodit primerno tam že, gde severnaja granica skifo-sarmatskoj toponimiki." Im Zusammenhang 
mit dieser Formulierung stellt sich die Frage, ob das Vorkommen derselben phonetischen Erscheinung im Tschechischen, Slowakischen und einem Teil der slowenischen Dialekte (was Abaev nicht erwähnt) nicht eher bedeutet, dass es sich im Grunde um eine anders bedingte Erscheinung handelt, die aber (nur zusätzlich) mit einer schon vorhandenen Substrat- bzw. in einem gewissen Sinne Adstrat-Tendenz unterstützt sein könnte. Es bleibt allerdings noch die Möglichkeit, dass die behandelte phonetische Wandlung in russischen Dialekten und diejenige auf dem tschechischen, slowakischen, slowenischen (und ev. noch einem weiteren) Gebiet nicht dieselbe Ursache haben. Der genannten "skytisch-slawischen phonetischen Isoglosse" schreibt Abaev grosse Bedeutung zu. 27 Für den Verlauf der Entwicklung $g>\gamma$ in einem Teil der slawischen Sprachen bzw. deren Dialekte lässt Abaev eine verhältnismässig breite Zeitspanne zu (S. 48). Aufschlussreich ist seine Deutung der ersten Erscheinungsformen des $\gamma$ auf slawischem Territorium (S. 48): "V načalınyj period skifo-slavjanskix kontaktov estestvennym kanalom, po kotoromu fonema $\gamma$ popadala $v$ slavjanskij, byli, nado dumatb, zaimstvovannye iranskie slova, soderžavšie etot zvuk. Odnim iz takix slov bylo sla. bogr iz sev.-iran. baya-." Abaev stimmt also ausdrücklich denjenigen Forschern zu, die slaw. bogr als eine nordiranische Entlehnung auffassen. ${ }^{28}$ Als Argumente für diese Interpretation nennt er folgendes: 1. Die Abwesenheit des Wortes im Baltischen und anderen europäischen Sprachen; 2. die angebliche Isolierung des Wortes auf dem slawischen Gebiet ohne internslawische etymologische Verbindungen; 3. Bedeutungs-Beschränkung auf dem iranischen und slawischen Sprachgebiet. Diese Argumentationsweise ist nicht neu. ${ }^{29}$ Als zusätzlichen Beweis wertet er noch die Tatsache, dass beim Wort bogr die Variante $\gamma$ nicht nur im Südrussischen und Ukrainischen, sondern auch allgemein im Russischen vorkommt. Als die Ursache dafür, dass bei diesem wort die erwartete substitution $\gamma>g$ nicht eingetreten ist, führt er (S. 49) ein Argument an, das zwar möglich, nicht aber zwingend erscheint und dem man, schon wegen der verhältnismässig seltenen potentiellen Beispiele dieser Art kaum die Dimensionen, welche 
die zit. Erscheinung in der weiteren Entwicklung erreichen müsste, zuschreiben könnte. Als den eigentlichen Grund für die übernahme des Lautes $\gamma^{\mu}$ sieht er: "Stremlenie proiznositb religioznyj termin 'pravilno' $t$. e. vozmožno bliže k pervoistočniku, moglo rasprostranits proiznošenie bogr $i \mathrm{v}$ takuju sredu, kotoroj fonema $\gamma$ voobšče ne svojstvenna" an. Das würde allerdings auf einen verhältnismässig alten Prozess hindeuten, was Abaev (im zusammenhang mit einigen archäologischen Daten) folgendermassen formuliert: "Stalo byts, jugo-vostočnye slavjane, dlja togo čtoby usvoits iz skifo-sarmatskogo fonemu $y^{\prime}$, imeli bolsše čem dostatočno vremeni: ot načala I tysjačeletija do n. e." Auf s. 50 versucht Abaev das Vorkommen des Phonems $h$ im Tschechischen und Slowakischen dem Einfluss der ukrainischen Dialekte zuzuschreiben. Nach der zweiten Variante, die er als möglich aufstellt, "nelızja isključatı i vozmožnostı togo, čto češskij i slovackij byli oxvačeny dannoj izoglossoj ešče togda, kogda predki čexov i slovakov byli rasseleny vostočnee nynešnej territorii i žili $\mathrm{v}$ neposredstvennom sosedstve s predkami ukraincev." Angesichts der Tatsache, dass der Wechsel $g>\gamma^{\prime}$, wie gesagt, auch in anderen sprachen vorkommt, wo man mit einem derartigen Einfluss kaum rechnen könnte ( $z$. B. in einem Teil der slowenischen Dialekte), scheint es jedoch angebracht, die Erklärung mittels Annahme eines verhältnismässig einfachen phonetischen Wechsels, wie ihn z. B. Bernštejn, Očerk sravnitelınoj gramm. slavj. jaz., S. 293, vorschlägt, beizubehalten. Vgl. dazu noch Vaillant, Gramm. comp. I 33. V. Kiparsky behandelt in seiner Russ. hist. Gramm. I 126ff. die Frage des Vorkommens des spirantischen $\gamma$ auf einem Teil des slawischen Territoriums ausführlich, mit Angabe der Literatur und der ältesten Belegstellen. Dabei soll seine Deutung des spirantischen $\gamma$ in einigen wörtern auch allgemein im Russischen erwähnt werden, einer Erscheinung also, der Abaev eine grosse Bedeutung zuschreibt. So stellt Kiparsky (S. 128) folgendes fest: "Unter dem Einfluss der ukrainisch beeinflussten Gelehrten- und Kirchensprache setzte sich später die Aussprache mit $/ 8 /$ in einigen wörtern fest. Bis 1917 wurde in russischen Mittelschulen diese Aussprache in Bog "Gott", gos- 
pód "Herr", bogátyj "reich" und in Zusammensetzungen mit brago(griech. $\sim$ eu-) vorgeschrieben." Diese Erklärung ist jedenfalls überzeugender und wegen des historisch dokumentierten Materials glaubwürdiger als die Interpretation Abaevs. Man kann sich schwer vorstellen, dass sich aus einzelnen Beispielen (Abaev führt sogar nur ein einziges an) eine verhältnismässig starke Tendenz entwickeln konnte. Es bleibt auch fraglich, wie wahrscheinlich die zitierte Erklärung des Phänomens im Tschechischen und slowakischen ist. Andererseits bleibt aber Tatsache, dass keine entsprechende Deutung, die das behandelte Phänomen zuverlässig erläutern könnte, zu Verfügung steht. Dementsprechend gibt es, wie es scheint, auch keine Argumente, die die von Abaev vorgeschlagene Deutung eindeutig widerlegen könnten.

In der Fortführung geht Abaev zu den sog. grammatikalischen Isoglossen über (S. 53ff.). In diesem Zusammenhang versucht er die slawisch-skythischen Beziehungen auch zeitlich näher zu bestimmen. ${ }^{30}$ Seinen Ausführungen nach handele es sich um zwei ossetisch-slawische grammatikalische Isoglossen: (1) Die Verwendung der Präverbia zur Bildung der Perfektiva und (2) der Gebrauch des Genetiv-Akkusativs. Der erste Teil dieses Kapitels befasst sich somit mit dem Gebrauch der Präverbia zur Perfektivierung der verbalen Handlung im Slawischen und Ossetischen. Abaev geht dabei von der Tatsache aus, dass im ossetischen "vse preverby narjadu s lokativnym značeniem imejut četkuju vidoobrazujuščju funkciju: $v$ infinitive, $v$ prošedšem $i$ buduščm vremeni, $v$ pričastijax oni obraščajut nesoveršennyj vid $v$ soveršennyj". Dieser zustand käme sekundär, als Resultat einer langen Entwicklung im Kontakt mit den slawischen Sprachen, zustande (S. 58). Im Weiteren versucht Abaev am Beispiel ossetischer Verba seine stellungnahme zu präzisieren. ${ }^{31}$ Eine besondere slawisch-ossetische übereinstimmung sieht Abaev in der Verwendung des Präverbs slaw. po- und osset. $f \propto$, das die ursprüngliche Bedeutung einbüsste und überwiegend die Funktion eines Wortbildungselementes annahm. Als Beweis dafür, dass die genannte Funktion der Präverbia nicht aus dem Altiranischen ererbt sein konnte, verweist er auf die Tatsache (S. 63f.), dass 
in dén Fällen, in welchen das Präverb mit dem Verbum verschmolzen worden ist, die perfektive Bedeutung nicht auftritt. ${ }^{32}$ Weiter (S. 64) macht er auf den parallelen Gebrauch der Präverbia slaw. vrz-, vrs- osset. yz-, ys- aufmerksam. Abaev stellt fest, dass es möglich ist, einige Beispiele, wo die gleiche Verwendung des Präverbs bei derselben verbalen Basis vorliegt, anzuführen. Etymologisch führt er osset. $y z-, y s-$ auf iran. *uz-, *us- (<*ud-) zurück. Er bezieht auch slaw. vъz- auf dieselbe Urform und bemerkt (S. 65): "Neskolbko smučajuščee $v$ etom slučae $z \mathrm{v}$ vъz-polučaet obъjasnenie kak arealınaja izoglossa, vključajuščja skifskij, slavjanskij i baltijskij (lit. ùz̆-, latys. uz-)." Vgl. Vasmer I 214, der als etymologisch zusammenhängend die zit. slawischen und baltischen Belege und noch arm. $z$ - angibt. Spricht die armenische Vertretung in diesem Falle für eine auf breiterem Gebiet als von Abaev angenommen ererbte Form, oder könnte sie eventuell iranischen Ursprungs sein? Wahrscheinlich müsste sowohl die Funktion als auch die Bedeutung genauer bestimmt werden. ${ }^{33}$ Pokorny 1103f. rekonstruiert $* \stackrel{u}{u} d-$ "empor, hinauf" und $* \frac{u}{u} d-s$ (mit der Verweisung auf die Parallele in lat. $a b$ : $a b s)$. Dabei nimmt er als eine mögliche Vorform *uds- auch für das air. uss-, oss- an. Zu germ. Varianten schreibt er (S. 1104) folgendes: "wesentlich auf *uds vor tönenden Verschlusslauten beruht germ. us- (uz-; vor $r: u r-$ ) Präf. und Präp. 'von, aus'." Es besteht kein Grund, dass man die oben genante Verbindung als eine skythisch-baltoslawische Sonderübereinstimmung ansehen sollte. 34

Im Weiteren (S. 65) kommt Abaev auf die schon genannte Verbindung slaw. po-, balt. pa- und osset. fo- zurück. Er vergleicht noch sak. $p a-$, das normalerweise auf iran. apa-oder pati-zurückgeführt wird, und das toch. Ipv.-Präfix pä- (S. 66). Unklar. Auch wenn das toch. Präfix wirklich auf diese weise zu verknüpfen ist, spricht das wohl eher für eine ursprünglich breitere Vertretung des Präfixes in der genannten Bedeutung und Form auf dem idg. Territorium als für eine Sonderübereinstimmung zwischen den genannten Sprachen.

Auf S. 66 führt Abaev eine Liste der Verba, die offensicht- 
lich in der Opposition nicht-perfektiv : perfektiv sowohl im Slawischen als auch im Ossetischen verwendet werden können. Dieses Verzeichnis scheint eindrucksvoll genug, um die Annahme einer abhängigen Verwendung der Präverbia zur Bildung der Perfektiva im Ossetischen und Slawischen bis zu einem gewissen Grade rechtfertigen zu können. Dennoch bleibt - trotz der zusammenfassenden Feststellung auf S. $68^{35}$ - der Verlauf der angenommenen Übernahme der zit. Wortbildungs-Möglichkeit, diesmal in der Richtung Slawisch $\rightarrow$ Ossetisch, unerklärt.

Im Weiteren (S. 68-79) behandelt Abaev das Phänomen der Verwendung des Genetiv-Akkusativs im Slawischen und Ossetischen. ${ }^{36}$ Beim Versuch der Deutung dieses Phänomens geht Abaev (S. 71) von der Frage aus "počemu i tam i tut $v$ kačestve markirovannogo akkuzativa vystupaet imenno genitiv, a ne drugoj padež? Javljaetsja li eto sovpadenie slučajnym, kak rezulbtat nezavisimogo razvitija $\mathrm{v}$ skifskom $i$ slavjanskom? Ili, byts možet, imelo mesto arealınoe vlijanie skifskogo na slavjanskij ili - obratno - slavjanskogo na skifskij?". Diese, seiner Meinung nach Schlüsselfrage, versucht er zuerst von der slawischen Seite her zu erläutern. Er führt dabei mehrere Deutungsversuche an. 37 Hinsichtlich der Ausbreitung des Phänomens kommen ihm die Interpretationen, die nur vom slawischen Material ausgingen und demnach eine internslawische Entwicklung voraussetzen würden, unglaubwürdig vor. ${ }^{38}$ Infolgedessen schliesst er "čto genitiv-akkuzativ otnositsja k specifičeskim arealbnym skifo-slavjanskim izoglossam i stoit $v$ rjadu drugix leksičeskix i grammatičeskix skifo-slavjanskix izogloss" (S. 73). Forderung der Areallinguistik folgend versucht Abaev den Mittel- bzw. Ausgangspunkt der genannten Erscheinung zu finden. Er geht dabei von der Tatsache aus, dass die Erklärung des Genitiv-Akkusativ-Gebrauchs im Slawischen mit beträchtlichen Schwierigkeiten verbunden ist, wohingegen die Erklärung derselben Erscheinung für das nordiranische Gebiet verhältnismässig einfach wäre. Im Iranischen ist nämlich die Anzahl der Kasus auf casus rectus und casus obliquus reduziert worden. In der Funktion des letzteren kommt sehr häufig gerade der Genitiv vor. Abaev stellt hinsicht- 
lich der Chronologie der Erscheinung (S. 75) folgendes fest:

"Tendencija k prevraščeniju genitiva $v$ universalınyj obъektivnyj padež namestilası ešče $v$ drevneiranskom." ${ }^{39}$ Für das verständnis seines Standpunkts ist die zusammenfassende Feststellung von Bedeutung (S. 78): "Ne otricaem, čto pojavleniju i zakrepleniju genitiva-akkuzativa $v$ slavjanskom mogli sposobstvovatb $i$ te momenty, na kotorye ukazyvali prežnie issledovateli: suščestvovanie staryx priglagolbnyx genitivov vrode Gen. partitivus, vlijanie mestoimennogo sklonenija i pr. No nam predstaljaetsja, čto opredelennuju rols sygrali zdesь $i$ arealbnye skifo-slavjanskie kontakty." Offensichtlich hat Abaev in den Schlussbemerkungen seine These, nach welcher der Ausgangspunkt der Erscheinung auf der iranischen Seite läge und sie eigentlich einen der Entlehnung in der Lexik vergleichbaren Prozess wiederspiegele, gemildert. Diese modifizierte Deutung scheint im Rahmen der beiden Möglichkeiten die wahrscheilichere. Strittig aber bleibt die von Abaev vorgeschlagene Lokalisierung der Genitiv-Akkusativ-Anwendung oder besser - die Begründung derselben auf dem slawischen Gebiet. In diesem Zusammenhang schreibt er (S. 78f.): "V svete etix kontaktov stanovitsja ponjatnym i to, počemu iz vsex slavjanskix jazykov najbolıšee rasprostranenie polučil genitiv-akkuzativ $v$ russkom. Zdesь tolbko $v$ edinstvennom čisle ženskogo roda uderžalsja staryj akkuzativ. Vo vsex drugix kategorijax imen 'oduševlennyx' $v$ edinstvennom $i$ množestvennom čisle gospodstvuet genitiv-akkuzativ. Dialektnoe členenie slavjanskogo nametilosь, nesomnenno, ešče $v$ obščeslavjanskij period, i uže togđa predki russkix dolžny byli bytb bližajšimi sosedami skifo-sarmatskix plemen, a ix narečie najbolee podverženo vlijanijam so storony severnoiranskoj." Vgl. zur Situation im Russischen z. B. V. Kiparsky, Russ. hist. Gr. II $31 f .40$ Hinsichtlich der Tatsache, dass die behandelte Erscheinung in einem gewissen Umfang schon im Altkirchenslawischen vorkommt und die weitere Ausbreitung wenigstens teilweise das Ergebnis interner Entwicklung sein muss, ist es unwahrscheinlich, dass der genannte Gebrauch in den iranischen sprachen seinen Ausgang genommen hätte und von dort in das slawische gelangt wäre. Ob man anneh- 
men darf, dass das Russische die ursprüngliche Anwendung der Genitiv-Akkusativ-Konstruktion unter dem Einfluss des Ossetischen erweitert hat, ist schwer zu entscheiden. Jedenfalls muss man die Frage berücksichtigen, ob die zeitlichen Gegebenheiten die Wahrscheinlichkeit der russisch-osstetischen Beziehungen in der angegebenen Richtung zulassen (dabei muss man, trotz aller Bedenken, von den historischen Belegen im slawischen, insbesondere im Russischen, ausgehen). Vgl. zu der Ausbreitung der Genetiv-Akkusativ-Verwendung auf dem slawischen Gebiet und zu möglichen Gründen z. B. Vaillant, Gramm. comp. II/I S. 17f. ${ }^{41}$ Die von Abaev vorgeschlagene Hypothese des iranischen Ursprungs der slawischen Genitiv-Akkusativ-Anwendung bei Bezeichnungen von Lebewesen scheint zu wenig fundiert zu sein. Eine typologische Gleichung ist einer genetischen vorzuziehen. ${ }^{42}$ Eine solche Hypothese setzt jedenfalls sehr nahe slawisch-iranische Beziehungen, eigentlich Bilinguismus voraus. Vgl. noch Abaev, OJF I 129 ff.

Ein umfangreiches Kapitel widmet Abaev (S. 82-117) dem mythologischen Parallelen, in deren Rahmen auch einige slawisch-ossetische Sonderübereinstimmungen behandelt werden. Vom methodologischen Gesichtspunkt aus ist seine stellungnahme bei der Deutung einer italisch-ossetischen Parallele von Bedeutung. Er lässt dabei (S. 92) drei Möglichkeiten zu: (1) Dass es sich um eine typologische Parallele handele; (2) dass die parallele als Resultat einer genetischen Verbindung bzw. (3) der Areal- und Substrat-Beziehungen anzusehen sei. Bei seinem konkreten Beispiel lehnt er die beiden ersten Möglichkeiten ab und zieht die dritte vor. Die Ablehnung der zweiten Möglichkeiten scheint methodologisch kaum berechtigt. ${ }^{43}$

Slawisch-ossetische mythologische Gleichungen behandelt der Abschnitt mit der Überschrift "Vostočnoslavjanskie božestva Rodr, Xorsz, Sěmarglr" (S. 109-117). Auf S. 110f. leitet Abaev slaw. Rodr etymologisch von dem Appelativum rodr "gens" her und vergleicht damit die ossetische Gottesbezeichnung Naf, die aus dem osset. Appelativum nāfah- "gens" (iran. *nābh- "Nabel") hergeleitet wird. Er bemerkt dazu (S. 111): "Polnoe semantičes- 
koe toždestvo slavjanskogo Rodr i osetinskogo Naf pozvoljaet otnesti etu paru k čislu skifo-slavjanskix religiozno-tipologiCeskix izogloss." Einer derartigen typologischen Parallele kann man nicht einmal im Rahmen der sprachlichen Fakten eine beweiskräftige Geltung zugunsten der Annahme näherer sprachlicher Berührungen zuschreiben, destoweniger ist ein solches verfahren bei dem mythologischen Material, das, wie es scheint, weniger eindeutig ist als das sprachliche, zu empfehlen. 44

Es folgt (S. 111f.) der Vergleich zwischen osset. Wcojyg/ Wcejug "Pförtner der Unterwelt" und apreuss. Wéjopatis "der Herscher Vej" auf der einen und mit dem ukr. myth. Wesen Vij auf der anderen Seite. Ukr. Vij leitet Abaev (S. 113) von einem ursprünglichen *véj her, das er weiter mit iran. Vāyu-verbindet. Er bemerkt dabei, dass keine iranische Entlehnung vorliegen kann, sondern ein gemeinindogermanisches ererbtes Wort anzunehmen ist. Dié vermutete engere Verbindung zwischen dem Slawischen und Iranischen begründet er folgendermassen (ibid.): "I esli my možem govoritb zdess ob irano-slavjanskoj izoglosse, to eto potomu, čto funkcija boga smerti, kotoraja prisušča ukrainskomu Viju, xarakterna dlja Vaya imenno na iranskoj počve, $v$ avestijskom $i$ osetinskom." Aus dem Awesta führt er (S. I13f.) Aogəmadaeča 77-81 an und folgert (S. 115) daraus: "V etom tekste 'Avesty' i povesti Gogolja vystupaet odin i tot že mifologičeskij obraz, zloveščj i strašnyj obraz neumolimogo boga smerti. I eto sbližaet ukrainskogo Vija imenno s iranskim Vayu." Es. stellt sich aber die Frage, ob man bei der ererbten Basis, die auch Abaev anerkennt, eine solche Bedeutungsübereinstimmung als eine gemeinsame Innovation deuten kann. Wenn man das nicht (wenigstens mit einer grösseren Wahrscheinlichkeit) zeigen kann, darf die angeführte Gleichung nicht als gültiger Beweis für die Annahme iranisch-slawischer Sonderübereinstimmungen angesehen werden. 46

Die slaw. Gottesbezeichnung Xors (Vasmer III 265 "Sonnengott", aruss. Xrrsz), die sonst auf aw. hvarašētam, mpers.

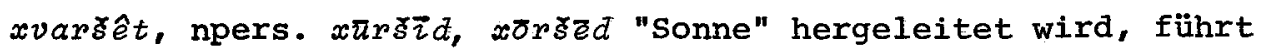
Abaev aus phonetischen Gründen lieber auf osset. xorz/xwarz 
"gut" (iran. *hvarzu-) zurück. Er weist daraufhin, dass in der osset. Mythologie und Religion dieses Epitheton oft im Zusammenhang mit einigen Gottesbezeichnungen gebraucht wird. Als Beispiel nennt er digor. xwarz Nikkola bzw. Nikkola xwarz. Aus diesem Gebrauch schliesst er (S. 116): "Možno byt uverennym, Čto do 'Dobrogo Nikoly' u osetin sušcestvoval tože 'dobry' jazyčeskij bog. I vot etot-to stary alanskij bog, kotorogo zvali xorz "dobryj" i byl zaimstvovan v drevnerusskij, pričem epitet xorz byl vosprinjat kak sobstvennoe ime božestva." Vgl. auch Abaev, OJF I 597. Diese Etymologie scheint im Vergleich mit der vorigen besser begründet, besonders hinsichtlich der Phonetik, aber auch hinsichtlich der Semantik. Von den bisher vorgeschlagenen ist sie vielleicht am ehesten annehmbar. ${ }^{47}$

Anschliessend (S. 116f.) behandelt Abaev die russ. Gottesbezeichnung Semarg 23 , die schon Trever 48 mit dem Iranischen, und zwar pers. Sinmury", aw. marajō saenō * "Vogel Saina" zusammenbrachte. ${ }^{49}$ Wegen des vokalismus der russischen Bildung verbindet sie Abaev lieber mit einer allerdings unbelegten skythischen Bildung * Sénmarg. Das auslautende $-\tau_{6}$ im Russischen fasst er als sekundären Zusatz auf, der ev. auf Kontamination mit dem biblischen Sim und Nergel beruhen könnte. Die vorgeschlagene Etymologie scheint zwar - ähnlich wie bei dem vorigen Beispiel - möglich, sie bleibt aber hypothetisch.

Im letzten Kapitel seiner Abhandlung versucht Abaev die vorgelegten skythisch (bzw. ossetisch)-europäischen Isoglossen auch zeitlich $\mathrm{zu}$ bestimmen. ${ }^{50}$ Dabei berührt er auch die Frage der sog. alteuropäischen Sprachgemeinschaft, die durch seine Annahme skythisch-europäischer Sonderübereinstimmungen vorausgesetzt wird (S. 127f.). ${ }^{51}$ Es folgen kürzere Zusammenfassungen seiner Schlüsse über die Verbindungen der Skythen mit einzelnen europäischen Sprachen. Die Beziehung der Skythen und Balten behandelt er auf S. 133f. Da das Material, wie aus den Anfangskapiteln der Abhandlung ersichtlich, sehr beschränkt ist und deswegen nicht besonders überzeugend wirkt, beugt Abaev möglichen diesbezüglichen Vorwürfen folgendermassen vor (S. 134): "Količestvennye (statističeskie) pokazateli imejut značenie dlja 
suždenija o dlitelbnosti i intensivnosti kontaktov. Dlja ustanovlenija že principialbnogo fakta sosedstva i vzaimodejstvija daže odin ediničny fakt imeet vpolne dostatočnuju silu, esli nikakie drugie predpoloženija, krome prjamogo kontakta, ne mogut byts privedeny dlja ego obъjasnenija. I mne takže kažetsja, čto my imeem delo imenno s takim slučaem." Eine solche Stellungnahme scheint nur in dem Falle berechtigt, dass die Isoglosse keine andere Erklärung zulässt (z. B. Entlehnung, die durch phonetische Charakteristika der behandelten wörter bestätigt wird, unter der Bedingung allerdings, dass kein Kulturwort vorliegt) oder aber zugunsten deren auch noch nachweisbare aussersprachliche Fakten anzuführen sind. 52

Es folgen (S. 134ff.) die zusammenfassenden Feststellungen über die skythisch-slawischen Beziehungen. Diesen Exclusiv-Isoglossen schreibt Abaev grosse Bedeutung zu. Er beruft sich dabei in erster Linie auf die schon genannten phonetischen und grammatischen Isoglossen, die aber offensichtlich nicht so klar und eindeutig sind, dass sie weitreichende schlüsse in dem zit. Sinne zulassen würden. Eben sie deuten aber nach Abaev auf besonders nahe Beziehungen zwischen den beiden Sprachgruppen hin. Wegen der möglichen, sogar wahrscheinlicheren Alternativerklärungen dieser "Isoglossen" scheinen jedoch die von Abaev vorgebrachten Schlüsse schwerlich berechtigt. Die slawisch-skythischen Beziehungen bestimmt Abaev (S. 135) mit der Zeitspanne von dem 4. Jh. n. Chr. (anscheinend: vor Chr.!) bis $\mathrm{zu} \mathrm{11./12.}$ Jh. n. Chr. Auf S. 136 datiert er den Anfang der iranisch-slawischen Beziehungen schon in die vorskythische Epoche, in die Zeit der indogermanischen Dialekte. Besonders diese frühen $\mathrm{Be}-$ ziehungen sind aber von Standpunkt des Indogermanischen her schwer bestimmbar, weil sei eine Abgrenzung der einzelnen Stufen der indogermanischen Ursprache, wie sie aus den historischen Sprachen rekonstruierbar ist, fordern. In der Auffassung dieser Fragen gehen die Indogermanisten weit auseinander, insofern sie solche theoretischen Ausgangspunkte überhaupt explizit berühren. Wenn aber die theoretischen Grundlagen (wenigstens im Sinne einer Arbeitshypothese) nicht möglichst präzis bestimmt 
sind, hängen auch die Schlüsse solcher Abhandlungen in der Luft. ${ }^{53}$ In dem Kapitel "O xronologii palatalizacii" (S. 140) versucht Abaev etwas konkreter die Entstehung der sog. skythisch-europäischen Isoglossen zu bestimmen. Er setzt sie in die Mitte des 2. Jh. v. Chr., als die alte europäische Gemeinschaft noch als eine Einheit, obwohl in sich selbst schon stark differenziert, bestanden habe. In dieser zeit sei noch der Fall, dass "vsja drevneevropejskaja jazykovaja obščnostb, vključaja baltijskie i slavjanskie jazyki, byla ešče 'kentumnoj'" (s. 141). Später, als die Balten und die Slawen in näheren Kontakt mit den skythen gekommen seien, hätten sich "v baltijskom i slavjanskom $v$ porjadke novoj fonetičeskoj izoglossy, svjazyvajuščej $k^{9}, g^{9} v$ sootvetstvujuščie sibiljanty, balto-slavjanskie jazyki 'satemizirovalisb'" (ibid.). Im bezug darauf, dass die sog. Satemisierung - selbst nach der Meinung Abaevs ${ }^{54}$ - in den einzelnen sprachen unabhängig zustande gekommen sei, ist es schwer $\mathrm{zu}$ behaupten und noch schwieriger $\mathrm{zu}$ beweisen, dass der genannte Prozess im Baltischen und Slawischen bei der Berührung mit den Skythen bzw. unter dem Einfluss dieser entstanden sei. Eine solche Interpretation ist zwar nich ganz auszuschliessen, sie bleibt aber hypothetisch.

Auf S. 142f. folgt eine kurze historische Information, nach welcher die Skythen den Ackerbau von den europäischen völkern übernommen hätten, und die Abaev mit einigen schon behandelten Isoglossen (z. B. aus dem Slawischen osset. xsyrf "Sichel") erläutert. Er verweist weiter (S. 143f.) auf einige archäologische Daten, die die Feststellung der skythisch-westeuropäischen Verbindungen ermöglichten (S. 144, Anm. 45).

Es folgen zuletzt (S. 144-147) noch einige theoretische Bemerkungen zur Areallinguistik. So stellt Abaev (S. 145) hinsichtlich des ossetischen fest, dass mán neben den ererbten und entlehnten wörtern noch zwei Kategorien berücksichtigen muss: die Substrat- und die Areal-Lexik. Den Begriff "Areal-Isoglosse" definiert er (S. 145f.) folgendermassen: "Pod arealbnymi ponimajutsja obyčno takie izoglossy, kotorye ne vozvodimy $k$ edinomu prajazyku $i$ voznikali $v$ posleprajazyčnyj period 
na počve istoričeski skladyvavšixsja territorialbnyx obščnostej." 55 Die Kategorie der "Areal-Lexik" bleibt somit noch immer unerklärt, wenigstens hinsichtlich der Herkunft bzw. der Entstehung solcher wörter und deren weiterer morphologischer Analyse, wie sie in der historischen Sprachwissenschaft gefordert wird. Eine solche Wortkategorie setzt eine besonders nahe Beziehung zwischen den miteinander in Kontakt stehenden sprachen voraus. In diesem Rahmen wären einige Beispiele in der Tat nur dann verständlich, wenn man mit Bilinguismus rechnen könnte. Einen solchen status für die baltoslawisch-iranischen sprachbeziehungen anzunehmen scheint mir gewagt und unbeweisbar.

In seiner studie "Iz slavjano-iranskix leksičeskix otnošenij", Etimologija (1965), Moskva 1967, S. 3-81, stellt O. N. TRUBAČEV einführend den heutigen stand der Literatur zum Problem dar und versucht $z u$ einigen grundlegenden Fragen kritisch Stellung zu nehmen. In diesem Rahmen fällt besonders die Problematik des sog. monolitischen slawischen auf. ${ }^{56}$ Im Gegensatz $z u$ dieser $\ddot{i b l i c h e n ~ A u f f a s s u n g ~ s t e h t ~ T r u b a c ̌ e v ~ a u f ~ d e m ~ S t a n d p u n k t, ~}$ dass man vom dialektisch gegliederten Urslawischen ausgehen muss und dass man den lokalen Charakter vieler slawisch-iranischer Wortgleichungen beweisen kann (S. 4). Diese These, die den roten Faden der ganzen Abhandlung vorstellt, wird explizite an mehreren Stellen formuliert. 57 Ähnliche Forderungen stellt er auch für das iranische Material, wo man, seiner Meinung nach, das Awestische überprüfen müsste, besonders bezüglich der Daten, die in den ostiranischen sprachen zur Verfügung stehen (S. 9). Hinsichtlich der chronologischen Bestimmung der slawisch-iranischen lexikalischen Beziehungen nimmt Trubačev an (S. 10), dass sie zwar verhältnismässig alt seien, jedoch jünger als z. B. die iranisch-ugrofinischen, iranisch-germanischen und iranisch-baltischen, begründet aber seine These nicht weiter.

Anschliessend befasst sich Trubačev in seiner Abhandlung eingehender mit den baltisch-iranischen Sprachbeziehungen ( . 12ff.). Er widersetzt sich entschieden der Meinung Porzgis, dass wir in diesem Rahmen nur von erhaltenen Archaismen in den Rand- 
gebieten sprechen können. Er führt zur Bestätigung seiner These: "... eto celyj rjad razroznennyx balto-iranskix etimologičeskix sbliženij, kotorye sami po sebe nedvusmyslenno ukazyvajut na naličie specifičeskoj balto-iranskoj svjazi v slovoobrazovanii, leksike, terminologii, na suščstvovanie neosporimyx odnostoronnix zaimstvovanij narjadu s etim (kak pravilo - iz iranskogo v baltskij)" (S. 12) Beispiele an, die aber nicht analysiert werden und demnach neu zu überprüfen wären.

Auf S. 12 zählt er die vermuteten baltisch-iranischen Isoglossen auf: iran. maiz- "säen" : lit. miez̃ys, lett. miezis "Gerste"; iran. dānā "Korn" (auch ai. dhānā) : lit. dúona "Brot"; aw. ai. yava- "Korn" : lit. javaz "Getreide" (Trubačev verweist darauf, dass bei dieser Gleichung auch Belege aus anderen Sprachen, z. B. aus Griechischem, dazukommen); aw. $x$ švid"Milch" : 1it. svíestas "Butter"; osset. bclon "Taube". : lit. balañdis, lett. baluôdis "Taube"; npers. kabūtar "Taube" (auch in den ostiranischen Sprachen gut bezeugt) : apreuss. ketauris "Taube"; sogd. čakt, pahl. čakāt "Stirn" : lit. kaktà "Stirn". Die Forscher, die diese Gleichungen vorlegten, haben, der Meinung Trubačevs nach, daraus nicht die adäquaten Kosequenzen gezogen. Er verweist darauf, dass im Bereich des Flusses Sejm sowohl iranische (Osmon6, Kamennaja Osmon6ka usw.) als auch baltische Flussnamen (Obesta, Klevent usw.) vorkommen. Gegen Norden, im Tal des Flusses Desna kommt der Flussname Lopanka vor, dass als eine Lehnübersetzung zum iranischen Rop ̌̌a und slawischen Lisið̌ka zu stellen sei. ${ }^{58}$ Anhand dieser Beispiele schliesst Trubačev (S. 13) auf unmittelbare baltisch-iranische Kontakte, die, wenn die genannte Flussnamen-Bezeichnung richtig gedeutet ist, auch sehr genau lokalisierbar wären. Bevor wir $\mathrm{zu}$ den weiteren baltisch-iranischen Gleichungen, die Trubačev vorlegt, übergehen, sollen die bereits angeführten wortgleichungen kritisch besprochen werden. Dazu gehören:

1. Iran. maiz- "säen" : lit. miežỹs, lett. miezis "Gerste". Die Gleichung ist problematisch, weil die beiden Seiten nicht genug klar sind. Für die iranische Seite führt Bartholomae $s$. 1108f. gaw. maēz- "hegen", Präs. $3 \mathrm{~m} \vec{\imath} z a-$ "sorglich pflegen (das 
Rind)" an (< indoir. "smaig-) und vergleicht mhd. smeichen "schön tun". Anscheinend ist wenigstens für das Altiranische die Bedeutung "säen" nicht zuverlässig zu bestimmen. Fraenkel, LEW 451, zitiert zahlreiche Nominalerweiterungen auf der baltischen Seite, so z. B. neben den schon Erwähnten lett. màize "Brot", apreuss. moasis "Gerste", eine etymologische Deutung ist jedoch nicht gegeben. Angesichts der problematischen Bedeutungsbestimmung des iranischen Wortes und der etymologischen Undurchsichtigkeit der Belege scheint derzeit nicht angemessen, weitreichende Schlüsse zu ziehen. Pokorny führt die genannten Bildungen nicht an und hat offenbar auch keine entsprechende Wurzel, von der sie befriedigend herzuleiten wären. 59

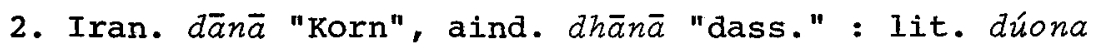
"Brot". Bartholomae 734 zitiert das jav. Kompositum dānō.karš" (Getreide)körner (ver)schleppend, Bezeichnung einer Ameisenart". Mayrhofer II 98 führt neben den schon genannten noch mittel- und neuiranische Bildungen (so z. B. khotansak. dāna f. "Getreide, Korn", sogd. $\delta_{n}$ "Getreidekorn", mpers. dānak, npers. dāna "Korn") und toch. tāno "Korn, Samenkorn, Getreide" an und bemerkt, dass das Etymon in der Bedeutung "Getreide(korn)" unverlässlich bleibt. Das toch. Wort könnte zwar aus dem Indischen oder Iranischen entlehnt worden sein, notwendig ist das aber nicht. Von Windekens, Le Tokharien I 497, führt als verhältnismässig wahrscheinlich toch. B tāno unmittelbar auf idg. *dhōnā zurück, wofür auch B -tāane im ynaiketā̃ne spreche. In dem Falle würde es sich nicht um eine iranisch-baltische Parallele (das ist schon wegen altindischen Beleges unmöglich) handeln, vielmehr hätten wir es mit einem Kulturwort, das auf einem breiteren Gebiet vertreten ist, zu tun. Fraenkel 111 führt auf der baltischen Seite lit. dúona "Brot" und lett. duõna "Schnittbrot, bes. Brotende" an. Vgl. noch Duchesne-Guillemin, BSL 4l, S. 180 und Fraenkel, Balt. Sprachen 36.

3. Aind. yava- "Korn" : lit. javã̃ Pl. "Getreide". Für die Annahme, dass es sich in diesem Falle um eine altindisch-baltische Isoglosse (Trubačev führt nicht einmal die iranischen Bildungen an) handele, scheint es keinen zwingenden Grund zu geben. 
Pokorny 512 rekonstruiert idg. *yewo- "Getreide, vor allem Gerste" mit den folgenden Vertretungen in den einzelnen Sprachen: aind. yáva-m. "Getreide, Gerste", aw. yava-m. "Getreide", npers. jav, jo "Gerste", lit. jâvas m. "Getreideart", hom. att. zeiai f. P1. "Spelt". Mayrhofer III 3f. fügt als eine wahrscheinlich urverwandte Parallele noch heth. eua- "eine Feldfrucht und das daraus bereitete Gericht" hinzu. Vgl. noch Frisk, GEW I 608. Es handelt sich offensichtlich um ein sog. Kulturwort mit einer weiteren Vertretung. Vgl: noch Porzig, Gliederung 169.

4. Aw. xšvid- "Milch" : lit. svíestas "Butter". Bartholomae 562 führt keine etymologische Deutung an. Fraenkel 953 verbindet lit. svíestas "Butter", lett. sviêsts, sviests "dass." mit lit. svíesti "werfen usw.". Vgl. Fraenkel, Balt. Spr. $36 \mathrm{f}$. Pokorny (S. 1043) rekonstruiert eine Wurzel *swēid- "Milch", wo er (mit Fragezeichen) die aw. und balt. Formen anführt, wenn sie nicht eher, wie er selbst vorsichtig vorschlägt, zu *swĕ (i)-, *sweid- "biegen, drehen, schwingen" (S. 104lf.) zu stellen sind. ${ }^{60}$ Wenn die beiden Bildungen zusammengehören, könnte es sich wohl um ererbte wörter handeln. Eine gemeinsame Bedeutungsinnovation bzw. Bedeutungsbeschränkung wäre zwar möglich, ist aber nicht beweisbar.

5. Osset. bcelon "Taube" : lit. balañdis, lett. baluôdis "dass.". Nach Abaev, IES I 249, handele es sich um ein idg. Wort, das auf einem beschränkten Gebiet belegt ist. Osset. bceIon wäre sekundär anstatt bceron. Seiner Interpretation nach wäre die ursprüngliche Bedeutung wahrscheinlich "vöglein" und demnach vergleicht er die Sippe vom aind. bala- "Kind", bāzaka"Kind, Tier-junge" usw. Im Zusammenhang mit dem Bedeutungswechsel "Kind" $\rightarrow$ "Taube" verweist er auf aind. bā $z \bar{g} g r a-$ "Taubenfleisch" : bāza- "Kind". Wenn wirklich ein solcher Bedeutungswandel vorläge und die Verbindung mit aind. bă $z_{a}$ - elnleuchtend wäre, würde es sich um die Wurzel *bel- "stark" (Pokorny 96) handeln. ${ }^{61}$ Lit. balañdis und lett. baluôdis werden allerdings von der Wurzel *bhel(a)- "glänzend, weiss" hergeleitet und hinsichtlich des suffixes mit slaw. *olbqd "Schwan" vergleichen 
(vgl. z. B. Skok II 256). In dem Falle aber, dass sowohl die osset. als auch die balt. Bildung auf *bhel(a)-zurückzuführen wären, würde sich aller Wahrscheinlichkeit nach um ererbte Bildungen handeln, obwohl der verhältnismässig einfache Bedeutungsübergang auch unabhängig auf beiden Seiten zustandegekommen sein könnte.

6. Npers. kabütar "Taube" (auch in den ostiranischen Sprachen vertreten) : apreuss. ketauris "Taube". Nicht klar. ${ }^{62}$

7. Sogd. čakt, pahl. ¿̌akāt "Stirn" : lit. kaktà "dass.". Etymologisch unklar. Fraenkel 206 führt bei lit. kaktà die bisherigen Deutungsversuche ( lat. conquiniscere "sich niederbücken"). Man könnte vielleicht von der wurzel *keg, *kengbzw. *kek-, *kenk- "Pflock zum Aufhängen, Haken, Henkel" und auch "spitz sein" (Pokorny 537f.) ausgehen und die letztgenannte Bedeutung als die ursprüngliche annehmen. Die Bedeutungsverbindung "Spitze" - "Stirn" zeigt z. B. auch die Wurzel *kel(a)"ragen, hoch (heben)" (Pokorny 544) in den Bildungen wie aksl. čezo "Stirn, Haupt, Spitze" usw. Pokorny 538 zitiert t-Erweiterungen von einer Wurzelvariante mit stimmhaften Auslaut: slaw. *kogrto im russ. kógot6 "Klaue, gekrümmte Eisenspitze", osorb. kocht "Dorn, Stachel" und germ. *hakuda- neben *hakida im ags. hacid usw. Vgl. auch Vasmer I 558.

Die von Trubačev auf S. 12 seiner Abhandlung angeführten "baltisch-iranischen Isoglossen" sind, wie es scheint, nicht so beschaffen, dass sie a priori Sonderbeziehungen zwischen den beiden Gruppen gegenüber den anderen idg. Sprachen voraussetzen oder sogar fordern würden. Anhand der angeführten Gleichungen kommt Trubačev (S. 13) zum folgenden Schluss: "Na etom i nekotoryx drugix primerax udaloss pokazats kontakt baltijskix i iranskix nazvanij $v$ ramkax odnogo gidronimičeskogo landšafta, a glavnoe - vydvinutb i obosnovatb tezis o neposredstvennyx balto-iranskix kontaktax." Seiner Meinung nach kann man auf diese Weise die baltisch-iranischen Beziehungen eindeutig lokalisieren, was aber, wie schon gesagt, in erster Linie von der Richtigkeit der etymologischen Deutung der angeführten sowie einiger anderer Flussnamen-Bezeichnungen auf dem genannten Gebiet abhängt. 
In der Fortführung seiner Abhandlung fügt Trubačev (S. 14ff.) mehrere neue baltisch-iranische lexikalische Gleichungen, die folgende, vermutlich neue Eigenschaften aufweisen, dazu: "Zdesь estb leksičeskie paralleli, sovmestnye innovacii i sxoždenija slovoobrazovanija i semantičeskogo razvitija, oxvatyvajuščie baltijskie jazyki ili ix častb i iranskie (kak pravilo eto vostočnoiranskie jazyki)" (S. 13). Es seien auch einige Entlehnungen aus dem Iranischen ins Baltische vorhaden. Auf $S$. 14 führt Trubačev folgende baltisch-iranischen Gleichungen an:

1. Lit. mẽtas "Zeit", P1. mẽtai "Jahr", lett. mets "Zeitspanne, Zeitabschnitt" (es kommt auch alb. mōt "Jahr" vor). Den baltischen Bildungen entsprechen, seiner Meinung nach, am besten die in den ostiranischen Sprachen auftretenden Zeitbezeich-

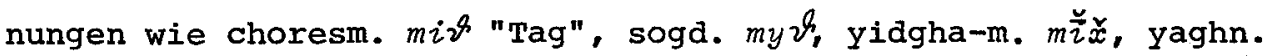
$m \bar{e} t, m \bar{e} \imath$, šughn. $m \bar{e} \vartheta_{\text {r }}$ sangl. $m \bar{\varepsilon} i$ "Tag", osset. met, $m \bar{\imath} t$ "Schnee", ${ }^{63}$ alle aus iran. $*_{m} \bar{a} \vartheta_{y} a-\left(<\right.$ idg. $\left.*_{m} \bar{e}-t-y-o-\right)$, während er

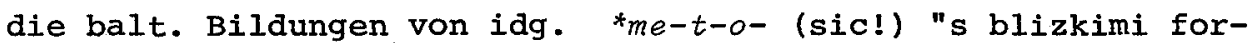
mantami ot edinogo i.-e. "mü- 'meritb'" herleitet. Was die formale Seite der zit. Gleichung anbetrifft, muss man zweierlei betonen: 1. Die beiden Urformen sind nicht identisch, sind aber mit verwandten Wortbildungsverfaren gebildet (Thematisierung); 2. Idg. *me-ti- und ${ }^{*} m e-t o-$ bzw. ${ }^{*} m-e-t-o-$ (vgl. gr. métron usw. Pokorny 703) stellen produktive Wortbildungen dar und setzen keine spezifischen Entwicklungsstufen im Baltischen bzw. Iranischen voraus. Die Bedeutungsseite ist, wie es scheint, eher günstig, obwohl man auch hier mit einer unabhängigen, parallelen Entwicklung und einem verhältnismässig einfachen Bedeutungswandel rechnen kann; vgl. z. B. alb. mōt "Jahr, Wetter", got. mēl n. "Zeit", ags. mel "Mass, Zeitpunkt, Mahlzeit", aha. māl "Zeitpunkt, Mahlzeit" usw. Allerdings muss man auch bei der formalen Seite der Gleichung die Existenz der albanischen Bildung berücksichtigen. Es scheint besser, bei der genannten Gleichung das Vorhandsein eines sog. "passiven Sprachbundes" (was in der Tat vielleicht eine bedingte Beibehaltung eines Archaismus bedeutet) anzunehmen als mit einer gemeinsamen baltisch-iranischen Neuerung zu rechnen. Wegen der albani- 
schen Bildung ist vielleicht nicht einmal eine solche Deutung berechtigt. Vgl. Fraenkel, LEW 445 und Pokorny 703.

2. Lit. piẽtuss "Mahlzeit, Mittag" aw. pìwa- "Nahrung, Speise", sangl. padf "Fleisch", osset. fyd "Fleisch"< iran. *pitu-, wozu auch aind. pitú- "Nahrung, Speise" zu stellen ist. Trubačev vergleicht weiter auch aksl. pitati, pitěti, pišta. Baltisches tpeitu- und indoiranisches *pitu- seien als u-Bildungen enger verbunden. Man muss aber bemerken, dass die u-Basis nicht auf das Baltische und Indoiranische beschränkt ist, sondern z. B. auch im Keltischen vorkommt. Pokorny 794 führt in diesem Zusammenhang folgendes an: air. ith " (*Nahrung), Korn, Getreide", acymr. it, ncymr. yd (< *pitu-) "dass."; weiter mir. ith "Talg" (< *pitu-) und aus der Vollstufe *pei-tu- noch mir. $\vec{a} a t h$ n. "(fette) Wiese, Land". Vgl. noch Mayrhofer II 278.

3. Lit. plónas "dünn", und noch besonders lett. plâns "eben, flach", plañs "von Lehm festgeschlagene oder steinerne Diele", apreuss. plonis "Tenne" sollten, der Meinung Trubačevs nach, eng mit den folgenden ostiranischen (pāmir.) wörtern zusammengehören: sangl.-iškāš. frūn "Diele, Brett", wah ī rün usw., das er auf iran. frāna- $\left({ }^{*} p(\bar{a} n o-)\right.$ zurückführt. Es liegt offensichtlich eine idg. Bildung * $p \bar{a}-n o-$ vor, die aber nicht auf das Baltische und Iranische beschränkt ist, sondern auch z. B. in lat. plānus "platt, eben, flach" usw. vorkommt. Vgl. Pokorny 806 und Fraenkel 628f. Es ist nicht ersichtlich, in welchem Punkt Trubačev engere zusammengehörigkeit der baltischen und ostiranischen Bildungen findet.

4. Lit. Šálti "frieren, gefrieren", lett. sâtt "dass." verbindet Trubačev als eng verwandt mit osset. sælyn "gefrieren, frieren", sald "Kälte, Frost" und mit aw. sarata-, npers. sard "kalt, kühl". Fraenkel 960f. führt als verwandte Formen auch aruss. slota "Schlack-, Unwetter" und versehentlich noch aisl. kelda (:kaldr "kalt") "Quelle, Brunnen, Sumpf" an, wo aber offenbar ein * $g$ - vorliegt. Die iranischen und baltischen Formen stellen keine gemeinsame Neuerung, sondern bestenfalls einen isolierten Archaismus dar, was aber ebenfalls bedenklich ist, da die Wurzel auch im Germanischen vorkommt (vgl. Pokorny 551f.: 
z. B. ndl. hal n. "gefrorener Boden"). 64 Dazu sind neue Angaben, die Benveniste, Études sur la langue ossète, S. 71, bringt, von grosser Bedeutung. Er schreibt: "L'adjectif iranien sarta'froid, gelé' (aw. sarata-, sogd. srt, pers. sard, pš. sōro etc.) a toute l'apparence d'un adjectif verbal en -ta; mais la racine, qui serait *sar-, n'a pas encore été reconnue en iranien. Or le lituanien a non seulement l'adjectif šáltas 'froid, gelé' qui recouvre exactement ir. sarta-, mais aussi le verbe šálti 'geler' dont šáltas est le participe. Il est donc usuel, en étymologie indo-européenne, de poser une racine *kel-, garantie par lit. $\check{s} a l-t i$, et un adjectif verbal *kel-to-, d'après lit. šaltas, av. sarata-, etc. Mais personne (même parmi le iranistes) ne semble avoir remarqué que l'ossète possède à la fois le verbe et l'adjectif: sœl-in'geler': sald 'gelé', c'est-à-dire ir. *sal-: sal-ta-. Le fait est même deux fois intéressant: nous avons ici un $l$ ossète qui continue un $l$ indoeuropéen; et un radical oss. scel- qui represente i.e. *kel- au même titre que lit. $\check{s} a l-$. On voit donc que le couple oss. scl: sald et aussi probant et doit être mis au même plan que lit. šal-: šáltas pour la restitution de i.e. *kel-: *kelto-. Au point de vue iranien le verbe ossète scel- nous donne directement le radical verbal sardont dependent av. sarata- et les formes apparentées, et que jusqu'ici il fallait déduire de composés ou dérivés tels que av. sarəə⿱夂口a- 'qui gèle', sārasti- 'frigidité, fièvre froide', m.parthe. vi-sār-, wakhi wasēr 'refroidir', pers. asfurde 'refroidi'." Das Faktum, das Benveniste hier darstellt, die Abwesenheit einer archaischen Bildung in den alten iranischen Sprachen und deren Vorkommen in einer modernen - konkret der ossetischen - Sprache, erhellt seinerseits die situation, die für viele idg. Rekonstruktionen kennzeichend ist: wie schwierig und oft problematisch das Auseinanderhalten der Archaismen und Innovationen ist, da die Vertretung bzw. Nicht-Vertretung einer bestimmten Bildung in einer Sprache von verschiedenen, meistens unvorhersagbaren Faktoren, die üblicherweise als "Zufall" bezeichnet werden, abhängt. Hinsichtlich der Rekonstruktionen stellen sich zwei Fragen: 1. Wie kann man die Vollstufe des Wurzelvokalismus erklä- 
ren, wenn ein ursprüngliches Partizip vorliegt, und 2. ob man dieselbe Ablautstufe für die awestische und litauische Bildung annehmen kann. Weist die litauische Intonation im Infinitiv und dem entsprechend (wenn ein altes Partizip vorliegt) šáltas auf eine alte langvokalische Basis hin? Wie ist dann das aw. -ə- im diesem Kontext $z$ deuten? Bezüglich der ersten Frage wird normalerweise für das Partizip Schwundstufe der. Wurzel und akzentuiertes Suffix -tó- angenommen. Diejenigen Bildungen aber, die nicht in das Verbalsystem eingegliedert sind, können verschiedene Anwendungsmöglichkeiten der Ablautsstufe des Wurzelvokals gehabt haben. ${ }^{65}$. Was aber die ev. Annahme einer langvokalischen Basis anbelangt, soll auf die bekannte Tatsache, dass die aw. Form sarəta- ein anaptyktisches -ə- enthält, ${ }^{66}$ und ein Laryngal in dieser stellung schwinden würde, hingewiesen werden. ${ }^{67} \mathrm{Zu}$ lit. Akut in der zit. Stellung vgl. Stang, Vergl. Gramm. der balt. Sprachen auf mehreren Stellen. ${ }^{68}$ Fraenkel 961 geht von einer leichten Basis aus. 69

5. Lit. aliótis "Rasereien, unsinn machen", lett. ã lêtiês "sich unruhig gebärden, lärmen, toben", ã z̧a "Kapriolenmacher, unsinniger Mensch, Dummkopf" sei nach Trubačev am nächsten mit aw. ara-, sogd. $r^{2} k$ ( $*^{2} \bar{r}_{a k a-}$ "wild, verrückt, dumm"), osset. cerra "verrückt, wahnsinnig" zusammenzubringen. Pokorny 29 führt die balt. Bildungen auf eine lautnachahmende wurzel *alā-usw. "hallo!", die auch im Griechischen und Slawischen vorkommt, zurück. Er verzeichnet aber keine entsprechenden iranischen Bildungen. Auch Bartholomae 185 deutet keine Etymologie-Möglichkeit an. Vgl. auch Fraenkel 7. Unklar.

6. Weiter (S. 14f.) verbindet Trubačev lit. šúdas "Dreck, Mist, excrementum", lett. süds "Mist, Dünger, Exkremente, Dreck, Unflat, Eiter" (neben den gr. gloss. hyskythá hyòs aphódeuma, kythnón" spérma Hes.) mit aw. xšudra- "semen" und leitet beides aus idg. * $k^{\prime} s u d(h)-/^{*} k^{\prime} s \bar{u} d(h)$ - her. Fraenkel 1030 bezeichnet die Etymologie als unklar, die wahrscheilichste scheint ihm die Anknüpfung an die zit. gr. Bildungen zu sein. Pokorny 627 verzeichnet eine Wurzel $k^{3} \underline{u} d h$ - "Mist, Kott"?? mit den zit. gr. und balt. Belegen. Es ist nicht ganz klar, welche Bedeutung bei 
jaw. $x \bar{s} u d r a-, x \bar{s} u \delta r a-$ als die ursprüngliche anzusetzen ist. Bartholomae 555 führt folgende Bedeutungen an: 1. "flüssig"; 2. n. "Flüssigkeit" usw.; a) alkoholische, "Wein", b) "Samenflüssigkeit, semen virile". Als offenbar aus derselben wurzel erweiterte Bildung führt er ibid. noch g. und jaw. xšusta"flüssig, spez. breiflüssig"; a) vom Lehm, sva. "aufgeweicht"; b) vom Metall (Eisen), sva. "geschmolzen" an. Schwer deutbar. 70 Wenn auch die zit. Hes. Glosse dazugehört, kann es sich allerdings nicht um eine baltisch-iranische sonderübereinstimmung handeln.

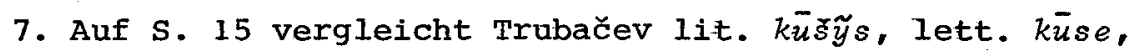
küsis "Schamhaar, weibliche Scham" mit npers. kus "weibliche Scham", aind. kukşi- "Darm". Mayrhofer I 219 führt die aind. Bildung auf *quk'-si- zurück und vergleicht sie vorsichtig mit lit. kus̃ys (qūk'si-?). Pokorny 953 verzeichnet unter den $k^{\prime}-E x-$ weiterungen der Wurzel *(s)keu-, *(s)keuə-, *(s)ku- "bedecken, umhüilen" aind. kukṣi- m. "Bauch, Mutterleib, Höhlung", npers. kus urd die angeführten baltischen Bildungen, die er auf. *küki-

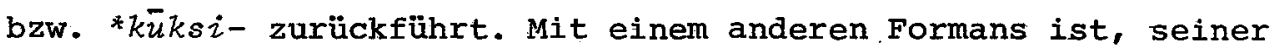
Meinung nach, gr. kýsthos "weibliche Scham" gebildet. In diesem Falle liegt, wie es scheint, eine gewisse baltisch-iranische Parallele vor, der aber keine zu grosse Bedeutung zuzuschreiben ist. Vgl. zur baltischen Vertretung noch Fraenkel 321.

8. Auf S. 15ff. behandelt Trubačev eine westbaltisch-ostiranische Isoglosse für den Begriff "Abend". Das Altpreussische bezeugt nämlich eine Bildung bïtai "abends" (im Gegensatz zu anderen baltischen Sprachen: 1it. vãkaras, lett. vakars), die eine erstarrte Dativform von apreuss. *batan $n$. "Abend" vorstellt. Die etymologische Deutung ist alt: *ab-i-ta-mit lat. ob-i-tus (soziis) "Sonnenuntergang" usw. zu vergleichen (S. 16). 71 Trubačev (ibid.) verweist in diesem zusammenhang besonders auf die Verbindung mit ostiran. *abi-ayāra- (in: man. sogd. $\beta_{y}$ 'ryy, $\beta_{y}{ }^{\prime}{ }^{\prime}$ "Abend", choresm. biyāri "dass.", yagh. viyóra "dass.", šugh. biyōr "gestern", parāčĩ wyār "Nacht"). Im Iranischen sei die Bezeichnung für "Abend" in erster Linie zu der Bezeichnung für "Tag" (vgl. z. B. aw. ayar, osset. izor), 
die ebenfalls aus der Wurzel *ei- herzuleiten ist, zu stellen. Von derselben Wurzel mit demselben Suffix ist z. B. auch d. Jahr gebildet (S. 16f.). Als Argument für die Annahme einer apreuss.-ostiran. Sonderübereinstimmung führt Trubačev (S. I7) folgendes an: "obšČee dlja drevneprusskogo i iranskogo nazvanija večera oformlenie etogo kornja $* \bar{i}-/ * e i-v$ dannom terminologičeskom upotreblenii pristavkoj *ab(i)-, a takže ne menee krasnorečivaja obక̌nostb upominjavšegosja vyše otsutstvija i.-e. *wesper-/*weker- "Abend" kak raz $v$ časti baltijskix (drevneprusskij) i iranskix (kuda primykaet $\mathrm{v}$ etom poslednom otnošenii takže germanskij s ego opjatb-taki otličnymi nazvanijami večera *abanda-/*abana-) sostavljajut svoeobrazynj, xotja i neskolbko problematičnyj, balto-iranskij leksiko-slovoobrazovatelbnyj parallelizm. Opisannaja parallelb baltijskogo $i$ iranskogo otnositsja k leksiko-semantičskoj gruppe oboznačenij vremeni, kak i nazvannaja nami neskolb-

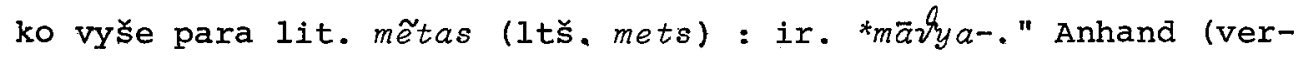
mutlicher) Übereinstimmungen und gemeinsamer Neubildungen auf dem Gebiet der Lexik (bzw. teilweise spezialer Terminologie) und Wortbildung nimmt Trubačev (S. 17) Kontakte der altbaltischen Dialekte (bzw. von Teilen derselben) mit den altiranischen Dialekten (bzw. den östlichen Teil derselben) an. Diese Annahme sollen auch die Entlehnungen, die er im Weiteren behandelt, bestätigen. Seine Behauptungen werden jedoch weder historisch noch chronologisch genauer bestimmt. Das wäre jedenfalls aus mehreren Gründen erforderlich. Denn, insofern es sich nicht um Erscheinungen handelt, die schon auf die Ursprache (ev. aus der zeit der schon dialektisch differenzierten Ursprache) zurückzuführen sind, müssen die angenommenen kontakte zwischen den einzelnen Sprachen sowohl geographisch als auch zeitlich definiert, die damals erreichte Entwicklungsstufe der verglichenen Sprachen (wenigstens hypothetisch) bestimmt werden. Wenn das nicht der Fall ist, bleibt auch die formale Rekonstruktion der angenommenen gemeinsamen Innovationen usw. in der Luft hängen. Die zuverlässigkeit der getroffenen Feststellungen ist somit ohne historisch überprüfbaren Hintergrund sehr fraglich.

Bei der Erforschung der iranischen Entlehnungen ins Balti- 
sche betont Trubačev, dass die Arbeit auf diesem Gebiet noch in den Anfängen steht. In der Fortsetzung (S. 17ff.) angeführte zusammenstellungen stammen von Trubačev, alt ist die Deutung des lit. vãnagas, lett. vanags "Habicht".

1. Als die erste iranische Entlehnung ins Baltische behandelt Trubačev (S. 17f.) lit. nãmas, PI. namã̃ "Haus, Wohnung", lett. nams "aus geraden stangen zusammengestellte kegelförmige Sommerküche, mittlerer Teil des Wohnhauses, der Küche, Vorbau in der Badestube, Hütte, Haus" (Bedeutungen nach Fraenkel 482), das er zu iran. *nam- ( aw. nmāna- neben damă na- "Wohnung, Heim") stellt. Trubačev verweist weiter auf žem. numã "Haus", das die stufe *nam-, die gleichzeitig auch die Vorstufe des aw. nmäna-wäre, wiedergebe. Wegen der besonderen aw. Orthographie und der Variante $a>a$ vor Nasal schlägt er (S. 18) als mögliche iranische Urform *nam-, eine dialektische Variante des zu erwartenden *dam-, vor. Der litauische Vokalismus könnte, seiner Meinung nach, lokalen, sekundären Ursprungs sein. Da aber die zitierten baltischen Bildungen aus der gut bezeugten Basis *domo- bzw. *damo- (einer Thematisierung zum *dŏm-, *dm-, *dm-) mit dem Wechsel $d->-n$ in bestimmten Stellungen (vgl. Fraenkel 483 und Pokorny 198f.) unmittelbar erklärbar sind, scheint die Annahme einer iranischen Entlehnung und damit verbundenem sekundärem Vokalismus im Litauischen, überflüssig. Die iranische Urform ist aller Wahrscheinlichkeit nach *dmāna-, was die Glaubwürdigkeit der von Trubačev vorgeschlagenen Deutung zusätzlich mindert.

2. Lit. spindëti "glänzen, strahlen, glitzern, funkeln, leuchten", spindà "Glanz, heller schein", spindùs "strahlend,

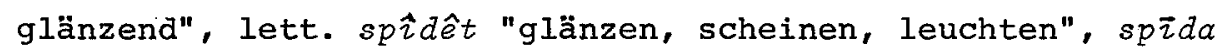
"Lichtschein"; weiter lit. spintà "Glanz, Schein", spitras "schwachsichtig, mit schwachen Augen, blind, dial. kurzsichtig", spitrëti "mühsam sehen können", spytréti "schwache Augen bekommen, dial. kurzsichtig werden; mit Anstrengung beobachten, ansehen" (Bedeutungsangaben nach Fraenkel 870, 875) .weise nach Trubačev (S. 18) eine Basis *spit-/*spid-/*spitṛ- auf, die unmittelbar aus einer iranischen Grundlage mit der Bedeutung 
"leuchten, Licht, Helle" ( jaw. spita- "weiss", apers. spivra"hel1") entlehnt wäre. Somit wäre, nach Trubačev, balt. *spit-, *spitro- eindeutig aus dem Iranischen erklärbar, während die regulären baltischen Bildungen von derselben Wurzel švisti, švintù "dämmern, hell werden", šviẽsti, švieěiù "leuchten, beleuchten", švaitýti; švitrùs, švytrùs "flimmernd, glänzend" (Fraenkel 1046: "blinkend, blitzend, glänzend; schnell, flink, lebhaft") lauteten. Bezüglich der phonetischen seite scheint die Annahme einer iranischen Entlehnung im ersten Falle möglich, wenn allerdings nicht zwei unabhängige, d. h. von zwei verschiedenen Wurzeln gebildete Formen vorliegen. Der Meinung Trubačevs nach sind *spit-, *spitr- die archaischeren Basen, während die Basis *spid- jünger wäre und die schon mitteliranische vertretung $-d-<-t-$ zwischen Vokalen aufweise. $\mathrm{Zu}$ den Bedeutungsverhältnissen bemerkt Trubačev, dass auch die Bedeutung "kurzsichtig, schwachsichtig" mit "leuchten, glänzen, flimmern" vereinbar ist und sekundären Ursprungs sein kann. Er weist auf das Paar švitrùs/švytrùs "flimmernd, glänzend": spitras "schwachsichtig, kurzsichtig" hin, wo die beiden Bildungen von derselben Basis und nach demselben Wortbildungsverfahren vorgenommen sind und sich (diachron gesehen) in der Bedeutung nahe stehen. Dennoch sei die erste (švitrùs) ursprünglich baltisch, die zweite (spitras) aber aus dem Iranischen entlehnt. ${ }^{72}$ Bezliglich des Ursprungs zahlreicher von spind-gebildeter balt. Ableitungen meint Trubačev (S. 19), dass sie oft sekundären Ursprungs mit infigiertem - $n$ - sind, teilweise aber auch andere Entstehungsmöglichkeiten (z. B. spingéti, spiñgti) haben. Falls die behandelten baltischen und iranischen Formen wirklich zusammengehören, dann wäre es angebracht, wegen des baltischen $s p$ - mit einer Entlehnung zu rechnen. Es bleibt aber fraglich, ob man einem Lehnwort eine verhältnismässig grosse Bedeutungsentwicklung zuschreiben kann. Vielleicht könnten sich die sekundären Bedeutungsnuancen erst in Opposition zu dem schon genannten Adj. švitrùs/švytrùs entwickelt haben. Oder könnte man nur mit einer phonetischen Anlehnung rechnen? (Vgl. noch Pokorny 984, Fraenkel 870f. und 875.) Trubačev gibt nich genauer an, auf welchem 
Wege die altiranische Bildung ins Baltische entlehnt worden sei. 73

3. Bei der Behandlung lit. mantà "Vermögen, Gut" (S. 19f.) verweist Trubačev auf die - seiner Meinung nach - unzweifelhafte Verbindung mit zahlreichen lit. Personennamen wie Nor-mantas, Dau $(g)$-mantas, Viz-mantas, Algi-mantas. Er lässt die Möglichkeit $z u$, dass ein Teil derartiger Bildungen spät, schon aufgrunc des Appelativums mantà zustande gekommen sei. Nach Trubačev wäre das Appelativum als Sublimation des ursprünglichen zweiten Teils des Komposita auf -manta-mit der Bedeutung "etwas habend, Macht über etwas habend" zu erklären. Als Beispiel führt er das Verhältnis Algi-mantas : algà "Lohn, Sold" an. Er stellt eine These auf von der Isofunktionalität der Komponente -mantdे- in alten litauischen Namen einerseits und des suffixes bzw. Formans -manta- in iranischen Adjektivbildungen, wie z. B. jaw. gaomant"mit Rindern versehen" ( $\sim$ aind. gomant-), fsumant- "Vieh besitzend" andererseits. Er erwähnt auch die Variante -vant- (z. B. jaw. haoma-vant- = aind. sóma-vant- "Soma enthaltend, mit Soma gemischt" (Mayrhofer III 505: "von Soma begleitet") und rekonstruiert ein Sekundärsuffix -mant-/-vant- "damit versehen, was die Grundform ausdrückt". Das Suffix und Wortbildunsmuster sei demnach ins Baltische aus dem Iranischen entlehnt worden. Fraenkel 408 zitiert neben lit. mantà "Habe, Besitz, Schatz, Eigentum, Vermögen, Kram, Plunder, Gebrauch, Nutzen" auch lett. mañta "Hab und Gut, Schatz, Erbe" mit der Bemerkung "aus dem das lit., hauptsächlich im žem. belegte Wort wohl übernommen ist". Wie aus der bei Fraenkel zitierten Literatur ersichtlich ist, sind die bisherigen etymologischen Deutungversuche unbefriedigend. Trotz allem scheint die von Trubačev vorgeschlagene These wenig wahrscheinlich. Das Suffix *-ment- ist offensichtlich zwar nur im Indoiranischen produktiv (vgl. Brugmann II/1, S. 465), was aber noch nicht bedeutet, das es niemals auch in anderen Sprachen bekannt gewesen wäre. Wenn es sich um eine Entlehnung aus dem Iranischen in der angeführten Weise handeln würde, müssten die zitierten Namen im Litauischen bzw. Lettischen synchron noch so durchsichtig gewesen sein, dass sich (der Deutung Trubačevs 
folgend) das Appelativum mantà daraus verselbständigen haben könnte. Und das scheint kaum glaublich.

Den Abschnitt über die baltisch-iranischen Beziehungen schliesst Trubačev (S. 20) mit der Bemerkung, dass seiner Untersuchung zwar noch weitere folgen werden, jedoch "my uže sejčas predstavljaem sebe balto-iranskie leksičeskie otnošenija kak dovolbno značitelbnyj i plodotvornyj epizod $v$ istorii obeix jazykovyx grupp" .

In dem zweiten Kapitel seiner Abhandlung behandelt TrubaČev die slawisch-iranischen lexikalischen Beziehungen, die er in zwei Gruppen teilt: a) Entlehnungen aus dem Iranischen ins Slawische; b) gemeinsame slawisch-iranische Neuerungen und Parallelen. Für das Verständnis seiner Argumentation bei den neu aufgestellten Gleichungen scheint es notwendig, die Ausgangspunkte, die er bei der Analyse der bisherigen Untersuchungen zu der behandelten Problematik vertritt, näher kennenzulernen. Trubačev macht an dieser stelle wiederholt auf die umstrittene Aufstellung der sog. "gemeinslawisch"-iranischen Isoglossen aufmerksam. Seinem Urteil über die Auswahl der vorgelegten Isoglossen kann man durchaus beistimmen. ${ }^{74}$ Seiner Meinung nach kann der grössere Teil der bisher in der Literatur vorgeschlagenen slawisch-iranischen Isoglossen schärferen Kriterien nicht standhalten. Er zählt dazu (S. 21): 1. die lautnachahmenden wörter (z. B. slaw. *vъpiti $\sim$ aw. ufyemi "invoco" $75 ; 2$. die Pronominalbildungen (z. B. slaw. ovz $\sim$ apers. ava-; slaw. mene $\sim$ aw. mana usw. ); ${ }^{76}$ 3. die Gleichungen, welche auch in anderen sprachen Anknüpfungen haben. Er führt (S. 22) slaw. tajati osset. tajun, ${ }^{77}$ slaw. gora $\sim$ aw. gairi-, slaw. svetr $\sim$ aw. sponto 78 und zahlreiche andere an; 4 . einen Teil in diesem zusammenhang angeführten wörter deutet er als Resultat interslawischer Entwicklung. Er verzeichnet z. B.: aw. (pairi)haraite "sich behïten, retten" $\sim$ slaw. *xorniti. ${ }^{79}$ Nach Trubačev sei das slawische Verbun sekundären, denominalen ursprungs. Weiter zitiert Trubačev mpers. jumbin $\bar{\imath} t \bar{a} r$ "Verderber" $\sim$ slaw. gybnqti "zugrundegehen" mit der Bemerkung, dass das slawische Verbum eine morphologisch-semantische Neuerung aufgrund slaw. grbnqti/gubiti 
"biegen" vorstelle, und noch osset. tag "Faden, Faser, Gewebe" $\sim$ slaw. trkati "weben", 80 wo der sekundäre Charakter des slawischen Wortes im wortbildungsmässigen und semantischen Sinne klar sei; 5. weiter (S. 22f.) streicht Trubačev drei in der Literatur ständig zitierte Isoglossen, die schon Meillet, RESl. VI, 1926, S. 166f., augestellt hat. Dazu gehören: a) die Verbindung aksl. radi $\sim$ apers. -rādiy, npers. $r \bar{a} y$ "wegen". 81 Für slaw. radi schlägt Trubačev (S. 23) eine internslawische Etymologie vor, und zwar handele es sich um einen erstarrten Gen.-Dat.-Lok. des $i$-Stammes *rads "Arbeit". Er verweist auf ein ähnliches Verhältnis bei aksl. dělja dělo, dělati und lat. causa frz. $\grave{a}$ cause de "wegen", cause "Arbeit" ; 82 b) aksl. $-j 6 \sim$ aw. $-y i ; 83$ c) die Gleichung slaw. samr $\sim$ aw. hämo-84 lehnt Trubačev (S. 23) mit folgenden Argumenten $a b$ : "No nezavisimosts $i$ ispolbzovanija mestoimennogo elementa $v$ slavjanskom i iranskom (...) sliškom

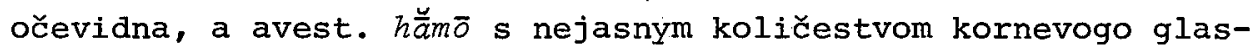
nogo ne imeet dostatočnogo vesa dlja obosnovanija mysli ob obščnosti innovacionnogo udlinenija $v$ iranskom slove i slav. samz"; 6. auf S. 24 streicht er weiter aus dem Verzeichnis der slawisch-iranischen Isoglossen solche Verbindungen, bei denen die iranische Anknüpfung etymologisch unklar oder problematisch ist. So führt z. B. an slaw. s $Z_{6 z a}$, vina, ${ }^{85}$ vatra, ${ }^{86}$ čăa, ${ }^{87}$ xoméstor ${ }^{88}{ }^{8}{ }^{2} d z,{ }^{89}$ russ. $i r e j{ }^{90}$ und sobaka ${ }^{91}$. Iranischer ursprung scheint Trubačev bei einer verhältnismässiq beschränkten Gruppe der sog. Kulturwörter annehmbar. So führt er (S. 24) slaw. kotr (ksl. "Bude, stall"), 92 ěrrtogr, 93 gun $a,{ }^{94}$ kordr, 95 *korguj6, 96 toporr, 97 und bogr 98 an. Weiter betont Trubačev (ibid.), dass unter die Bezeichnung "gemeinslawisch" nur drei Beispiele gehören (kotr, gun'a, toporr), während die anderen lokalen charakter aufweisen (こ̌brtogr - südslawisch, *korguj6 - westsüdslawisch; bezüglich des kordz bemerkt er, dass es zwar im süd-, West- und Ostslawischen bezeugt ist, jedoch "svoej formoj vydaet pozdnij xarakter svoego 'obščeslavjanskogo' rasprostranenija"). Ibid. macht er zu Recht darauf aufmerksam, dass besonders die Kulturwörter verhältnismässig leicht von einer in die andere sprache übergehen und deshalb nicht massgeblich für spezielle Beziehun- 
gen der betreffenden Sprachen sein können. Für slaw. *korguj6, ¿6rtog7, kordz lässt er die Möglichkeit mitteliranischen Ursprungs (vielleicht mit türkischer Vermittlung) zu (S. 24). Somit bleibt als anerkannte "gemeinslawisch-iranische" Isoglosse nur die Gleichung slaw. bogr iran. baga-, die ausführlich in der Fortführung der Abhandlung behandelt wird. Von Bedeutung für das Verständnis seiner Auffassung des gemeinslawischen Charakters der wörter ist die Voraussetzung, welche er auf S. 25 formuliert und nach welcher existierte "vozmožnosts vtoričnogo pojavlenija 'obščeslavjanskogo' xaraktera $v$ rezulbtate samostojatelbnogo rasprostranenija slov, zaimstvovannyx pervonačalıno cast6ju (pra)slavjanskix dialektov". Bezüglich dieser These muss man zu Vorsicht raten. Eine derartige Deutung sollte nur in den Fällen, in welchen die sprachlichen Fakten (z. B. Abweichungen von den für eine bestimmte Epoche strikt geltenden phonologischen Regeln; Einführung eines phonetischen odere anderen $\mathrm{zu}-$ ges, der ursprünglich nur für ein bestimmtes Territorium möglich bzw. charakteristisch war, auf das ganze Gebiet usw.) ausdrücklich eine solche Lösung fordern, anzuwenden sein. Solche sprachlichen Fakten müssen jedenfalls klar und präzis angebbar sein. In anderen Fällen scheint die Anwendung eines solchen Prinzips bedenklich.

In der Folge seiner Abhandlung geht Trubačev zu der Analyse des Termins bogr, der, seiner Meinung nach, "neosporimo centralbnoe mesto sredi vsej slavjano-iranskoj leksiki" (S. 25ff.) einnimmt, über. Das Verhältnis slaw. bogr : iran. baga- lässt, wie bekannt, mehrere Deutungen $z u$, ohne dass man entscheiden kann, welche von denen gültig, ja nicht einmal, welche mehr oder am meisten glaubwürdig ist. Trubačev (S. 26) macht auf die Tatsache, dass es sich bei iran. baya- um eine typisch iranische semantische Neuerung handelt, die nicht einmal alle altiranischen Dialekte umfasste, aufmerksam und bemerkt dazu: "Takim obrazom, obščee terminologičeskoe značenie 'bog' vo vsej polnote javljaetsja udelom tolbko iranskogo i slavjanskogo" (ibid.). Vgl. Bartholomae 921 und zum Stand im Altindischen Mayrhofer III 457f., wo auch die Literatur zu der slaw.-iran. etymologi- 
schen Zusammenstellung angeführt wird. Trubačev (S. 26f.) weist im Zusammenhang mit der Analyse der morphologisch-semantischen Bildungen innerhalb des slawischen auf die zweite Möglichkeit, nämlich "vlijanie iranskogo religioznogo termina $v$ opredelennyj period na iskonno slavjanskoe obrazovanie" (S. 27), hin. Wie Trubačev (S. 28) richtig feststellt, bestehen keine Beweise für die Annahme, dass das slawische Wort aus dem Iranischen entlehnt wäre, da es sich um eine verhältnismässig leichte Bedeutungswandlung, die auch in beiden sprachgruppen unabhängig entstanden sein konnte, handelt. Ex nimmt somit für die betreffende Wortsippe auf der einen seite eine slawisch-iranische Neuerung (slaw. bogr "Gott" apers. baga- "Gott") und auf der anderen gemeinsame Beibehaltung eines Archaismus (slaw. *bogatstvo "Reichtum, Vermögen", u-bogr, ne-bogr, bog-atr aw. baya- "Anteil, Schicksal") an. Weiter behandelt er noch slaw. Personennamen mit Bogo-/Bogu- (z. B. poln. Bogdar, Boguchwaz) und vergleicht sie mit den iranischen, wie *Baga-xvarna- (z. B. med.-pers. Baga-farna-). Ausser in den westiranischen (Apers., Med.) kommt baga- "Gott" auch in den ostiranischen Sprachen, so auch im Skythischen, vor. Trubačev führt (S. 30) folgende Belege an: sogd. By-, *Bay-; sak. vaga-, vag'a-, vaka- "Gott" usw. Angesichts der angeführten Tatsachen kommt er (S. 31) zum folgenden Schluss: "V vidu naličija v. rjade jazykov skifskoj (vostočnoiranskoj) gruppy slova baga- "bog" i ličnyx imen s etoj osnovoj možno sčitatı verojatnym vlijanie na slav. bogr so storony časti etix jazykov. My dopuskaem naličie $v$ slavjanskom slovare sledov opredelennogo religiozno-kulbturnogo vlijania Irancev na Slavjan, odnako usmatrivaem eti sledy ne tam, gde ix videli predšestujjuščie issledovateli (...), krome togo, v našem predstavlenii front slavjano-iranskix obščenij drevnej pory byl inym, menee protjažennym. Dlja togo čtoby stats dejstvitelınym dostojaniem bolьšogo čisla praslavjanskix dialektov, iranizm dolžen byl samostojatelbno prodvigat sja, peresekaja vnutrislavjanskie dialektnye granicy, čto zaviselo ot mnogix faktorov, $i$ $\checkmark$ nemaloj stepeni - ot sobstvennogo udelbnogo vesa slova. Sle-. dovatelsno, nekotorye drevnie i osobenno rasprostranennie ira- 
nizmy $v$ principe dolžny bili 'putešestvovatb' po slavjanskoj jazykovoj oblasti."

Tatsächlich stehen aber keine zuverlässigen Argumente zur Verfügung, anhand welcher man die Gültigkeit der bisherigen Deutungen slaw. bogz bestätigen oder ablehnen könnte. Iranischer Einfluss wäre möglich, jedoch bleibt auch diese Interpretation hypothetisch. Ahnlicher Meinung ist auch Mayrhofer III 458: "Aksl. bogr "Gott" (...) ist in seiner Sonderbedeutung nicht ohne zusammenhang mit dem Iranischen verständlich: dass völlig unabhängig von diesem in einer anderen idg. Sprache, die noch dazu das Verbum *bhag- "austeilen" in geschichtlicher zeit nicht mehr aufweist, über 'Verteiler' ein Wort für 'Gott' entstanden sei, lässt sich kaum vorstellen. Aber auch für die Annahme einer blossen Entlehnung aus dem Iranischen (...) fehlen durchschlagende Argumente." 99 Er rechnet mit der Möglichkeit, dass eine gemeinsame slawisch-iranische Neuerung im Rahmen der religiösen Terminologie vorliegt, eine Erscheinung, die auch sonst angenommen wird. Es handele sich um eine Entlehnung bzw. Adaption des altiranischen Terminus. ${ }^{100}$ Eine genauere chronologische Präzisierung auf beiden Seiten sowie eine Auseinandersetzung mit ev. weiteren Entlehnungen dieser Art wäre erwünscht. 101

Als ein Iranismus, das erst sekundär ein breiteres Gebiet umfasse, betrachtet Trubačev (S. 3if.) die alte stamm-Benennung *xzrvati, xorvaty. Diesen Namen trug ein alter stamm in der Nähe von Peremyšlb, er kommt aber auch in Alt-Polen und -Böhmen sowie bei den Sorben vor. Besonders ausgeprägt ist er als Bezeichnung des südslawischen Volkes der kroaten. Trubačev nimmt an, dass das Ethnikon *xrrvati sein Zentrum ursprünglich in der Nähe von Peremyšlb in Alt-Russland hätte, und von dort habe es sich zuerst gegen den Westen und dann gegen den süden des slawischen Gebiets ausgebreitet. Er schliesst daraus (S. 32): "Dlja nas zdesb važen nesomnennyj fakt vtoričnogo rasprostranenija po slavjanskoj jazykovoj territorii slova, iranskoe proisxoždenie kotorogo ne vyzyvaet sporov. Slav. *xrrvati, udačno identificirovanoe s iranskim ličnim imenom Chróathos v nadpisi iz Tranaisa ešče Pogodnym, a zatem Sobolevskim, otražaet ir. *harvată-ili (s epentezoj) *haurvatā-, 
po-vidimomu, etnonim s xarakternym skifsko-sarmatskim pljuralbnym suffiksom -ta-, oset. -ta." Vasmer III 261 führt den behan-

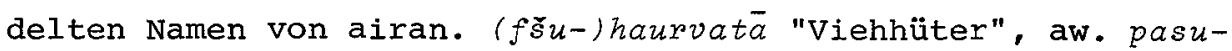
-haurva- usw. aus. Vgl. noch Skok, Etim. rječnik I $690 f f$.

Im Weiteren behandelt Trubačev noch einige neue slawisch-iranische Gleichungen. So verbindet er (S. 32f.) urslaw. *sv6rkz (belegt in poln. swierk, swirk "Fichte", slowak. svrecina) mit

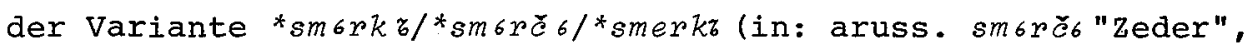

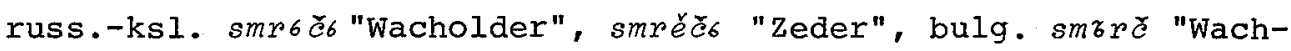
older", serbk. smrëka "Wacholder", slowen. smreka, tschech. smrk "Fichte, Tanne" usw.) mit iran. Bildungen *sprva-, *sprma-bzw. in der späteren Form *sarva-/*sarma-, das in mpers., npers. sarv "Zypresse", sarv, siȳah "juniperus, Wacholder" belegt ist. Diese iranischen wörter knüpft ex weiter an einige andere iranische Baum-Bezeichnungen, wie z. B. mpers. Varmi- und osset. talm "Ulme", das, nach Abaev, OJF I 140, aus dem Persischen entlehnt sei. Auf S. 33 erklärt Trubačev die urslawischen Varianten *sv6rkr/*sm6rkr/*smerkr mit der Entlehnung aus den iranischen dialektischen Bildungen *srvaka-/*sarvaka-bzw. *sromaka-/*sarmaka-, wobei das Element - aka- ein produktives iranisches Suffix vorstelle. Dabei deutet sogar der Verfasser selbst die Schwierigkeit der Etymologie in Einzelpunkten an. Die Konsonantenfolge im Slawischen erklärt er mit einer Methathese: -rv-> $-v r-,-r m->-m p-$. Zu der weiteren etymologischen Anknüpfung beruft er sich auf Bailey, Ro XXI, 1957, S. 68f., wo der Autor von einem anlautenden *k- ausgeht. Vgl. noch Vasmer, REW II 672 .

Die vorgeschlagene Etymologie Trubačevs ist keinesfalls evident. Sehr problematisch scheint die Annahme der zit. Metathese, die bei einer solchen Deutung vorausgesetzt wird. ${ }^{102}$ Die angenommene Entlehnung wird von Trubačev weder zeitlich noch räumlich genauer bestimmt. Deswegen bleibt auch unklar, ob ex mit gemeinslawischer Entlehnung oder mit sekundärer Ausbreitung im Sinne seiner oben besprochenen Hypothese rechnet. Wahrscheinlich denkt er an die zweite Möglichkeit, obwohl er anders als beim Ethnikon *xrvati nicht versucht, einen relativ plausiblen dialektalen Ausgangspunkt zu bestimmen. 
In der Fortführung (S. 33f.) geht Trubačev zur Behandlung des slawischen wortes für "Blei" über: russ. svinéc, russ.-ksl. svinbc6 "plumbum", aruss. svinec6, slowen. svinec, alles aus urslaw. *svin6e6, *svinz. Er führt die bisherigen Etymologien an und bemerkt (S. 33): "S drugoj storony, nelbzja ne otmetits verojatnoj blizosti kak formy, tak $i$ značenija praslav. dial. *svinr (...) i vost.-ir. *spana- "železo" : oset. (œ) fscen "sošnik, lemex", voobšče - "železo", xorezm. ispani, sogd. 'spn-, *aspan- "železo"." Dazu gehört (in Verbindung mit *hu-/*hau"gut") auch aw. haosafnaena- "stählern" usw. Abaev, IES I 481, rekonstruiert zwei altiranische Urformen: *spana- und durch Metathese entstandenes *safna-, die in den oben genannten iranischen Bildungen vertreten seien. Mit einer iranischen Entlehnung im slawischen *svinz, *svin6e6 ist jedoch kaum zu rechnen, wie schon die Folge slaw. sv- : iran. $s p-$ und die Unterschiede im Vokalismus zeigen. Auch eine andersartige Sonderübereinstimmung zwischen den iranischen und slawischen Formen scheint in diesem Falle fraglich; es könnte sich ev. um urverwandte Bildungen handeln, was aber nichts über spezielle slawisch-iranische Verhältnisse aussagt. Die slawischen Bildungen sind wahrscheinlich trotz allem mit lit. švinas "Blei, zink", lett. svins urverwandt. In diesem Falle wäre mit einem idg. * $k^{\prime}$ wei- zu rechnen, was auch dem slawischen Vokalismus entsprechen würde. Vgl. Vasmer II 592, Pokorny 594 und Fraenkel 1045.

In drittem Teil seiner Abhandlung versucht Trubačev spezielle Beziehungen der iranischen Sprachen $z u$ den einzelnen urslawischen Dialekten aufzustellen, was als eine natürliche Folge seiner Auffassung des nicht-monolithischen Urslawischen anzusehen ist. An erster stelle behandelt er die slawisch-iranischen lexikalischen Beziehungen vom Standpunkt des Südslawischen aus. Dabei stellt er schon einleitend fest, dass es sich um "periferijnostb južnoslavjanskogo ili predšestvujuščix emu praslavjanskix dialektov po otnošeniju $k$ rajonu intensivnyx slavjanoiranskix jazykovyx obščenij" handele (s. 35). Er beruft sich auf die Unselbständigkeit der genannten Verbindungen (es handelt sich nämlich um exclusive südslawisch-iranische Gleichungen) und 
auf die wahrscheinliche zeitliche Differenzierung derselben. Angesichts dessen betont er (S. 35), "Čto lišb nekotorye južnoslavjansko-iranskie sootvetstvija predstavljajut soboj problematičnye otraženija slavjano-iranskix kontaktov do slavjanskoj migracii na Balkany, togda kak drugie južnoslavjansko-iranskie svjazy objazany bolee pozdnemu obščeniju uže na territorii novoj rodiny". Als erstes Beispiel, das diese Thesen bzw. Schlüsse veranschauliche, führt er das schon behandelte Ethnikon *xzrva$t i /{ }^{*} x o r v a t y$ an. Weiter verweist er auf die Verbindung urslaw. *xorna mit aw. xvarana- "Essen, Trinken". Slaw. *xorna kommt in bulg. xraná, serbk. hrána, slowen. hrána, kaschub. charna usw. vor. Für die iranische Seite führt Trubačev ausser der aw. Form noch osset. xwar "Getreide, Gerste" sowie die iranischen Personennamen Khoárgaros, Khuársazos aus dem nördlichen schwarzmeergebiet an. Vgl. auch Abaev, OJF I 190. Trubačev stellt dabei als ein Kuriosum fest, dass urslaw. *xorna ausser in den südlichen auch in einigen westslawischen Dialekten vertreten sei, in den östlichen dagegen nicht vorkomme. In Zusammenhang damit stellt sich aber die Frage, nach welchen Kriterien ein Wort mit einer derartigen Distribution überhaupt zu den sog. südslawisch-iranischen Isoglossen (trotz den einleitenden Bemerkungen über den Charakter dieser Beziehungen) gerechnet werden kann. Wenn südslawisch-iranische Exclusiv-Isoglossen nicht nachzuweisen sind und wenn man ev. sekundären Charakter des Auftretens ausserhalb des Südslawischen nicht beweisen bzw. mit grosser Wahrscheinlichkeit annehmen kann, scheint die Annahme solcher Beziehungen (auch mit den auf. S. 35 von Trubačev angeführten Beschränkungen) unbegründet und widerspricht (in dieser Form) den sprachlichen Fakten.

Als Iranismus aus späteren Zeit behandelt Trubačev (s. 36) bulg. Asparux, den Namen einer Führers der Turk-Bulgaren aus dem 6. Jh. n. Chr., den er auf iran. Asparuk "helles Pferd" bzw. "helle Pferde besitzend", das als iran. Name Asphórugos in gr. Inschriften in Olbia vorkommt, zurückführt. Trubačev rechnet mit der Möglichkeit, dass ein türkischer Khan einen iranischen - konkret skytho-sarmatischen - Namen hätte, oder es 
habe sich bei den Turk-Bulgaren eine dünne iranische schicht bis zum Einzug auf die Balkanhalbinsel erhalten.

Auf der Annahme langer Erhaltung der iranischen Schicht bei den Turk-Bulgaren beruht auch die etymologische Deutung einer sonst isolierten bulg. Wortes stopán(in) "Hausherr" (S. 37). Er erklärt es als entlehnt aus iran. *asta-pān- "Beschützer, Behüter des Hauses" (aw. asta- "Heim, Heimstätte", sogd. 'st-, *ast"Vermögen" + iran. Nominalstamm -pāna- "Schutz, Obhut, Beschützer"). 103 Die zitierte iranische Deutung scheint wegen der begrenzten Vertretung des bulg. (und serb. dial. stópanin) Wortes und wegen der regulären phonetischen und Bedeutungs-Verhältnisse zwischen der iran. und slaw. Bildung verhältnismässig wahrscheinlich.

In dem vierten Kapitel seiner Abhandlung (S. 37ff.) bespricht Trubacev die iranisch-ostslawischen Beziehungen. Er stimmt der Meinung S. B. Bernštejns (Ǒerk S. 68-70), dass die Ost-Slawen zu Beginn der nachchristlichen Zeit den östlichen Teil des urslawischen Territoriums einnahmen, zu. Demzufolge stellt Trubačev ein theoretisches postulat auf, das für das Verständnis seiner Auffassung bzw. Lokalisierung der slawisch-iranischen Beziehungen von Bedeutung ist. So schreibt er (S. 38): "... Čto drevnie svjazi s neslavjanskimi jazykami, primykavšimi k slavjanskoj territorii s vostoka i jugovostoka okolo rubeža našej ery, dolžny byli kasatısja prežde vsego vostočno-slavjanskogo."104 Wie Trubačev bemerkt, ist das Material, das nur in den iranischen und ostslawischen sprachen vertreten ist, sehr beschränkt und ausserđem sowohl in der semantischen Richtung als auch chronologisch heterogen. Die angenommenen iranischen Lehnwörter in Ostslawischem teilt er (S. 39) in: 1. alte russische Iranismen, 2. alte ukrainische Iranismen und 3. späte russische Iranismen. Als Beispiel für eine möglicherweise auf Urverwandtschaft beruhende Gleichung stellt er (S. 39) - Bailey, BSOAS XXVI, 1963, s. 83f., 87f. - russ. step6, ukr. step dar. Das Wort 1st verhältnismässig spät belegt (ab XVII. Jh.), es dürfte aber, seiner Interpretationen nach, schon viel früher in der Sprache existiert haben (er verweist auf die Verwendung in 
Shakespeares Midsummernight Dream von ca. 1600). Trubačev stellt - im Einklang mit der zit. Literatur - russ. steps zu osset. digor t’cepon "flach, eben" < iran. *tap- "dass." < idg. *(s) tep"flach, eben sein". Problematisch. Pokorny verzeichnet keine solche Wurzel in der angeführten Bedeutung. Vielleicht denkt Trubačev auf eine Verbindung mit slaw. teptati usw., was aber onomatopöischen Charakters sein kann. Vgl. noch Vasmer III S. 11 und Pohl, Kratylos XXII S. 9.

Im Weiteren geht Trubačev zur Behandlung der Lehnwörter nach der erwähnten Verteilung über. So erklärt er (S. 39f.) russ. sapóg, aruss. sapogr, aksl. sapogr "hypodēma" aus iran. *sapaga-, einer miran. Variante zu ursprünglichem *sap-aka- (Morgenstierne folgend; vgl. dazu Trubačev S. 40, Anm. 68: wahì *sap (ak), burušaski sap, aw. safa-, sak. saha- "Huf" < airan. *sāpa- "Huf") . Zur Zeit der Entlehnung bemerkt Trubačev (S. 40) folgendes: "S točki zrenija russkogo slovarja slovo sapog - staryj element, no $\mathrm{v}$ masštabah rassmatrivaemyx nami zdess $\mathrm{v}$ celom slavjano-iranskix leksičeskix otnošenij ono ne možet sčitatssja očens drevnim iranskim vključeniem, o čem svidetelsstvuet naličie $v$ nem uže ozvočennogo, srednjeiranskogo $-g-<-k-. "$ Vgl. Vasmer II 578 und Pohl, Kratylos XXII S. 9. Die zit. Deutung scheint verhältnismässig wahrscheinlich und begründet, besonders, weil das wort sonst keine Etymologie hat.

Ebenso erklärt Trubačev als Iranismus auch das innerhalb des Slawischen isolierte russ. Wort štany, das üblicherweise als türkisches Lehnwort angesehen wurde. Nach Trubačev (S. 40) "eto plurale tantum s iznačalınym -a- (ne iz -o-) možet prodolžatb ir. *ร̌tāna- "noga, štanina, nogavica", sr. avest. paiti-štāna"noga" i rjad blizkix form v pamirskix jazykax." Diese Deutung scheint jedenfalls nicht weniger plausibel als die aus Turkotatarischem ( atürk. išton "Unterhose" usw.). Vgl. Vasmer, REW III 429 und Pohl, Kratylos XXII s. 9.105

Als wahrscheinlichen Iranismus deutet Trubačev (S. 41) russ. dial. baz "Hürde, Stall", das er von iran. *baza<*upa-baza"Hürde, Pferch; russ. za-gon" herleitet. Ein entsprechendes osset. Wort ist nicht belegt, er zitiert aber khotansak. bāysa- 
"Garten". Auch Vasmer I 39 (baz, bazok "1. Hürde, Viehhof; 2. Ort zum Bereiten von Heizziegeln aus getrocknetem Dünger") denkt wegen der geographisch beschränkten Vertretung an eine Entlehnung aus dem Osten. Vasmer lehnt aber die bis zu einem gewissen Grade der obigen ähnliche Erklärung Iljinskis (Prace fil. ll, 186f.) ab, "der von einem durch Dekomposition veränderten *obazati ausgeht und an lat. ago, griech. ágo, avest. azaiti anknüpft. Ein entsprechendes Verbum lässt sich im slaw. nicht belegen, skr. bázati 'nichtstun, müssig umhergehen' weicht in der Bedeutung $z u$ sehr ab." Die Interpretation Trubačevs ist, wie es scheint, möglich, sie bleibt jedoch hypothetisch, da das entsprechende iranische wort, aus dem das russische entlehnt sei, fehlt. Trubačev denkt offensichtlich an eine mitteliranische Quelle.

Als letztes iranisches Lehnwort im Russischen behandelt Trubačev russ. mórda "Schnauze, Maul", das schon längst aus iran.

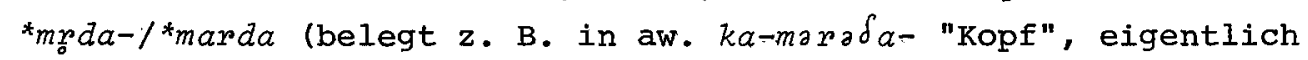
"was für ein Kopf, scheusslicher Kopf") erklärt wurde. Vgl. Vasmer II 156. Es ist nicht ersichtlich, in welcher zeit und aus welcher Sprache das wort entlehnt sei. 106

Es folgen die südostslawisch-, besonders ukrainisch-iranischen Isoglossen, die aber, nach dem von Abaev vorgelegten Material zu urteilen, noch spärlicher vertreten sind als die russisch-iranischen.

Als die erste derartige Isoglosse behandelt Trubačev (S. $41 \mathrm{f.}$ ) ukr. xáta "Bauernhaus, Hütte aus Lehm" (in anderen Teilen des Ost-Slawischen und im Polnischen handele es sich um ein Lehnwort aus dem Ukrainischen), die er als ein Lehnwort aus spätskyth.-sarmat. *xata-< iran. *kata-, aw. kata- "Kammer, Vorratskammer, Keller" erklärt, wobei es sich um einen übergang $k->x$ - im Ossetischen handele. Nach Trubačev (S. 42) sei ukr. xáta erst in der zeit, als das fremdsprachige $\breve{a}$ durch $a$ im slawischen substituiert sein konnte, entlehnt worden. Er verweist darauf, dass in der älteren zeit aus iran. kata- slaw. kotr "Keller" entlehnt wurde. ${ }^{107}$ Es wäre wünschenswert, durch ev. andere Lehnwörter mit gleichartiger Substitution die zeit der Entleh- 
nung näher zu bestimmen. Vasmer, REW III 233, geht zwar von aw. kata- "Haus, Grube" aus, nimmt aber eine altung. Zwischenstufe von ung. haz "Haus" an. Eine ungarische Vermittlung wäre überflüssig, wenn tatsächlich ein Lehnwort aus einer späteren iran. Quelle mit dem charakteristischen übergang $k->x_{-}$, wie es Trubačev annimmt, vorliegen würde. Die Hypothese ist aber bei dem vorliegenden Material nicht beweisbar. 108

Das zweite ukr. Beispiel ist schon der Meinung des Verfassers nach problematisch. Es handelt sich um den ukr. ethnologischen Terminus vij (S. 42). Trubačev beruft sich auf Abaev (vgl. oben S. 201), geht aber von einer anderen vorstellung aus. Da es sich bei ukr. vij angeblich um ein Wesen mit Wimpern, die bis zur Erde reichen, handele, verbindet er den Namen mit dem ukr. Wort vija "Wimper". Deswegen - seiner Meinung nach - (S. 43) "semantičeskaja xarakteristika ukr. víj "imejuščij. veki/ resnicy" - ne pozvoljaet naščupats ničego specifičeski obščego s ir. Vayu-". Da es sich, wie es schon der vergleich mit der Interpretation Abaevs zeigt, um verhaltnismässig unverbindliche mythologische zusammenstellungen handelt, die schon grundsätzlich - mit einigen gut begründeten Ausnahmen - schwer deutbar und von unstrittenem Wert sind, scheint die skepsis Trubačevs berechtigt.

In der abschlissenden übersicht über die ostslawisch-iranischen Isoglossen stellt Trubačev (S. 43) fest, "Čto vostočnoslavjansko-iranskie kontakty ni $v$ koej mere ne sleduet otoždestvijatb s drevnejšimi slavjano-iranskimi otnošenijami".

In dem fünften Kapitel (S. 44ff.) geht Trubačev zur Behandlung der westslawisch-iranischen Beziehungen ïber. Seiner Meinung nach spielen gerade diese Verhältnisse eine spezielle Rolle innerhalb der slawisch-iranischen lexikalischen Beziehungen. Wie er schon in den einführenden Bemerkungen feststellt, handele es sich um ein verhältnismässig homogenes Material, das sich am besten in den polnisch-iranischen lexikalischen Gleichungen wiederspiegele. Und gerade diesen wendet der Verfasser im weiteren seine besondere Aufmerksamkeit zu.

Als erstes Beispiel erscheint poln. Verbum baczyc "schauen, 
sehen, betrachten", älter "nachdenken, ïberlegen, durchsehen, merken, kennen". Das Wort ist seit dem XV. Jh. belegt. Es kommt noch in denjenigen slawischen sprachen, die an das polnische grenzen, vor und dürfte dort, nach Trubačev (S. 44), aus dem Polnischen entlehnt worden sein. Dazu gehören: ukr. baciti "sehen" (XVI. Jh.), wruss. bačyc6 "dass.", wahrscheinlich auch slk. dial. bačiti se. 109 Dabei verweist Trubačev auf eine in der Literatur unbeachtete Deutung E. Fraenkels (Afs1Ph XXXIX, 1925, S. 73), der poln. ob-aczyć "sehen, bemerken, erblicken, sich besinnen" mit aw.

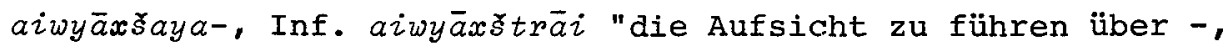
zu beaufsichtigen" (vgl. Bartholomae 97) und miran. choresm. (") Byxy- "lernen, im Herz aufbewahren" ( $\left.<{ }^{*} a b i-a x s a y \alpha-\right)$ und vielleicht yaghn. yax - "sichtbar sein, gesehen werden" vergliech. Auf S. 45 macht Trubačev auf den semantischen und formalen Parallelismus der slawischen und iranischen Bildungen aufmerksam. Er beurteilt ihn folgendermassen (S. 46): "I.-e. * $\bar{o} k^{w}$ - bylo izvestno različnym dialektam praindoevropejskogo, $i$ ego otraženie $v$ slavjanskom $i$ iranskom dolžno rascenivatısja kak soxranenie arxaizma. No upotreblenie etogo nezavisimogo arxaizma $v$ odnotipnom glagolınom složenii s etimologičeski toždestvennoj pristavkoj i toždestvennym semantičeskim razvitiem (...) javljaetsja uže sovmestnoj innovaciej polbskogo i iranskogo." Wie er weiter feststellt, handele es sich um eine Neuerung in einer frühen Zeitperiode, die nur einen Teil der iranischen Dialekte erreichte. Er lässt die Möglichkeit iranischen Einflusses auf die slawische Bildung $z u$, jedoch nicht im sinne einer Entlehnung. 110

Nach demselben Prinzip behandelt Trubačev auch poln. Verbum patrzye, patrzec "schauen, sehen" (S. 47ff.), das auch in tschech. patriti "schauen, sehen, betreffen, angehen, gehören", slk. patrit" "sich auf etw. beziehen" und kroat. dial. pätriti "gehören, pertinere" vorkommt. Als mögliche Parallelbildungen führt er noch ukr. pántriti, pantryváti "schauen, untersuchen" mit infigiertem $-n$ - an, wo man aber, seiner Meinung nach, mit einer Assimilierung des ursprünglichen poln. patrzyd, (wy)patrywad rechnen kann. Bezüglich des Bedeutungsunterschieds stellt er fest, dass teilweise sekundärentwickelte Bedeutungen, in 
einigen Fällen sogar interslawische Entlehnungen, vorliegen. Nach einem solchen Reduktionsverfahren folgert Trubačev, dass man als Ausgangspunkt der Bildung die westslawischen Sprachen, die an das Polnische grenzen, ansehen muss. Nach Erwähnung der bisherigen etymologischen Deutungen legt Trubačev seine Deutung vor: Verbindung des westslaw. bzw. urpoln. Verbums *patriti "schauen" mit jaw. Inf. pā $\hat{v}_{r} \bar{a} i$ "zu hüten, schützen, schirmen" (Bartholomae 888). Im Verhältnis zum slawischen Material sei urslaw. dial. *patriti - nach der Interpretation des Verfassers - isoliert, die aw. Form jedoch vom Iranischen her leicht erklärbar: es liegt ein Dativ-Infinitiv eines Nom. agentis auf -tar- (aw. pātar- "Hüter, Schützer, Schirmer") bzw. eines Nom. actionis auf -tra- (aw. pā rra- "Schutz, Schirm") vor. Die entsprechenden Nominalbildungen sind in den alt-ostiranischen Dialekten gut belegt. Im Zusammenhang mit der Analyse der slawischen Bildung macht Trubačev (S. 49) darauf aufmerksam, dass im Slawischen Nomina agentis auf *ter-l-tro- schon innerhalb der erhaltenen Archaismen selten sind, im produktiven Wortbildungsprozess jedoch überhaupt nicht vorkommen. Weiter verweist er darauf, dass im Slawischen in der Bedeutung "hüten, weiden" nur der Stamm *p $\bar{a} s-$, nicht aber * $p \bar{a}(i)-$, von welcher iran. *pātargebildet wird, erscheint. zeit und Art der angenommenen Entlehnung bestimmt Trubačev verhältnismässig genau auf S. 51: "Kak sleduet iz predyduščix svedenij po iranskoj istoričeskoj fonetike, slavjanskaja forma otražaet arxaičeskuju drevneiranskuju formu *pātr- do metatezi. Esli učestb, čto kolebaniem -tr-/-rtbyli uže oxvačeny skifo-sarmatskie imena, otražennye $v$ nadpisjax grečeskix pontijskix gorodov zadolgo do načala našej ery (...), to stanet jasnym, čto praslav. dial. *patriti proniklo iz skifo-sarmatskogo $v$ slavjanskij, bessporno, ešče $v$ I tysjačeletii do n. e." Die zitierte etymologische Deutung scheint verhältnismässig gut begründet, obwohl sich dennoch die Frage erhebt, inwieweit man mit einer internslawischen Entwicklung oder ev. mit einer anderen etymologischen Anknüpfung rechnen könnte.111 (Müsste man ev. die Formalstruktur einiger anderer Verben, z. B. russ. usw. smotret6 berücksichtigen?) Für das verständnis der 
Ausführungen Trubačevs muss man unbedingt seine Deutung zweier weiterer polnischer Verben, die derselben Bedeutungsgruppe angehören, hinzuziehen. Es handelt sich um poln. dial. szatrzyé (S. 5lff.) "wissen, kennen, verstehen, begreifen", apoln. szatraye się "schauen, rücksichtvoll sein, aufmerksam sein"; poln. dial. szatrac "sehen, gedenken", tschech. Štriti "beschützen, sparen, aufpassen, bewahren"; slk. šetrit "sparen, bedauern/bemitleiden" sei aus dem Tschechischen entlehnt worden. Es werden auch einige Bildungen aus der westlichen Gruppe der südslawischen Sprachen dazugestellt, so: slowen. ošatrati "verzaubern". §atrija "Zauberei" und serbk. satriti "fascinere", ošatriti "infascinere", šatrija "incantamentum" (vgl. die Quellenangabe 1. c.). In den anderen südslawischen und westslawischen Sprachen kommen keine entsprechenden Bildungen vor. Nach Trubačev (S. 51) ist der status des slowen. und kroat. Verbums und der dazugehörigen wörter unklar. Er behandelt folglich nur die tschechischen und besonders noch die polnischen Belege. Er führt zuerst (S. 52) die bisherigen etymologischen Deutungsversuche an und rekonstruiert dann die urslaw. dial. * Fatriti "schauen (viell. auf eine besondere Art schauen)", das in den urpolnischen und urtschechischen Dialekten vertreten sei. Dieses Verbum verbindet Trubačev mit elnem zwar unbelegten iran. denominalen Verbum ${ }^{*} x \check{s}_{a-}$ traya-, das von einem gut bezeugten Nom. actionis auf -tra-gebildet sei $\sim \sim$ aw. $x$ šatra- "imperium, regnum, Herrschaft, Reich; Herrschgebiet" - vgl. Bartholomae 542f.; apers. xšą̧am "regnum", osset. cexsar, xsart "nazvanie vysšej doblesti vo vremja vojny" usw.; vgl. noch Brandenstein-Mayrhoffer, Hdbch. des Altpersischen S. 126). Er macht ausdrücklich darauf aufmerksam, dass das wort auch in iranischen Namen des Schwarzmeergebiets vorkommt (z. B. Ksárthanos, Ksatrákēs, Aléksarthos usw.). Hinsichtlich der vermuteten Isolation des slaw. * satriti innerhalb des slawischen Wortschatzes und auch von der formalen seite her stellt Trubačev (S. 53) folgendes fest: "sbližaja praslav. dial. *§atriti 1 ir. *xگatraya-/*x̌̃atra-, my konstatiruem $i$ na etot raz s Iranskoj storony polnuju vyjasnennost slovoobrazovatelbno- 
-etimologičeskix svjazej i iskonno mestnyj, unikalbnyj xarakter obrazovanij (xšatra-), a so slavjanskoj storony - lišs udivitelbnuju vnešnjuju blizostb s iranskim, kotoroju nelbzja obbjasnitb ni slavjanskimi sredstvami, ni sredstvami kakogo-libo drugogo jazýka, krome iranskogo. Itak, my sčitaem, čto i praslav. *šatrit: zaimstvovano iz iranskogo, pričem ono soxranjaet otraženie drevnej iranskoj formy $x \check{s} a t r-$, ešče ne oxvačennoj metatezoj -tr-> -rt-." Zur Analyse des semantischen Hintergrundes der poln. Verben patrzyc und szatrayé bemerkt er, dass "dva slavjanskix slova s blizkimi značenijami "smotrets, byts osmotritelsnym, bljusti" vosxodjat $k$ dvum različnym iranskim "terminam vlasti" - iz religiozno-etičeskoj i iz politíčeskoj sfery" (S. 54). Auf S. 55 verweist der Verfasser auf ähnliche Bedeutungsübergänge, wie sie bei *patriti und *šatriti auftreten, in einigen modernen sorachen. Bei šatriti liege - nach Trubačev (S. 55) - folgender Bedeutungsübergang vor: "ir. x̌satra- 'vlastb, sila' $\rightarrow$ praslav. dial. *šatriti 'dominer du regard' $\rightarrow$ smotrets opredelennym obrazom'." Obwohl eine solche Bedeutungsentwicklung natürlich möglich und, wie es scheint, auch verhältnismässig häufig und leicht durchführbar ist, bleibt sie bei *šatriti jedoch bis zu einem gewissen Grade problematisch, da es sich ja um ein Lehnwort handelt. Ein entsprechendes iran. Verbum, das eine direkte Quelle der Entlehnung - sowohl von der formalen als auch von der semantischen Seite her - vorstellen würde, ist nicht bekannt. Wie die oben angeführten Ausführungen Trubačevs zeigen, scheint es, dass er einen Bedeutungswandel, der bei der Entlehnung aus dem Iranischen ins slawische erfolgt sei, annimmt. Denn auch ein slawisches Wort, aus welchem das poln. Verbum satrayci in der zitierten Bedeutung ev. entwickelt worden wäre, ist nicht bekannt. Es erhebt sich die Frage, ob man derartige Prozesse bei Lehnwörtern zu Recht erwarten kann. Sie wären jedenfalls verständlich, wenn es sich um urverwandte Bildungen handeln würde. Wegen des gemeinsamen Bedeutungskreises, welchem die beiden behandelten Verben angehören, könnte man vielleicht (!) an ev. analogische Einflüsse oder Umbildungen, ev, auch nach einem dritten Verbum, denken. Sehr schwierig. 
Weiter (S. 55ff.) behandelt Trubačev im Rahmen derselben Verbengruppierung ein, seiner Meinung nach, weniger klares und weniger charakteristisches Beispiel, nämlich poln. dbaé "sorgen, sich bemühen, sich interessieren, Vertrauen haben, hoffen", wozu auch tschech. dbáti "sich bemühen, sich interessieren" und slk. dbat" "sorgen für etwas, sich interessieren" zu stellen sind. Ukr. dbáti "sich bemühen, sorgen, sich interessieren" deutet er, wie schon in manchen Fällen, als ein Lehnwort aus dem Polnischen. Auf S. 56 führt er die bisherigen etymologischen Deutungsversuche an. Trubačev selbst vergleicht urslaw. dial. *drbati mit aw. dabaēs-, tbaěs-, dvaěš- "hassen, beleidigen" (Bartholomae 814: "anfeinden, feind sein, kränken, beleidigen") und mit einem t-Formans aw. dvaêva- "Bedrohung". Iran. kannte demnach neben einem *dvaiš- $/ * d b a i \check{s}-$ auch einen unerweiterten stamm *dvaya-/*dbaya- (alles zu idg. *dwei- "fürchten" - vgl. Pokorny 227f.). Auch hier sieht Trubačev, ähnlich wie bei den drei früher behandelten Verben, ein Verhältnis zwischen einer unklaren, isolierten slawischen Bildung und einex durchsichtigen iranischen und nimmt, nicht zuletzt wegen der Folge *db-im Slawischen, ein slawisches Lehnwort aus dem Iranischen an (S. 57). Für die slawische Urform schlägt er zwei mögliche Varianten vor: *drbati und *drbajati. Das Bedeutungsverhältnis zwischen der angeblich ursprünglichen iranischen und der slawischen Bildung ist nicht so eindeutig, dass es zwingend zugunsten der angeführten Etymologie sprechen würde. Dex Verfasser erläutert es (S. 57) folgendermassen: "Slavjanskie značenija 'staratısja, zabotitbsja' nekotorym obrazom srodni značenijam 'bojatssja', kotorye ležat v osnove zasvidetelbstvovannyx iranskix značenij, i proizvodny ot poslednego značenija." Im Vergleich $\mathrm{zu}$ den sonst vorgeschlagenen etymologischen Deutungen scheint die zitierte Interpretation mit einem iranischen Lehnwort nicht wesentlich weniger annehmbar, es gelten für sie aber die gleichen Bedenken wie für die anderen drei polnischen Verben in diesem Zusammenhang. Im letzten Falle geht Trubačev anscheinend von einem ursprïnglichen altiranischen Wort aus, wie man aus der dabei zitierten awestischen Bildung wahrscheinlich folgern kann. Das Problem 
der Deutung aller vier behandelten Verben schliesst er (S. 57) folgenderweise ab: "Etimologii polbsk. baczyć, patrzyć, szatrzyć, dbać vskryli celuju gruppu važnoj glagolbnoj leksiki z osnovnymi značenijami 'smotretb, bytb osmotritelbnym, zabotitbsja' i tesnymi svjazami s iranskim slovarem. Drevnostb etix slavjano-iranskix par bessporna v každom otdelınom slučae (vključaja poslednij, gde, pri vsex pročix realbnyx somnenijax, verojatno proisxoždenie imenno iz drevneiranskogo *dbaya-, s diftongom). No genezis otdelbnyx slov pri etom različen, tak kak zdesb $i$ drevnie iranskie zaimstovanija (patrzyć, szatrzyć, dbać), estb takže i projavlenija blizkogo slovoobrazovatelbno-semantičeskogo parallelizma (baczyé)."

Im zweiten Teil seiner Behandlung der sog. polnisch-iranischen Isoglossen wendet sich Trubačev dem Problem der alten morphologisch-lexikalischen gemeinsamen Neuerungen auf beiden seiten zu. Als das erste Beispiel einer Neuerung, die auf einen Teil der urslawischen und der altiranischen Dialekte beschränkt sei, führt er (S. 58ff.) das poln. Verbum trwac "dauern, beharren", tschech. trvati "dass.", slk. trvat" "dass." an. In anderen slawischen Sprachen ist das Wort nicht belegt. Als ein Lehnwort aus dem Polnischen deutet Trubačev nsorb. dial. trwaś, wruss. trvacs und ukr. triváti. Er lehnt die bisherigen etymologischen Vorschläge (Brückner 578, Machek 538 - auf S. $58 f$. mit ausführlicher Analyse) ab. Als das altertümlichste Areal des Verbums *trrvati nimmt er das Polnische an und vergleicht aw. taurwaya- "besiegen, überwinden" (< air. *tarvaya- < idg. *t پّ̆ova-). Seiner Meinung nach (S. 59f.) "Ir. *tarvaya- (...) točno sootvetstvuet praslav. dial. *trrvati<*trova- so značeniem, blizkim polbsk. trwaé 'dlitbsja, prodolžatbsja, uporstvovatı, nastaivatb'." Hinsichtlich der formalen Seite der behandelten Gleichung macht Trubačev auf das Formans -v- in beiden Fällen aufmerksam. Es sei an einer bestimmten Stufe der Innovation an die wurzel *tp- in den altiranischen und in einem Teil der urslawischen Dialekte, besonders in dem altpolnischen, angefügt worden. Trubačev bemerkt, dass zwar ev. auch ein Lehnwort vorliegen könnte, zieht jedoch, wegen des Fehlens zwingender Argu- 
mente in dieser Richtung (die aber auch bei seinen früher behandelten "iranischen Lehnwörtern" nicht immer vorhanden sind), eine Parallelentwicklung der urpolnischen und der iranischen Bildung aus ursprünglichem *tz-v-vor. Offensichtlich nimmt er also eine ursprünglich urverwandte Bildung, die in der Endform durch eine gemeinsame Neuerung geprägt worden wäre, an. Mit der Annahme einer Rekonstruktionsvariante *trrvaya- für poln. trwaé gewinnt Trubačev eine im Urslawischen und Altiranischen praktisch identische Grundform. Bezüglich der Bedeutung verweist er darauf, dass es sich um einen bedeutenden gemeinsamen zug im Rahmen der religiösen Terminologie handele (S. 60). Es bleibt dennoch trotz allem unklar, welcher Einfluss bei der Entstehung der slawischen Bildung dem Iranischen tatsächlich zuzuschreiben wäre bzw., was zugunsten einer speziellen Verbindung des Iranischen und Slawischen sprechen würde, wenn eine ererbte wurzel (vgl. Pokorny 1074f.), ein üblicher idg. Wortbildungsprozess sowie - ungeachtet der Erklärungșversuche Trubačevs S. 60f. erhebliche Bedeutungsdifferenzen auf beiden seiten vorliegen. Ebenso unerklärt bleibt auch das Verhältnis poln. usw. trwae zu slaw. trajati trotz einigen Anmerkungen Trubačevs in diesem $\mathrm{zu}-$ sammenhang. 112

Das nächste Beispiel einer gemeinsamen slawisch- (bzw. polnisch-)iranischen Neuerung stelle die etymologische Anknüpfung poln. tuszye "Hoffnung einflössen", otucha "Hoffnung, Vertrauen"; tschech. tuxiti "hoffen" (S. 61) vor. Diese Gruppe stelle (nach Trubačev) eine spezielle semantische variante dar zu urslaw. *tusiti/*tuxn̨ti in der Bedeutung "auslöschen, verlöschen" (belegt in: ksl. potuxnqti "beruhigen, auslöschen"; bulg. potusavam "erlösche", slowen. potúhniti - tuhhnem "verlöschen, verstummen", potuß̌ti "erlöschen"; russ. túxnut6, tuštt6; wruss. tušýc6). Für slaw. *tušti/*tuxn̨ti rekonstruiert Trubačev die Bedeutung "Feuer löschen, beruhigen, still machen" (S. 61) und verweist auf die üblichen etymologischen Anknüpfungen im Baltischen und anderen 1dg. Sprachen. Vgl. Trautmann, Bsl. Wb. 332, Vasmer III 158, Fraenkel 1068, Mayrhofer I 517f. Die spezifisch moralische Nuance der Bedeutung "Hoffnung" schreibt Trubačev innerhalb der 
slawischen Sprachen in erster Linie dem Polnischen und Tschechischen, von anderen idg. Sprachen aber dem Indoiranischen zu. An denselben Bedeutungskreis knüpft er die aw. Gottesbezeichnung tušnā.maitiš "bukvalıno 'udovletvorennyj um'" (ibid.) an. (Bartholomae 658 verzeichnet: g. tušnā.matay- f. ("schweigendes, schweigend fügsames Denken" /.../; nur als) Name einer Gottheit; ibid. weiter jaw. tušnă matay-f. "EN einer gläubigen Frau".) Aus den vermuteten engen Beziehungen in der Bedeutung auf beiden Seit.en zieht Trubačev (S. 6lf.) verhältnismässig weitreichende Schlüsse: "Esli priznatb v zap.-slav. *tušiti "nadejatbsja, vseljatь nadeždu, označatь dobroe predznamenovanie" (polssk., češ.) i u indo-iran. *tuš- "uspokaivatbsja, byts dovolbnym" xarakter semantiěeskoj inovacii, razvivšejsja na bolee širokoj baze (...), to kontaktnaja svjazb etix sxodnyx novšestv - po krajnej mere, meždu iranskoj vetvьju i častıju praslavjanskogo - v svete uže izvestnyx dannyx kažetsja dopustimoj." $\mathrm{Zu}$ der vorgeschlagenen etymologischen Anknüpfung scheint es notwendig auf zwei Umstände aufmerksam zu machen: das zitierte aw. Beispiel ist bedeutungsmässig keinesfalls so klar und eindeutig, dass es so bedeutende Schlüsse ermöglichen würde. Ausserden sei noch auf das slowen. Nomen potûha "Unterschlupf, Zuflucht", počuha "dass." hingewiesen, das anscheinend in denselben Bedeutungskreis wie die oben angeführten poln. und tschech. Bildungen gehört, so dass offenbar keine isolierte westslawische Entwicklung vorliegt. Die zitierte vermutlich westslawisch- (bzw. polnisch-)iranische Isoglosse kann jedenfalls nicht als Beweismaterial für die Bestimmung der slawisch-iranischen Beziehungen in einer bestimmten Epoche dienen.

Eine weitere polnisch-iranische Isoglosse stelle das poln. pitwać "coire cum femina; schwer schneiden; mit einem stumpfen Messer schneiden; ausweiden" vor. Die Bildung kommt noch in osttschech. dial. pitvati, pistvat, picvat "ausweiden, mit einem stumpfen Messer schneiden"; osorb. pitwać, nsorb. pitvas "stöbern, stochern" vor. Trubačev bemerkt, dass die osttschechischen Dialekte an das Polnische grenzen und rechnet bei den sorbischen Belegen mit der Möglichkeit polnischen Ursprungs. Hinsichtlich 
der etymologischen Deutung verweist er auf Brückner S. 415, 450 und Machek S. 369. Trubačev selbst (S. 62) vergleicht westslawisches, poln.-tschech. bzw. urslaw. dial. *pitvati "mit einem stumpfen Messer schneiden, zerlegen, zerdrücken" (vgl. Bartholomae 898f.: "zu tilgen, auszurotten, zu erschlagen" (...), PFP zum V. spā(y)"). Zur formalen Analyse der aw. Bildung bemerkt Trubačev (S. 62f.) folgendes: "Avest. pōitha-predstavljaet soboj intensiv ot formy *pail wa-, poslednjaja prodolžaet $v$ svoju očeredb doiranskoe *peitu-." Die Annahme eines Intensivums ist unnötig, da sie anscheinend auf falsch verstandenem aw. - bzw. dem Verhältnis -ōi- : -ae- - beruht. ${ }^{113}$. Aus dem ursprünglichen *peitu- leitet er (S. 63) auch urslaw. dial. *pitvati her. Er macht darauf aufmerksam, dass nicht eine Entlehnung aus dem Iranischen ins Slawische vorlege, sondern dass die Bildungen urverwandt seien. Ähnlich wie Gershevitch (s. die Quellenangabe bei Mayrhofer II 339) verbindet auch Trubačev aw. pōi aind. pináṣti. Im diesem sinne würde auch urslaw. *pitvati < *peitu-) eine Opposition zu *pis- in slaw. prxati "stossen, rütteln" vorstellen. Aus der Gleichung erschliesst Trubačev (S. 63) folgendes: "Praslav. dial. *pitvati $i$ avest. pōilwa-predstavljajut soboj, takim obrazom, skoree vsego, obščuju inovaciju (*peitu-) v vide osobogo dalbnejšego rasširenija i.-e. *pi(s)-, *pei(s)-." Die Neuerung weise eine spezielle terminologische Anwendung auf (ibid.): "i slavjanskoe $i$ iranskoe slovo oboznačaet preimuščestvenno dejstvija, proizvodimye nad životnymi ('rezats tupym nožom, potrošits' 'razdavlivats /jaički pri oskoplenii/")." Trubačev geht demnach von idg. *pei-, *pi-, einer sonst nicht belegten, kürzeren Variante der Wurzel *(peis?), *pis- "zerstampfen, zermalmen (bes. Getreide)" bei Pokorny 796 aus. Vielleicht wäre (wenigstens für die oben postulierten Bedeutungen) eher die Wurzel *(s)p(h) $\frac{u}{2}-$ "spitz, spitzes Holzstück", die selbständig oder mit verschiedenen suffixen erweitert vorkommt (vgl. Pokorny 981f.), anzunehmen. In diesem Falle würde höchstens eine "Isoglosse" im Sinne eines beibehaltenen Archaismus vorliegen. Vgl. im zusammenhang mit aind. pinasti die Bemerkung Mayrhofers (Tb. II 281) hinsichtlich der 
Wurzelvariante ohne $-s-:$ "Einfaches, unerweitertes *pi- neben pi-s-mag in osset. fid (*pi-ti-) "millstone", afghan., örmuri pal "dass." (*paiti-) vorliegen, vielleicht auch in avest. pōibwa-, wenn "to be crushed" bedeutend." 114

Unter iranischem Einfluss sei weiter das poln. Adj. zwawy "lebend, lebendig, flink" zustandegekommen (S. 63). Diese poln. Bildung bzw. deren urslawische Form *ž6vavij6, sei, nach Trubačev, nicht mit dem slaw. Verbum *żiti "leben" in Verbindung $z u$ bringen, da die Wurzel * $g^{w} e i(\partial)$ - im slawischen keine Ablautvariante mit *-i- aufweise. Demnach sei die zitierte slaw. Bildung mit ostiran. Juv- "leben", das seinerseits eine Umbildung des altiran. *jizv- ( aw. jw-, sak. $j \bar{u}-$, sogd. $j w-, z w-$, afgh. žwand) vorstelle, zu verbinden. Vgl. K. Hoffman, Hdbch. der orient. I/IV/1, S. 8. Als funktionell und formal verwandte Bildung führt Trubačev aw. jwaya- "lebendig" an. Nach der Deutung Trubačevs handele es sich um ein Lehnwort, obwohl er nur von einem 'iranischen Einfluss auf das Slawische' spricht. ${ }^{115}$ Unklar.

Im Weiteren (S. 64ff.) behandelt Trubačev ausführlich poln. raróg "ein Vogel aus dem Stamme der Falken, Monstrum", tschech. raroh "Falke, der grausamste unter den Falken", slk. rároh "weisslicher Falke". 116 In anderen slawischen Sprachen kommt das Wort nicht vor. Schon Machek stellte eine iranische Etymologie auf. 117 Dabei verweist er auf die aw. Benennung der Gottheit varavrayna-, die die Form des Vogels vāragan-, vāranganannimmt. Trubačev stimmt der etymologischen Deutung Macheks zu (s. 65): "Vse eto služit Maxeku zakonnym osnovaniem dlja togo, čtoby obsjasnitb slav. rarogr "sokol" kak zaimstvovanie iz ir. *vāragna- "sokol", točno tak že kak i mifologičeskij kontekst slavjanskogo nazvanija - iz sootvetstvujuščego iranskogo religiozno-mifologičeskogo istočnika. Assimiljativnye izmenenija pridali slavjanskomu slovu tot vid, kotoryj ono imeet $v$ zapadnoslavjanskix jazykax." Schon Machek zog auch lit. vãnagas "Habicht" hinzu, das, der Interpretation Trubačevs nach (S. 66), schon in einer älteren Epoche aus dem Iranischen entlehnt wurde, und zwar unabhängig von dem soeben behandelten slaw. Lehnwort. Der slaw. Beleg *rarogr stelle, nach Trubačev, ein wich- 
tiges Argument bei der Bestimmung der slawisch-iranischen Kontakte dar. ${ }^{118}$ Deshalb widmet ihm der Verfasser eine ausführliche formale und semantische Analyse (s. 66-71). Für die iranische Benennung der zitierten Gottheit bzw. des Dämons rekonstruiert er (S. 67) folgende Urformen: *vrtra-, *vrolra-, *varvira-, *vārabzw. *pati-vāra-. Im letzten Fall liege eine zusammensetzung aus einem Nom. act. bzw. Nom. agent. *vrotra-/*vāra- und einer Präposition *pati- vor. Eine dem iran. *pati-vāra- entsprechende baltoslawische Urform rekonstuiert Trubačev (S. 67) anhand zweler baltoslawischer wörter, und zwar poln. poczwara "ein grausames Phantom, Gespenst, Alp" und lit. áitvaras "Alp, Phantom, Drache". Das polnische und litauische Wort seien unabhängig aus dem Iranischen entlehnt worden (S. 68). Die polnische Bildung leitet Trubačev von einer iranischen Bildung altossetischen Charakters, die schon Assibilation $t i>c i$ aufweise, her und rekostruiert ein ostiran. dial. (skyth.-sarmat.) *pacvara-/*facvara-. Iranisches -cv-sei, seiner Meinung nach, durch - שv- substituiert worden. Für das lit. Wort führt er Varianten áitvaras, áitivaras, áičvaras an. Nach seiner Deutung weise die letzte Variante denselben Wechseltyp als die slawische Bildung auf, die phonetisch vollständigste Variante áitivaras stelle dagegen ein verhältnismässig altes Lehnwort aus iran. *pati-vära-dar. Hinsichtlich des fehlenden anlautenden $p$-lässt er (zwar mit leichtem Vorbehalt) die Möglichkeit tabuistischer Umwandlung zu. Vgl. Fraenkel, LEW S. 4. Es folgt auf S. 69f. der Versuch einer Rekonstruktion der Semantik von iran. *pati-vāra-. Dieser Terminus stelle in der Bedeutung "Drache, ein fliegender böser Geist" eine lexikalische Variante zu iran. *vāra-, *vprora- vor (s. 70). Die Ausdrücke *varagna-, *vproragna- wiesen noch die alte Bedeutung "Gott, der mit dem Drachen kämpft" auf. In der opposition *vris /*(pati)vāra- : *vrôragna-/*vāragna sieht Trubačev die alte Doppelheit des guten und bösen Prinzips in der Mythologie. Das Polnische habe die beiden Glieder der Opposition in poczwara "böser Geist, Drache" : raróg "Raubvogel, Falke" erhalten. 119

Der Vorschlag der Deutung der behandelten Beispiele als iranischer Lehnwörter scheint verhältnismässig gut begründet 
und man kann ihm (auch wegen der umstrittenen anderen Deutungsversuche) ein gewisses Mass an Glaubwürdigkeit zuschreiben. Wie bei allen anderen von Trubačev behandelten polnisch-iranischen Isoglossen bleibt aber die Frage nach den konkreten Umständen des Entlehnungverlaufes unbeantwortet. Kann man in der Zeit, als diese Entlehnungen zustandegekommen seien (im letzten Fall offenbar noch in altiranischer zeit), mit einem so stark bzw. so klar geographisch differenzierten Urslawischen rechnen? Darüber hinaus beruhen diese und ähnliche Gleichungen sehr oft auf einer sog. conclusio ex silentio, was der Verfasser in seinen Folgerungen nicht berücksichtigt.

Im Rahmen der westslawisch-iranischen Isoglossen behandelt Trubačev weiter (S. 71-76) einen Begriff aus der sozialen bzw. politischen Terminologie: poln. pan "Herr, Hausherr, Herrscher", tschech. pan "dass.", atschech. hpán, slk. pán "Herr, Hausherr". Ukr., wruss. pan "Herr, Gutsherr" und lit. põnas "Herr, Hausherr" (Fraenkel 637: "(Guts)herr, Regent") sei aus dem Polnischen (vgl. Fraenkel 1. c.), aus dem Tschechischen aber sei osorb. pan entlehnt worden (S. 71). Die ursprüngliche Form spiegele - nach Trubačev - am besten die atschech. Vertretung hpán (XIII. Jh.) wieder. Infolgedessen rekonstruiert er (S. 72) eine lokal-urslawische Form *grpanr. Trubačev zitiert die bisherigen Etymologie-Vorschläge (Machek 351f., Brückner 393, Vasmer I 432, II 308) und lehnt die Zusammenstellung des westslaw. *grpan mit dem aksl. županr ab. ${ }^{120}$ Er selbst erklärt urslaw. dial. *grpanr als ein Lehnwort aus iran. *gu-pāna-, *gau-pāna( afgh. yōba "Kuhhirt" < "Vieh-Hütter" (S. 73). Im Iranischen liege eine zusammensetzung mit produktivem zweitem Glied -pāna"Schutz, Beschützung; Beschützer, Schirmherr" vor. Er stellt (S. 74) fest, dass Nomina agentis wie *gau-pāna-, *fङu-pānatypisch iranische Bildungen darstellen. Obwohl dem iran. *gau-pāna- entsprechende Bildungen in den bisher bekannten skyth. und sarmat. Sprachresten nicht vorkommen, rechnet Trubačev mit einer realen Möglichkeit, dass sie einst auch dort vorhanden gewesen waren. ${ }^{121} \mathrm{Für}$ die verwendung von iran. pāna- in diesen Sprachen verweist er auf seine schon früher dargestellte Etymo- 
logie des bulg. stopánin, dass er aus spätskyth.-sarmat. *asta-pāna- erklärt. Ahnlich wie oben bei poln. patrzyce operiert er auch hier hinsichtlich des Ursprungs der slawischen Bildung mit dem Argument, dass das Slawische nur die mit dem Formans -s- erweiterte Grundform * $p \bar{a}-s-$, nicht aber eine unerweiterte Variante ${ }^{*} p \bar{a}-$, die im Iranischen vorkommt, kannte. Das alles spreche, der Meinung des Verfassers nach, für die einzig mögliche Erklärung des urslaw. dial. *grpanr aus iran. *gupāna-l *gaupāna- (S. 75). Hinsichtlich der semantischen seite des zitierten Verhältnisses ist die Folgerung des Verfassers, wie er sie auf s. 75 formuliert, von Bedeutung: "Zap.-slav. *grpanr "gospodin", krome iranskoj formy i struktury, soxranilo takže sled tipično iranskogo vzgljada na vlastb, obespečennuju materialınymi cennostjami. My xotim skazatı, čto značenie 'gospodin' opredelilosb u prototipa slav. *grpanz ešče na iranskoj jazykovoj požve." Die zitierte Etymologie scheint verhältnismässig glaubwïdig, sowohl der formalen als auch der semantischen seite nach annehmbar.

In dieselbe Bedeutungsgruppe gehört auch ein im Weiteren behandeltes (S. 76f.) Substantiv: poln. kat "Henker, Scharfrichter; Unheil, Teufel" (seit dem XV. Jh. belegt), tschech. kat "Henker (seit dem XIV. Jh.) und slk. kat in derselben Bedeutung. Vg1. Sławski II 98f., Machek 195. Trubačev leitet urslaw. dial. *katr aus dem Iranischen $\sim \sim$ aw. kấra- "Vergeltung, Busse" - vg1. Bartholomae 463) her. Zur Begrïndung der Etymologie greift Trubačev auf ähnliche Argumente wie schon oben bei patrzye und pan zurïck. Das Slawische kennt nämlich die Basis *koi-/*kai-, es scheint ihm aber unwahrscheinlich, dass sie auch eine unerweiterte Basis *ka- aufweisen könnte. Im Iranischen jedoch sei das Verhältnis $k \bar{a}-: k a y$ - gut zu rechtfertigen. Hinsichtlich der Chronologie des Bedeutungsverhältnisses zwischen der slawischen und iranischen seite kommt er zu anderen Feststellungen wie z. B. bei pan. So schreibt er (S. 77): "Okončatelsnaja specializacija značenija ('palač, ekzekutor') nastupila $v$ etom slučae, po-vidimomu, uže $v$ slavjanskom, xotja iranskoe značenie (avest. 'vozmezdie na strašnom sude') soder- 
žalo dlja etogo dostatočnye predposylki. V itoge zdesb sostojalsja stolb obyčnyj $v$ jazyke perexod nomen actionis $\rightarrow$ nomen agentis." Offensichtlich rechnet Trubačev mit einem verhältnismässig alten Lehnwort, noch aus der zeit der altiranischen Dialekte. Der angeführten Etymologie kann man eine ähnliche stufe der Wahrscheinlichkeit wie den anderen polnisch- bzw. westslawisch-iranischen Gleichungen dieses Kreises zuschreiben. Es könnte wohl möglich sein, dass urverwandte Bildungen vorliegen, besonders noch, wenn slaw. kazn6 mit kajat6(sja) zu verbinden ist. Vgl. dazu Vasmer I 504 und Pokorny 636f. (* $k^{w} e i-(t)$ - "worauf achten, (...) strafen, rächen, büssen" usw.). 122

Es folgt (S. 77-81) eine Zusammenfassung, wo einige Ausgangspunkte des Verfassers näher bestimmt werden. So präzisiert er (S. 77) den Status der slawisch-iranischen Beziehungen folgendermassen: "pod slavjano-iranskim leksičeskim sootvetstviem my ponimaem obščee innovacionnoe razvitie ili blizostb, osnovannuju na drevnem zaimstvovanii iz odnogo jazyka v drugoj." Den Mittelpunkt der westslawisch-iranischen lexikalischen Beziehungen sucht er auf dem polnischen Territorium, das Tschechische nehme dagegen in dieser Hinsicht eine periphere stellung ein (S. 77). Auf S. 78 macht er auf die Bedeutung, die diese Gleichungen für die Untersuchung der iranischen Sprachen haben, aufmerksam. 123 Den Komplex der behandelten Isoglossen benennt Trubačev "polono-iranica". Es folgen (S. 81) noch die abschliessenden Feststellungen, die aber nichts bringen, das nicht in der vorhergehenden Abschnitten wenigstens angedeutet wäre.

Das letzte Kapitel der Abhandlung, das sich auf die westslawisch- (genauer: polnisch-)iranischen Isoglossen konzentriert, stellt das Hauptinteresse des Verfassers vor. Dadurch sind auch einzelne Etymologien besser bzw. genauer ausgeführt als das in den vorhergehenden Kapiteln der Fall war. Dennoch bleiben sie meistens hypothetisch, insofern sie nicht chronologisch sowohl von der slawischen als auch von der iranischen seite her bestimmt sind und mit historisch überprüfbaren Fakten übereinstimmen. Weiter bleibt, wie schon erwähnt, die Frage nach dem Grad der dialektischen Gliederung des Urslawischen in der zeit des ange- 
nommen iranischen Einflusses offen. Ebenso wäre jedenfalls auch der Stand der iranischen Sprachen bzw. Dialekte und deren Entwicklungsstufe in der betreffenden zeit näher zu bestimmen. Wenigstens teilweise sollte auch die Frage, was man denjenigen Sprachen, die sehr schlecht oder kaum belegt sind (z. B. nur in einigen Glossen, Namen usw.; Problem der skyth.-sarmat. Sprachresten usw.), zuschreiben kann, beantwortet werden. In denselben Rahmen fügt sich zuletzt noch das Problem, wie eine Entlehnung zu beurteilen ist, wenn die Ausgangsform (möglicherweise auch zufällig) nicht (oder noch nicht) bekannt ist.

1 Vgl. S. 3: "Po rjadu priznakov - leksičeskix, fonetičeskix, grammatičeskix - osetinskij jazyk, poryvaja s drugimi indoiranskimi jazykami, smykaetsja s perečislennymi evropejskimi jazykami. Eti čerty my nazyvaem skifo-evropejskimi izoglossami."

2 "Dopuskaja v principe specifičeskie svjazi severnoiranskogo s evropejskimi jazykami, M. Mayxhofer, kak my dumaem, ne ošibaetsja. Naš material rešitelbno eto podtverždaet."

3 "os. xsirf po oglasovke $i$ po značeniju primykaet neposredstvenno $k$ slavo-baltijskomu."

4 (S. 13): "to sakskij mog soxranitb izoglossy drevnejšego perioda skifo-evropejskix kontaktov, v tom čisle i takie, kotorye $v$ osetinskom ne zasvidetelostvovany."

5 Diese Verbindung schlagen schon J. Rozwadowski, RO I, 1914-5, S. 104, und H. Arntz, Sprachliche Beziehungen zwischen Arisch und Balto-slawisch, Heidelberg 1933, s. 37 vor.

6 Zu arm. Beleg vgl. Pokorny 632 und 564 und jetzt auch KIingenschmitt, Altarmenisches Verbum, S. 225.

7 Fraenkel verzeichnet kein tapuoti, er bemerkt aber I. c. folgendes: "Lett. tapât "schreiten (mit kleinen schritten)", Interj. tapa oder tapu wird zu slov. topòt "Getrampel, stampfen" (...), skr. töpot "dass.", russ. topaţ "stampfen" gestellt, die wie lit. tapýti mit bulg. tepam "walken, stampfen, schlagen", russ. tepti "schlagen" usw. (...) ablauten." Vgl. ibid. noch tapýti 2. (tapiju) "tappen, treten".

8 (S. 16): "Povsjudu $v$ etix slovax my naxodim zakonomernyj dlja iranskogo $r$ ili 1 iš́ osetinskij primykaet $k$ baltijskomu, davaja prostuju (bespreverbnuju) sprjagaemuju formu $s$ 1."

9 Zu balt. Belegen vgl. Fraenkel s. $960 f$.

10 Diese Verbindung hat schon Vasmer, RSIVI, 1913, S. 173. 
11 Zur morphologischen Analyse osset. belon/bcel@w vgl. Abaev, IES $I$ 249, und zur lit. Vertretung Fraenkel, LEW 31.

12 Vgl. z. B. Brugmann, Grdr. II/1, S. 296.

$13 \mathrm{Vgl}$. ibid. S. 77: "In der Mehrzahl der Fälle gehen in altererbten wörtern ir, il, im, in, ur, ul, um, un auf ieur. r, $\frac{1}{8}$, m, n zurück." Weiter, s. 78f., führt er die bisherigen Deutungsversuche an (z. B. Trautmann, Slavia II S. 1ff.; Vaillant, Gramm. comp. I S. 171; Kuryłowicz, Apophonie S. 227f.). Er selbst geht von einer anderen Begründung aus. So schreibt er auf S. 79: "Nun ist erstens klar, dass der gewöhnliche Reflex von ieur. ${ }^{*}{ }_{0},{ }^{*}{ }^{1},{ }^{*} \mathrm{~m},{ }^{*} \mathrm{n}$ sowohl im Balt. wie im slaw. *ir, *il, *im, *in ist. Dieser Reflex ist auch der einzige, der am lebendigen Ablautwechsel teilnimmt. (...) Die Verbindung uR bezeichnet also die seltenere Entwicklung. Dies zeigt sich auch darin, dass die u-Verbindungen geneigt sind, eine expressive valeur anzunehmen. Besonders im. Balt. lässt sich dies in einer erstaunlichen Anzahl von Fälien feststellen. Die Bedeutungen, die durch wörter mit uR usw. zum Ausdruck kommen, sind vor allem die folgenden: 1. "schwer, dumm, faul", 2. "klumpig", 3. "krumm", 4. "mit körperlichen Gebrechen, oder anderen herabsetzenden Eigenschaften versehen, elend", 5. "dunkel, schmutzig", 6. dazu kommen lautmalende Wörter." Zur möglichen Vereinbarkeit der von Trautmann und Kuryłowicz vorgeschlagenen Deutung mit der stangschen vgl. noch stang, ibid. S. $81 f$.

14 Fraenkel 399 verzeichnet 1it. mãkas "(Geld)beutel", lett. maks "Beutel" (...), lit. makštìs, PI. mãkštys "Scheide, Futteral, Etui", makšnà "(Geld)beutel" (...), lett. maksts "Netzbeutel, Scheide, Futteral" - mit leichten Bedeutungsabweichungen also, die aber besser zu slawischen Belegen passen.

15 Es bleibt die Frage, ob der osset. Vokalismus ev. aus einer Schwundstufe derselben wurzel erklärbar wäre. oder denkt Abaev vielleicht an Einfluss der slawischen Form auf die ossetische? Problematisch.

$16 \mathrm{Vgl.} \mathrm{dazu} \mathrm{Fraenkel} \mathrm{309:} \mathrm{kùmetis,} \mathrm{kumetỹs} \mathrm{"Instmann,} \mathrm{Gärtner"}$ $<$ aruss. kbmetь; apreuss. kumetis "Gebuer" (= "Bauer") < apoln. kßmet' usw.

17. Dieselbe zusammenstellung verzeichnet schon A. A. Zaliznjak, Voprosy slavjan. jazykoznanija 6 (1962), S. 41, wo er einige Umstände, die zugunsten des möglichen Einflusses des slawischen auf die nordiranischen Dialekte sprechen könnten, anführt. Hinsichtlich der Ursache einer solchen Entlehnung schliesst er sich der Deutung Abaevs, OJF I 334 an, der eine soziale Differenzierung der Alanen annimmt.

18 Denn (ibid.): "Esli by reč́ šla o pervonačal to my imeli by vosetinskom ne fext, a *fist.".

19 In diesem Zusammenhang wäre vielleicht angebracht, die geographische und chronologische Verbreitung des Terminus 
pextilb zu überprüfen. Vasmex II 363 führt noch eine weitere dialektische Variante pixtelb an.

20 zu dem Verhältnis iran. a : osset. @ vgl. Miller, GIPh I Anhang I S. 14 und zu iran. $t$ : osset. d Beispiele wie aw. mātar : osset. madœ "Mutter" oder aw. satam : osset. sœdœ "hundert". $z u$ russ. Belegen und Bedeutungen vgl. Vasmer II 330 .

21 Zur Möglichkeit eines typologisch verwandten Prozesses vgl. Dressler, Sprache XI, 1965, S. 37: "Im Altkirchenslawischen entspricht (vielleicht als Lehnübersetzung) griech. aêr ein Wort vъzduchb."

22 Zu ai. vápra- "Aufwurf von Erde, Erdwall" (ep., kl.) vgl. Mayrhofer III 145, der zu dem oben genannten ossetischen Beispiel eine wirklich schlagende parallele aus dem Iranischen beibringt: "Ein vergleichbares *vap-ra- setzt das Iranische in der Bedeutung "Schnee" fort: aw. vafra-, neup. barf usw." Zum Verbum vápati "streut, sprengt aus, wirft, sät"vgl. Mayrhofer III 144. Vgl. auch Vasmer II 126.

23 Vgl. Miller, GIPh I Anh. S. 20 \& Anm.

24 Könnte ev. der vokalismus eines solchen synonims - falls im ossetischen überhaupt bekannt - die Bildung mītmet beeinflussen? In diesem Fall könnte vielleicht (!) eine ähnliche Doppelheit wie im Awestischen, das sowohl den Ausdruck snaēža-wie auch vafra- "Schnee", wahrscheinlich mit einem ursprünglichen Unterschied in der Bedeutung, etwa "Gestöber" : "Schnee", kennt, vorliegen.

25 Vgl. schon Rozwadowski, RO I, 1914-15, 104.

26 So schreibt ex auf s. 38 folgendes: "Areal6nye slova vxodili v osetinskuju leksiku v raznye periody istorii jazyka. V drevnejšij period jazyk ešč ostavalsja veren unasledovannym iranskim fonetičeskim normam, $v$ tom čisle i iranskomu rotacizmu. (...) so vremenem jazyk v processe kontaktov s drugimi jazykami stal otxoditb ot drevneiranskix zvukovyx norm $i$ stali vxodit $v$ silu normy areal6noj fonetiki, $v$ tom cisle otkrylis6 dveri dija fonemy l."

27 VgI.'s. 47: "Izoglossa $\gamma(\mathrm{h})$ informiruet nas o bolee glubokom i znaćitel6nom uc̆astii skifo-sarmatskogo elementa $v$ etnogenetičeskom processe na juge Rosii, čem eto mogut sdelat 6 toponimika i arxeologija."

28 Zum slaw. bogb vgl. noch Vasmer, RSIVI, 1913, 173; Meillet, RESIVI, 1926, 168; R. Jakobson, Slavic Mythology, Funk and Wagnalls standard Dictionary of Folklore, Vol. II, $1950 . \mathrm{Vgl}$. noch weiter $s .221$.

$29 \mathrm{VgI}$. z. B. Porzig, GIiederung S. 168.

30 (S. 53): "Ix kontakty načalis6, verojatno, so vremeni obosoblenija slavjanskoj gruppy, $t$. e. so vtoroj poloviny II tysjaceletija, (...) do IV V. n. e., stalobyt6, okolo pjatnadcati vekov." 
31 (S. 59f.): "Blizost6 meždu slavjanskim i osetinskim sostoit ne tol6ko $v$ tom, čto preverbov mnoge $i$ vse oni obrašcajut nesoveršennyj vid $v$ soveršennyj, no $i v$ tom, čto $i v$ slavjanskom, $i$ osetinskom preverby ne utračivajut pri etom $i$ svoix slovoobrazovatel6nyx funkcij, utočnjaja značenie dejstvija $v$ otnošenii ego prostranstvennoj napravlennosti $i$ pr. (...) I v slavjanskom, i v osetinskom perfektivirujušc̆aja rol6 preverbov vystupaet $v$ prošedšem $i$ buduščm vremeni."

32 (S. 64): "V etot otnositel6no drevnij period, kogda v osetinskom proisxodilo srašcenie nekotoryx preverbov s glagol6nymi osnovami, preverby ešč ne soobšcili glagolu perfektivnogo značenija, t. e. soxranjalos6 ešče to položenie, kotoroe bylo $v$ drevneiranskom."

$33 \mathrm{Vgl}$. noch z. B. Meillet, MSL 9, S. 55; MSL 20, S. 111;RS 8, S. 297 und Fraenkel S. $1173 f$.

34 Vgl. auch Arumaa, Ursl. Gramm. II, S. 52 : vbz- (-z-<-g'h-).

35 "Eta blizost6 Iučše vsego možet byt6 obrjasnena kak rezul6tat areal6nyx skifo-slavjanskix jazykovyx kontaktov v vostoc̆noj Evrope, našedšix svoe vyraženie i v rjade drugix leksičeskix i grammatičeskix izogloss."

36 (S. 70): "Analogija meždu slavjanskim i osetinskim, kak my vidim, daleko iduščaja i pokazatelbnaja: v slavjanskom $v$ obširnoj gruppe imen i mestoimenij, vosetinskom $v$ imenax, a takže ličnyx, voprositel6nyx i otnositel6nyx mestoimenijax suščestvuet genitiv-akkuzativ, pričm $i$ tam $i$ tut upotreblenie ego svjazano $v$ konec̆nom sčete s različeniem klassa ličnostej (persona) $i$ klass ne-ličnostej ili veščej (res)."

37 Delbrück, Vgl. Syntax I 320, 154; Meillet, Recherches sur I'emploi du génitif-accusatif en vieux-slave, Paris 1897; Berneker, $K Z 37,1901, S .364-386$; Meillet, Le slave commun, S. 407 .

38 (S. 73) : "Počemu že tol6ko vosetinskom, vostočnoarmjanskom $i$ slavjanskom $v$ etoj roli vystupaet forma genitiva?"

$39 \mathrm{Vgl}$. noch s. 78: "V osetinskom že pojavlenie genitiva-akkuzativa risuetsja kak zakonomernyj process, podderživaemyj vsej istoriej iranskix i daže, šire, indoiranskix jazykov."

40 "Die Einführung der Genitivform bei Bezeichnungen für Lebewesen hängt mit der Ausbildung der Kategorie der Belebtheit zusammen, die in verschiedenen slavischen sprachen verschieden weit (im Russischen am weitesten) gegangen ist. In allen Einzelheiten ist dieser Prozess fürs Russische zuletzt von Kuznecov 1959, 92-107 dargestellt worden. Es erweist sich, dass der sogenannte Genitiv-Akkuzativ zuerst bei Personennamen auftritt $(1229 / \ldots /)$, dann bei den gleichen Bezeichnungen mit präpositionen $(1375 / \ldots /)$, und schliesslich bei Bezeichnungen für männliche Tiere $(1521 / \ldots /)$."

41 "Cette distinction est nouvelle et inconnue du baltique, mais elle est déjà fixée en vieux slave (...). Et elle s'élargit 
(...) Ie génitif-accusatif se développe au pluriel et au duel, d'abord dans la flexion pronominale avec les pronoms et adjectifs employés absolument, puis, pour une partie des langues, dans la flexion des substantifs. (...) Le russe, avec I'obscurcissement de la notion de genre au pluriel, l'étend au pluriel des féminins et des neutres."

$42 \mathrm{Vgl}$. noch Meillet, Recherches sur l'emploi du génitif-accusatif en vieux slave, S. 172: "Le nominatif et l'accusatif de tous les thèmes masculins en -o- ont été identiques pendant un temps; I'accusatif des adjectifs déteminés, influencé par les pronoms et les démonstratifs, a pris la forme du génitif-accusatif que possédaient ces mots; en se transmettant aux formes nominales, cet usage a permis d'écarter la confusion du nominatif et de l'accusatif d'abord dans les noms de personnes, puis dans ceux d'êtres animés."

43 Er schreibt in diesem zusammenhang (1. c.): "O genetičeskom edinstve, $t$. e. o vozvedenii obeix legend $k$ obščj indoevropejskoj mifologii, takže ne prixoditsja govorit6, tak kak $v$ etom slučae my mogli by prosledito elementy etogo mifologičeskogo kompleksa po vsem indoiranskomu i evropejskomu miru, a ne tol6ko v osetinskom i latinskom."

44 Vgl. noch Abaev, IES II $148 f$.

45 VgI. weiter S. 230.

46 Vgl. Abaev, Mélanges Benveniste, 1975, S. $4 f$.

$47 \mathrm{Vgl}$. jedoch Gimbutas, to Honor R. Jakobson, Vol. I, S. 747.

48 Abaev, ibid., Anm. 82 .

49 Vgl. dazu auch R. Jakobson, Slavic Mythology, F. and W. Stand. Dict., Vol. II, S. 1027, und ausführlicher M. Gimbutas, To Honor R. Jakobson, Vol. $I, 1967, S .745$.

50 (S. 120): "čto drevnejšij sloj rassmotrennyx nami izogloss otnositsja ko vremeni, kogda drevneevropejskie jazyki naxodilis6 ešc̆e $v$ neposredstvennom obščenii meždu soboj $i$ so skifskim jazykom, a predki italikov ne pereselilis 6 eše iz Srednej Evropy v Italiju (...). A kak eto pereselenije otnositsja $k$ koncu II tisjac̆eletija do $n$. e., to drevnejšie skifo-evropejskie izoglossy prixoditsja datirovat6 vremenem ne pozdnee vtoroj poloviny II tysjačletija do n. e."

51 (S. 27): "Kogda xettskaja, grečeskaja, praarmjanskaja, indoiranskaja gruppy uže davno otdelilis6, utratili neposredstvennye kontakti meždu soboj $i$ vstali na putb samostojatel6nogo razvitija, buduščie balto-slavy, toxary, germancy, kelty i italiki soxranjali ešč areal6nuju obščnost6 v srednej $i$ Vostočnoj Évrope, razvivajas6 v uslovijax vzaimyx kontaktov."

52 Für die zweite Möglichkeit könnte vielleicht das Material bei Toporov-Trubačev, Lingv. analiz (1962), z. B. S 231, sprechen; vgl. jedoch die kritische Stellungnahme von P. Arumaa, Baltes et Iranes, Studi 
linguistici in onore V. Pisani, Vol. I, 1969, S. 73-90, so z. B. S. 87: "De la critique présentée ci-dessus ressort clairement que toutes les étymologies iraniennes proposées jusqu'à présent conceriant les habitats septentrionaux des Iraniens reposent sur les bases très fragiles. quand Toporov et Trubačev nous disent qu ils ont constaté un nombre double des hydronimes iraniens sur le cours supérieur du Dniéper, en comparaison avec les résultats antérieurs de vasmer, on pourrait bien expliquer une telle prétention par le fait que les onomatologues russes ont été dans leur jugement moins circonspects que vasmer. Même les étymologies conjecturales de Vasmer, bien que mieux fondées, sont difficiles d̀ défendre" und noch besonders ibid. S. 90: "D'autre part aussi, I'appréciation exacte des anciens dialectes de l'iranien du Nord, respectivement des langues iraniennes de la Russie méridionale, se heurte difficultés considérables. La publication la plus récente d'un spécialist qualifié dans la domaine de la langue ossète, V. I. Abaev, Skifo-evropejskie izoglossy (Moscou 1965) $n^{\prime}$ apporte non plus aucune image détaillée de la structure de ces dialectes, malgré qu' une méthode de la linguistique géographique y ait été largement adaptée. L'une des thèses essantielles d'Abaev est, $1 . d^{\prime}$., p. $121 \mathrm{sqq.}$ que les tribus nord-iraniennes étaient des habitants autochtones de I'Europe orientale et que la Russie méridionale doit être envisagée comme le berceau des Iraniens. Il est difficile de faire accorder cette théorie avec les très pauvres emprunts de $I^{\prime}$ iranien en langues slaves et avec la question: pourquoi n'y a-t-il dans les langues baltes, que nous connaissons, aucune trace sûr de l'influence iranienne? Nous ne croyons pas, en définitive qu'on puisse même d'un seul fait probant dans l'hydronymie, étayer l'hypothèse d'une connexion étroite et vive entre les Baltes et les Iraniens."

53 Vgl.z. B. ibid. S. 136: "Čto slavo-iranskie jazykovye svjazy načalis6, po-vidimomu, ešce v doskifskuju epoxu $v$ ramkax pozdnej indoevropejskoj obščnosti. V bolbsinstve slučaev net takix otličitel6nyx priznakov, kotorye pozvolili by s uverennost6ju otdelito ranneskifskoe ot obščeiranskogo."

54 Ibid. S. 141: "Im Baltoslawischen später als im Indoiranischen und Armenischen."

$55 \mathrm{Vgl}$. dazu noch die weiteren Ausführungen ibid. S. 146, die aber nichts wesentliches beitragen. Die Kategorie der "Areal-Lexik" bleibt somit noch immer unerklärt, wenigstens hinsichtlich der Herkunft bzw. Entstehung solcher worter und deren weiterer morphologischer Analyse, wie sie in der historischen sprachwissenschaft gefordert wird. Eine solche wortkategorie setzt eine besonders nahe Beziehung zwischen den miteinander in Kontakt stehenden sprachen voraus. In diesem Rahmen wären einige Beispiele in der Tat nur dann verständlich, wenn man mit Bilinguismus rechnen könnte. Einen solchen status für die baltoslawisch-iranischen sprachbeziehungen anzunehmen scheint mir gewagt und unbeweisbar. 
56 Eine solche Auffassung verteidigt z. B. Moszynski, Pierwotny zasizg jęz. prasł., 1957; Zaliznjak, VSJa 6, 1962, 28ff. und KSIS 38, 1963, 3ff.

57 (S. 9): "rassmotrenie slavjano-iranskix jazykovyx otnošenij dolžno byto pereneseno iz tradicionnogo obščslavjanskogo plana"v plan praslavjanskoj dialektologii i lingvističeskoj geografii" und weiter ibid.: "Aktualbnoj zadačej izučenija slavjano-iranskix leksičeskix (i voobšče jazykovyx) otnošenij javljaetsja rasširenie privlakaemogo materiala - praslavjanskoj dialektnoj leksiki, onomastiki (v častnosti, antroponimii)."

58 Vgl. Toporov-Trubačev, Lingvističeskij: analiz gidronimov verxnego Podneprov6ja, Moskva 1962, S. 225 und Arumaa, Studi 1. in onore di V. Pisani, Vol. I, S. 84.

59 Lit. miež̃̆s usw. wird von čop, mündlich, zu idg. *meit(h)(Pokorny 715) gestellt, also *mei-g'h-.

$60 \mathrm{Zu}$ einem ähnlichen Bedeutungsverhältnis bei aind. návanitam "frische Butter" vgl. Mayrhofer, AIEW II 143.

61 H. Eichner hat mich auf $p w I V, 1959^{2}, S .222$ *bālāgra- $n$. "Taubenschlag" aufmerksam gemacht. zu bālá- vgl. Mayrhofer II $426 f$.

62 Nach Čop, mündlich, mit aind. kapotá- "Taube" zusammenzubringen.

63 Vgl. oben S. 191.

64 Dieselbe Zusammenstellung behandelt u, a. schon Arntz, Sprachliche Beziehungen zwischen Arisch und Balto-slawisch, S. 45, Beispiel 32 .

$65 \mathrm{Vgl}$. Brugmann, Grdr. II/1, s. 395: "Als lebendige Glieder eines Verbalsystems scheinen die to-Adjektiva von uridg. Zeit an durchgängig oxytoniert gewesen zu sein" und ibid., s. 411: "Bald haben sich, wie das auch in anderen Formklassen der Fall war, rein nominale Adjektiva einem verbum angegliedert, bald sind. verbale Adjektiva zu rein nominaler Geltung zurückgeführt worden. Hier seien noch Beispiele für rein nominalen Gebrauch gegeben. Av. sarəta-, lit. száltas "kalt", zu ai. Si-Sira-s "kalt"."

66 Vgl. Bartholomae, GIPh I, S. 175 und Reichelt, Aw. Elementarbuch, S. 76 .

67 Vgl. z. B. Lindeman, Einführung in die Laryngaltheorie, S. 104 und Kuiper, Sprache VII, S. 21, 29 u, a.

68 So z. B. S. 128: "Ebenso hat die Verbindung Vokal + Sonant + präkons. a (eRaT) akutierten Diphtong ergeben." Part. pret. pass. wird im Baltischen von dem Infinitivstamm gebildet. Vgl. ibid. S. 446 .

69 "Vielleicht liegt die Tiefstufe vor in lit. šilti (...), denn auszugehen ist von der idg. Wz. *k'el-, *k'ol-, die "kalt", daneben auch "warm" bedeuten kann." 
70 Cop, mündlich, stellt aind. kșodati "zerstampft" dazu.

71 Anstatt *ab-五-ta- ist eher *abi-ita- anzunehmen (so H. Eichner, brieflich). Vgl. z. B. ai. vītá- (*vi-ita-), ags. wíd usw. Pokorny 294-5.

72 zur Frage des u-stamms im Baltischen vgl. Arumaa, Arsbok 1948-49, Lund 1951, S. 70 .

73 Cop, mündlich, verweist auf die mögliche Verbindung mit lat. paetus "Ieicht schielend". Vgl. Walde-Hofman, LEW II 235 .

74 "v ponjatie slavjano-iranskix leksičeskix otnošenij nami vključaetsja edinstvenno special6nye slavjano-iranskie innovacii $i$ besspornye zaimstvovanija, to estestvenno ožidat v rezul6tate sokrašc̆enie suščestvujušc̆ix slov" (s. 21 ).

75 So z. B. Rozwadowski, RO I, 1914-15, S. 103 und R. Jakobson, F. and W. Stand. Dict. II, S. 105.

76 So z. B. Meillet, RESI VI, S. $166 f$.

77 Vgl. z. B. Arntz; O. C., S. 45, Ex. 39.

78 Vgl.z. B. Meillet, RESI VI, S. 169; Arntz, S. 44,Ex. 21; Benveniste, To Honor R. Jakobson, 1967, S. 197.

79 B. Čop hat mich mündlich auf das myk. opi-oromai "Herde hüten" aufmerksam gemacht. In diesem Fall könnte es sich nicht um eine iranisch-slawische Isoglosse handeln.

80 B. Cop, mündlich, denkt an onomat. Ursprung. Vgl. dazu die Belege bei Pokorny 1058.

81 So u. a. noch: Arntz, S. 33; Benveniste, To Honor R. Jakobson, 1967, S. 198 .

82 Vgl. dazu noch die Deutung von'szemerenyi, Die Welt der Slawen XII/3, 1967, S. 272.

83 Vgl. schon Meillet, RESI VI, S. $166 f$.

84 Vgl.z. B. Meillet, RESI VI, S. 167.

85 Vgl. z. B. R. Jakobson, I. C., S. 1025.

86 Vgl. z. B. Rozwadowski, RO I, S. 108f.; Jakobson, I. C., S. 1025 .

87 Vgl.z. B. Vasmer, RSIVI, S. 173; Jakobson, S. 1025.

88 Vgl. z. B. Vasmer; RSI VI, S. $173 f$.

89 Vgl. Abaev, Ezyk. izsl. V C̆ast na akad. St. Mladenov, Sofija 1957, S. $321-8$.

$90 \mathrm{Vgl}$. Vasmer, RSI VI, S. 176f. und Bezlaj, Etim. slovar I 212 .

91 Vgl. z. B. Vasmer, ibid. 175 und auch Kiparsky, Russ. hist. Gr. III, S. 60 .

92 VgI. z. B. Vasmer, RSI VI, S. 174f. und s. weiter S. 229. 
94 Vgl. Vasmer I $321 \mathrm{E}$. und noch Abaev, Sb. Borkovskogo (1971) S. 13 .

$95 \mathrm{Vgl.}$ schon Rozwadowski, RO I, S. 107 . und Vasmer I 624.

96 Vgl. z. B. Rozwadowski, RO I, S. 107; Vasmer I 653 und Pohl, Kratylos XXII, S. 8 .

$97 \mathrm{VgI.} \mathrm{Vasmer,} \mathrm{RSI} \mathrm{VI,} \mathrm{S.} \mathrm{176;} \mathrm{Vasmer} \mathrm{III} \mathrm{121f.;} \mathrm{Rozwadowski,}$ RO I, S. 107 und Meillet, RESI VI, 1926, S. $173 f$.

$98 \mathrm{Vgl}$. oben S. 194 und 221.

$99 \mathrm{Vgl}$. anders Mladenov, RESI IV, 1924, $190 f \mathrm{f}$.

$100 \mathrm{Vgl}$. noch Palmer, TPS 1950, S. 167 und Hommages Niedermann (1956), S. 259.

101 Vgl. Vasmer, REW I 98; Vaillant, Gramm. Comp. I, S. 16; Moszyński, zasiąg s. 82ff.; I. Grafenauer, Slov. etnograf 5, 1952. S. $237 f$. usw. Sadnik-Aitzetmüller, Vergl. Wb., Lief. 5, 1970, S. 361, rechnen - ähnlich wie Mayrhofer 1. c. mit iranischem Einfluss.

102 zum Reflex der Gruppe *r + m schreibt z. B. Arumaa, Ursl. Gr. II, S. 145, folgendes: "Die Gruppe Liquida + Nasal ist im slawischen reichlich vertreten, weil $\mathrm{m}$ in der wortbildung als primäres Formans gilt. Da wo es sich um sonantisches $r$ handelt, bleibt rm bis in die Neuzeit erhalten, so

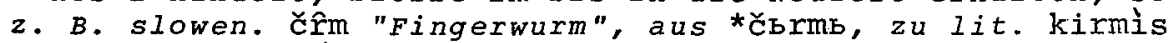
"Wurm", aind. kŕmi- "dass." Zum Reflex der Gruppe *r + u meint er ibid. S. 150: "Diese Gruppe entsteht meistens bei Wurzeln, die auf u auslauten. Das Wort für 'Eber, Kleinvieh', urslav. *borvb in sloven. brâv, poln. browek ist ein verbauter u-stamm (...); oder abulg. drëvo 'Baum', lit. dervà 'Kleinholz' (...). Daneben hat auch suffixalen Charakter angenommen, $z$. $B$. im Wort für 'Leib, Eingeweide': abulg. črěvo neben apreuss. kẽrmens 'Leib'; r.-ksl. mraviji' Ameise' aus urslaw. *morví; ar. Čsrvb'Wurm' neben abulg. Črbmonb 'rot'."

103 Vgl. MIadenov, ASIPh XXXIII, S. 16-9 und Skok III 339.

$104 \mathrm{VgI}$. Abaev, OJF I 240: "Skify javljajutsja takže tem edinstvennym iranskim narodom, kotoryj dolgo i neposredstvenno sosedil so slavjanskim, v osobennosti vostočnoslavjanskim mirom."

$105 \mathrm{Vgl}$. jedoch Kiparsky, Russ. hist. Gr. III, S. 61: "Da das Wort erst 1625 belegt ist, dürfte türkische Vermittlung vorliegen."

106 Vgl. Abaev, Etimologija 1966 (1968), s. 246. Er nimmt an, dass auch das skythische das entsprechende Wort, das sonst nur im Awestischen belegt ist, enthalten haben müsste. Vgl. auch Kiparsky, Russ. hist. Gr. III, s. 60.

$107 \mathrm{Vgl}$. oben S. 220. 
108 Vgl. Kiparsky, Russ. hist. Gr. III, S. 60.

109 Vgl. dazu Berneker I, S. 23f.; Sławski I, S. 24; Brückner, S. 10 .

$110 \mathrm{Vgl}$. dazu Vaillant, Gr. comp. III, S. 429: "Le slave *ačiti, dans pol. ob-aczyć, d'où baczyć 'regarder, avoir égaxd', a un correspondant dans av. aiwy-äx̌̌eyeinti'ils surveillent' et il peut être le factitif d'un dérivé verbal du nom de l'oeil', oko, comme l'inchoatif lit. ankù, àkti 'recevoir des yeux', adj. akýlas 'attentif'. Vgl. noch ausführlich Mathiassen, studien zum slawischen und indoeuropäischen Langvokalismus (1974), S. 160f. Zu den formalen Möglichkeiten einer solchen Herleitung vgl. noch szémerenyi, Die welt der slaven XII/3, 1967, wo er auf $S .280$ zur Veranschaulichung des Begriffs 'depreverbalization' folgendes Beispiel anführt: "with the wellknown process of 'depreverbalization' (...) it is also relevant to point to Martynov's successful elucidation of slavic gněati sę 'to be angry': it is depreverbalized from *ognèati, earlier *ognèvati, from ognb (...)."

$111 \mathrm{Vgl}$. Čop, Živa antika III, 1-2, 1953, S. 186f.

112 Ibid. 58f. B. Čop, mündlich, rechnet mit einer Möglichkeit *truva- *trĕ̌u- "gedeihen" (Pokorny 1095).

$113 \mathrm{VgI}$. dazu Bartholomae, GIPh I/1, S. 172, \$ 297, P. 1: "Nach den gegebenen Beispielen scheint mir die Norm ae im anlaut und in offener silbe, $\bar{o} i$ in geschlossener (...). Doch ist sie in Inlautsilben häufig verletzt (...). Unregelmässiges ōi findet sich häufiger. Das gaw. bevorzugt öi, das jaw. āe."

114 cop, mündlich, nimmt eine Verbindung mit lit. peIlis, lett. peÎlis "Messer", slaw. pila, d. Feile, lat. pīlum usw. an. VgI. Fraenkel 563f.; Walde-Hofmann, LEW II $3 I^{3}$ 1954, S. 304.

115 Vgl. noch Bartholomae, Altiran. Wb. S. 610.

116 Vgl. R. Jakobson, I. C., S. 1026.

117. Machek, Linguistica Slovaca III, Bratislava 1941, S. 84-8. Vgl. auch sein Etym. Wb. S. 415 .

118 Vgl. I. C., S. 66: "Etimologičeskiji mifologičeskij anaIiz slova rarogb pokazyvaet intensivnosto slavjano-iranskix obščenij $v$ oblasti religii (na urovne drevnix primitivnyx verovanij) i mifologij $i$ odnovremenno možet služitb otvetom, kotoryj udovletvorit Ijubogo skeptika, somnevajušcegosja voobšče $v$ real6nosti sootvetstvujuščix vlijanij irancev na slavjan."

$119 \mathrm{zu}$ den zit. Lehnwörtern bzw. deren mythologischen Hintergrund vgl. noch die schlussbemerkungen ibid. S. 70f.: "Ir. pativāra- - *vāragna-polnost6ju otrazilos6 v pol6sk. poczwara - raróg, pri čem jasnye sledy mifologičeskogo upotreblenija pol $6 \mathrm{skix}$ prototipov govorit o tom, čto delo ne ograničevalosb odnim zaimstvovaniem slov, no celyj sjužet 
drevnix mifologičeskix verovanij byl vo vsem sušcestvennom pozaimstvovan čast6ju drevnix zapadnyx slavjan v epoxu intensivnyx kontaktov s sosednimi drevneiranskimi plemenami." Ähnliches stellt er (S. 71) hinsichtlich der Lage im Baltischen fest: "Iz predyduščgo izloženija sleduet, čto baltijskij $v$ rezulbtate samostojatel6nyx obs̆čenij s iranskim tože usvoil paru terminov ir. *pativāra- - *vāragna-, otraziv ee $v$ vide lit. áitivaras "letučij dux, zmej" vãnagas "jastreb". Net ničego udivitel6nogo $v$ tom, čto slavjane $i$ balty zaimstvovali u irancev odni $i$ te że terminy." Vgl. noch Fraenkel, S. 1194.

120 Die Gegenargumente, die er auf $s .72 f$. anfuhrt, sind: verschiedene Areale, abweichende Semantik, die Ablautverhältnisse der Urform.

121 zu gau- "Kuh, stier, Rindvieh" vgl. die Namen wie Gáos, Agauoi - Abaev, OJF I 166.

122 Über katb schreibt auch Gołąb, To Honor Roman Jakobson, Vol. I, S. 783, wo er katb "murderer, tormentor" als eine Vrddhi-Bildung darstellt. Wichtig ist die Auseinandersetzung mit dieser Meinung, die T. Mathiassen, Studien zum slavischen und indoeuropäischen Langvokalismus (1974), S. 215, bringt: "GOEĄBs Interpretation von kat ist nun die folgende: Es gehöre dies als vrddhibildung zu dem aus tabuistischer Rücksicht aus tok- umgestellten kot-. Die Entwicklung sei nomen actionis *koto- $\longrightarrow$ denominatives Adjektiv *koto (katъ). Ich finde diese Interpretation wenig überzeugend: kat ist ja nur im westslawischen belegt; m. E. könnte es sich somit sehr wohl um eine späte Ableitung von katati/katiti handeln. Die Annahme tabuistischer Umstellung wäre für kat 'Henker' verständlich, kaum aber für das hierfür zugrundeliegende kot-." Vgl. noch Darms, Schwäher und Schwager, Hahn und Huhn. Die Vrddhi-Ableitung im Germanischen, München 1978, S. $349 f$. und Jakobson, Word $8(1952), S .388$.

123 "Rešajušcee značenie nužno pridavat6 svidetel6stvam pol6skogo materiala o sostave leksiki v iranskix dialektax-istocnikax." strittig ist seine Interpretatiton der stellung der polnischen wörter im Rahmen der slawischen Lexik insgesamt. Vgl. dazu s. 79: "čto eti pol6skie slova otnosjatsja $k$ cislu drevnix elementov slavjanskoj leksiki nezavisimo ot svoego ograničennogo rasprostranenija (praslavjanskie leksičeskie dialektizmy)." 
Povzetek

K NOVEJŠ IM PREDLOGOM IRANSKO-BALTOSLOVANSKIH IZOGLOS

Pričujoči tekst analizira besedno in slovnično gradivo, ki ga prinašata $v$ svojih razpravah V. I. Abaev, Skifo-evropejskie izoglossy, Na styke vostoka i zapada, Noskva 1965, in o. N. Trubačev, Iz slavjano-iranskix leksičeskix otnošenij, Etimologija (1965), Moskva 1967, str. 3-81. 